\title{
REVISTA
}

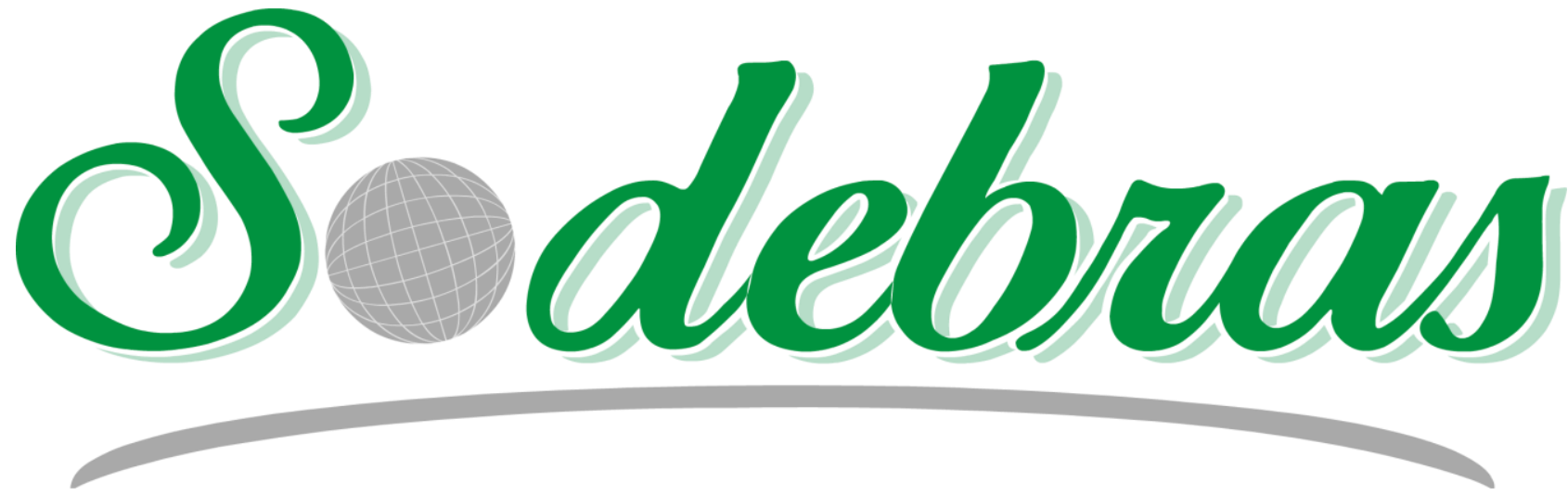

SOLUÇÕES PARA O DESENVOLVIMENTO DO PAÍS 


\title{
ARTIGOS PUBLICADOS
}

\author{
PUBLICAÇÃO MENSAL
}

Nesta edição

ERGONOMIA E A FORÇA DE PREENSÃO PALMAR QUANTIFICADA POR ELETROMIOGRAFIA DE SUPERFÍCIE EM INDIVIIDUOS SAUDÁVEIS DE AMBOS OS SEXOS

ERGONOMICS AND PALMAR PREHENSION STRENGTH QUANTIFIED BY SURFACE

ELECTROMYOGRAPHY IN INDIVIDUALS HEALTHY OF BOTH SEXES - Roque Antônio Moura; Nelson

Morini Júnior

A LIBERDADE CONCORRENCIAL MODELANDO O ESTADO: AS INSTITUIÇÕES BRASILEIRAS À LUZ DA 4를 REVOLUÇÃO INDUSTRIAL

THE CONCORRENTIAL FREEDOM MODELING THE STATE: THE BRAZILIAN INSTITUTIONS IN THE LIGHT OF THE 4TH INDUSTRIAL REVOLUTION - lúri Daniel De Andrade Silva

O SISTEMA MOODLE PODE SER CONSIDERADO UM MODELO DE GESTÃO DO CONHECIMENTO?

CAN THE MOODLE SYSTEM BE CONSIDERED A KNOWLEDGE MANAGEMENT MODEL? - Guilherme Cassarotti Ferigato; José Aparecido Pereira

PERSPECTIVAS DO ENSINO DE MATEMÁTICA NA BASE NACIONAL COMUM CURRICULAR DO ENSINO FUNDAMENTAL

PERSPECTIVES OF MATHEMATICS EDUCATION IN THE COMMON NATIONAL BASE CURRICULAR OF FUNDAMENTAL TEACHING - Idemar Vizolli; Alexandre Oliveira Da Silva; Wanessa Cardoso Gomes Muniz ..

\section{EFEITOS DO FORMALDEÍDO EM ESTUDANTES DE MEDICINA}

EFFECTS OF FORMALDEHYDE ON MEDICAL STUDENTS - Gabriela Lopes Do Carmo; Juliana Bertuci Pereira; Isabela Uchôa De Oliveira; Mariana Tamashiro Uezato; Wagner Alves De Souza Judice

EVOLUTION OF CHRONIC NON-CUMMUNICABLE DISEASES (NCDS) IN THE STATE OF SÃO PAULO, BRAZIL - 2007 TO 2016 - Rodolpho Telarolli Júnior; Leonor De Castro Monteiro Loffredo

IMPLEMENTAÇÃO DE CANAL SEGURO PARA TRANSMISSÃO DE DADOS MÉDICOS

SECURE CHANNEL IMPLEMENTATION FOR MEDICAL DATA TRANSMISSION - Samuel Henrique França Leite; Dalton Matsuo Tavares; Stella Jacyszyn Bachega; Olávio Gonçalves De Almeida

A EDUCAÇÃO E PRESERVAÇÃO AMBIENTAL NUMA TURMA DE $5^{\circ}$ ANO DO ENSINO FUNDAMENTAL L - BOA ESPERANÇA - ES

THE EDUCATION AND ENVIRONMENTAL PRESERVATION IN A CLASS OF 5 YEARS OF ELEMENTARY SCHOOL L - BOA ESPERANÇA - ES - Marcos Daher Oliveira; Marcus Antonius Da Costa Nunes

APLICAÇÕES DE SOFTWARES LIVRES PARA ANÁLISES DE SISTEMAS ENERGÉTICOS E OS RESPECTIVOS ESTUDOS DE EFICIÊNCIA ENERGÉTICA

APPLICATIONS OF FREE SOFTWARE FOR ENERGY SYSTEM ANALYSIS AND THEIR ENERGY EFFICIENCY STUDIES - Rafael Ayres Soares; Marcio Zamboti Fortes; Angelo Cesar Colombini .. 
OTIMIZAÇÃO DO TEMPO DE VIDA ÚTIL DE ELETRODOS UTILIZADOS EM UM PROCESSO DE SOLDA NA CARROCERIA EM UMA EMPRESA AUTOMOBILÍSTICA

OPTIMIZING THE USEFUL LIFE TIME OF ELECTRODES USED IN A WELDING PROCESS IN THE BODY IN AN AUTOMOBILE COMPANY - Nilo Antonio De Souza Sampaio; Alzira Ramalho Pinheiro De Assumpção; Helena Maria Perim De Almeida; Jéssica Crystina Ramos Medon De Oliveira; Luma Britto Pinto 


\section{Área: Interdisciplinar}

\begin{tabular}{|c|c|}
\hline $9-6$ & $\begin{array}{l}\text { ERGONOMIA E A FORÇA DE PREENSÃO PALMAR QUANTIFICADA P } \\
\text { ELETROMIOGRAFIA DE SUPERFÍCIE EM INDIVÍDUOS SAUDÁVEIS DE AMB } \\
\text { OS SEXOS }\end{array}$ \\
\hline & $\begin{array}{l}\text { ERGONOMICS AND PALMAR } \\
\text { SURFACE FIFCTROMYOGAP }\end{array}$ \\
\hline
\end{tabular}




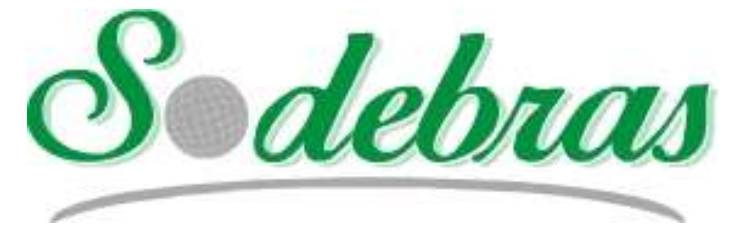

Revista SODEBRAS - Volume 14

$\mathrm{N}^{\circ} 161-\mathrm{MAIO} / 2019$

\title{
ERGONOMIA E A FORÇA DE PREENSÃO PALMAR QUANTIFICADA POR ELETROMIOGRAFIA DE SUPERFÍCIE EM INDIVÍDUOS SAUDÁVEIS DE AMBOS OS SEXOS
}

\author{
ERGONOMICS AND PALMAR PREHENSION STRENGTH QUANTIFIED \\ BY SURFACE ELECTROMYOGRAPHY IN INDIVIDUALS \\ HEALTHY OF BOTH SEXES
}

\author{
ROQUE ANTÔNIO MOURA ${ }^{1}$; NELSON MORINI JÚNIOR ${ }^{2}$ \\ 1 - FACULDADE DE TECNOLOGIA DE SÃO JOSÉ DOS CAMPOS - PROF. JESSEN VIDAL; \\ 2 - UNIVERSIDADE DE MOGI DAS CRUZES - UMC \\ roque.moura@fatec.sp.gov.br; nelmorini@hotmail.com
}

\begin{abstract}
Resumo - Rotineiramente, em diferentes atividades fabris se utilizam as mãos como ferramentas na montagem manual onde a força de preensão palmar exercida, será responsável pelo aperto e torque final, sem, contudo, verificar qual sexo executará tal atividade. Este artigo objetiva quantificar eletromiograficamente em 40 voluntários saudáveis de ambos os sexos, a força de preensão palmar para uma força pré-estabelecida de 40 Newtons controlada por um dinamômetro durante dez segundos, verificando se o mínimo conforto ergonômico está sendo atendido para ambos os sexos. $O$ método contou com uma vasta pesquisa literária alusiva ao assunto, uso de dinamômetro e um eletromiógrafo de dois canais com sensores de superfície. $O$ resultado indicou haver diferença significativa entre os sexos $e$ concluiu que o sexo feminino para executar a mesma atividade $e$ duração, tem um desgaste maior $e$, portanto, requer uma condição de conforto ergonômico diferenciada do masculino.
\end{abstract}

Palavras-chave: Ergonomia. Preensão Palmar. Indivíduos saudáveis.

\begin{abstract}
Routinely, in different manufacturing activities, the hands are used as tools in manual assembly where the palmar prehension force exerted, will be responsible for the final tightening and torque, without, however, verifying which sex will perform such activity. This article aims to quantify electromyographically in 40 healthy volunteers of both sexes, palmar grip strength for a pre-established force of 40 Newtons controlled by a dynamometer for ten seconds, verifying if the minimum ergonomic comfort is being served for both sexes. The method relied on extensive literature research on the subject, use of a dynamometer and a two-channel electromyograph with surface sensors. The result indicated a significant difference between the sexes and concluded that the female to perform the same activity and duration, has a greater wear and, therefore, requires a condition of ergonomic comfort differentiated from the masculine.
\end{abstract}

Keywords: Ergonomics. Palmar prehension. Healthy individuals.

\section{INTRODUÇÃO}

Nas últimas décadas, desconfortos relacionados ao punho vêm merecendo destaque na literatura científica, com progressivo aumento do número de indivíduos se afastando de suas atividades.
O advento da indústria 4.0, com suas máquinas e equipamentos acompanhados da tecnologia embarcada, são parte de um sistema produtivo, que buscam produzir "mais com menos". Porém, tais máquinas e equipamentos, atendem a produção, seja discreta ou seriada, mas infelizmente, ainda não distinguem as mãos de quem executa a atividade no posto de trabalho, ou seja, se a força de preensão palmar que será executada, respeita os limites tanto ergonômicos e antropométricos entre o sexo feminino e o sexo masculino.

Segundo Stark, et. al. (2013), a quantificação da força de preensão palmar, entre os sexos, pode ser facilmente mensurada por dinamômetros portáteis conhecidos como HHD (Hand Held Dinamometeers), cujos resultados são confiáveis e têm um custo mais popular além do fácil manuseio. Para ser cada vez mais competitivo, precisa-se observar o fator humano e entender sobre os efeitos da técnica da ergonomia no uso da preensão palmar, sendo oportuno a necessidade de um trabalho com embasamento técnico e científico na motivação e comprometimento de uma melhor harmonia entre a função muscular e o esforço biomecânico (IIDA e BUARQUE, 2016).

A relação entre o trabalho e a ergonomia, pode ser observada pelos dados de afastamento do posto de trabalho por desconforto dos trabalhadores e cuja tendência atinge principalmente as mulheres (IBGE, 2013), conforme o Gráfico 1.

Gráfico 1-Tendência de afastamentos na indústria

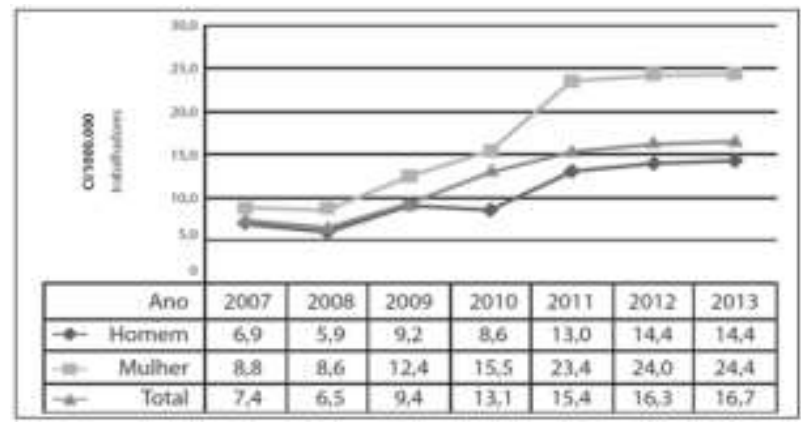

Fonte: IBGE (2013). 


\section{1 - Ergonomia}

A ergonomia tem seu amparo legal e obrigatoriedade definida pela norma regulamentadora (NR) número 17 a partir de estudos e pesquisas na área da fisiologia do trabalho, causas da fadiga no trabalho e no consumo energético pelo excesso de esforço que na maioria das vezes são compensados por uma postura ou ações incorretas durante a execução da tarefa laboral, não cumprindo assim, a premissa básica da NR 17 que é adequar o local de trabalho ao convívio humano e ainda desrespeitando o artigo $5^{\circ}$ da nossa Carta maior que prevê o principio da isonomia, tratando os desiguais na exata proporção de sua desigualdade (MOURA et. al., 2019; BRASIL, 2019).

\section{2 - Preensão Palmar}

A preensão palmar é a capacidade que a mão tem de apresentar os movimentos de pinça ou garra, que permitem desempenhar atividades cotidianas e de forma a manual (MAGEE, 2010).

A preensão palmar é mantida pela força muscular que por sua vez é influenciada por fatores internos e externos, sendo considerando fatores internos a seção transversal das fibras musculares, número de fibras recrutadas, membro dominante ou não dominante, velocidade de contração das fibras musculares, tipo de fibra muscular (tônicas ou fásicas), a idade e o gênero se é masculino ou feminino. Entre os fatores externos se enquadram o método de treinamento, a motivação e a nutrição entre outros (VIANNA, et. al., 2013).

\section{3 - Relação entre a ergonomia e a força de preensão}

A força de preensão é responsável pela força da mão. Está sujeita a doenças que acarretam limitações motoras e estudos indicam uma forte correlação da perda da força de preensão palmar e o estado de saúde principalmente no processo e nas atividades não ergonômicas. Quantificar a força de preensão palmar de cada sexo auxiliará reduzir a avaliação subjetiva e superficial da condição dos indivíduos, que são muitas vezes sonegadas pelo próprio trabalhador ou trabalhadora, por medo de perder o emprego (SOUZA et. al., 2014).

Assim, desenvolver procedimentos objetivos e consistentes de avaliação, delineará o tratamento a ser desenvolvido, pois, muita das doenças dos trabalhadores é porque não possuem força suficiente para suportar o ritmo repetitivo e a mobilidade digital necessária para a realização da atividade, sendo descrito na literatura internacional que o padrão e tamanho adequado dos dispositivos, instrumentos e ferramentas manuais, deveriam ser restringidos por princípios ergonômicos (FERREIRA et. al., 2015).

\section{4 - Eletromiografia de Superfície (EMGS)}

O eletromiógrafo é um aparelho usado na atividade de eletromiografia, que funciona conectado por USB a um computador e faz aquisição de sinais elétricos emitidos através de eletrodos bipolares posicionados superficialmente na pele sobre os músculos que serão monitorados. O eletromiógrafo e usa um software, que mensuram a soma algébrica dos potenciais de ação dos músculos os registrando em um computador. São gerados gráficos de imediata apreciação nas opções de leituras dos sinais na forma de espectros gráficos como a forma Crua - RAW,
Transformada Rápida de Fourier - FFT e Raiz Média Quadrática - RMS (MERLETTI e FARINA, 2016).

Conceitualmente, o traçado RAW do EMG é chamado de traçado de interferência porque é a soma de potenciais de ação de todas as unidades motoras naquele momento e naquela atividade, respeitando a hierarquia de recrutamento das fibras que prevê primeiro as fibras curtas e menores chamadas tônicas ou lentas e na manutenção do esforço podem ser também recrutadas as fibras fásicas ou rápidas para sustentação do esforço isométrico (HALL, 2015).

\section{5 - Contração Muscular e a Eletromiografia de Superfície}

Um músculo, durante uma contração, recruta fibras que geram sinais elétricos baseado em potenciais de ação durante um ciclo de despolarização e repolarização. A rápida inversão de polaridade da membrana de negativa para positiva é conhecida como despolarização e, quando ocorre a inversão da membrada de positiva para a negativa, há o fenômeno da repolarização, que é concluída pela hiperpolarização (WIDMAIER et. al., 2016).

Durante a quantificação e leitura foi utilizado um módulo condicionador de sinais de dois canais Miotool Fisio da MIOTEC, com transmissão de dados por USB, resolução 14 bits; taxa de amostragem: 2.000 amostras por segundo; ruído < 2 LSB; modo de rejeição comum de 126 Db; isolamento de segurança $3000 \mathrm{~V}(\mathrm{rms})$; tamanho aproximado de $135 \mathrm{~mm}$ X $140 \mathrm{~mm}$ X $50 \mathrm{~mm}$; peso aproximado de 470g; tensão de alimentação do sistema de aquisição: 1 bateria NiMH 7,2 Vcc $1700 \mathrm{mAh}$; corrente em repouso: 200 microA; corrente máxima: $120 \mathrm{~mA}$; potência máxima: 0,3 W; temperatura: de $10{ }^{\circ} \mathrm{C}$ a $40{ }^{\circ} \mathrm{C}$; tensão de alimentação dos canais analógicos: $3,3 \mathrm{~V}$; número de canais: 2 ou 4; tensão máxima de entrada: $2.048 \mathrm{mV}$. O Sensor de EMG: Tensão de alimentação: 5,0 V; Tensão máxima de entrada: entre $1 \mathrm{mV}$ para ganho 2.000 e $8 \mathrm{mV}$ para ganho 250 ; Impedância de entrada: $10 \quad 10$ Ohm // 2 pF; Ganho automático; Comunicação: LIN a 9.600 bauds; Temperatura: de $10^{\circ} \mathrm{C}$ a $40^{\circ} \mathrm{C}$; Filtro ativo passa-baixa de dois polos com frequência de corte em $1 \mathrm{kHz}$ elimina a frequências altas indesejadas; Comprimento do Cabo: 2 metros; Conexão com os Eletrodos por pressão: Cabo Mini Pinch $15 \mathrm{~cm}$ de comprimento Blindado Foram utilizados filtros passa alta $20 \mathrm{hz}$, passa baixa $500 \mathrm{hz}$ e um filtro notch de 60hz (MIOTEC, 2019).

\section{METODOLOGIA}

\section{1 - Comitê de Ética}

Essa pesquisa foi realizada com voluntários humanos sendo considerados os aspectos éticos que iniciou suas coletas após a aprovação pelo Comitê de Ética e Pesquisa registrado pelo CAAE 64513617.3.0000.5497 e registrado no Clinical Trials, sob o número de controle NCT03103048.

\section{2 - Desenho do Estudo}

Este estudo é caracterizado como um ensaio aleatorizado que contou com quarenta voluntários sendo vinte masculinos e vinte femininos, com idade entre dezoito e trinta e oito anos sem sintomas ou dores no antebraço ou que não tivessem nos últimos doze meses terem siso submetidos à cirurgia na região do músculo flexor radial e ulnal do carpo, tanto no membro superior dominante quanto o membro não dominante. Os voluntários depois de 
esclarecidos sobre o objetivo da pesquisa e respondidos suas eventuais dúvidas, preencheram o Termo de Consentimento Livre e Esclarecido - TCLE.

Um dinamômetro eletrônico, devidamente calibrado, para força de preensão palmar de 40 Newtons com cabo flexível, leitura em Newtons, equipado com alarme luminoso para ação de biofeedback e controle máximo da força de 40 Newtons exercida nas tomadas, limitou o controle da força dos voluntários.

A coleta por EMGS foi realizada durante a contração isométrica dos membros superiores dominantes e não dominantes durante 10 segundos, exercendo uma força préestabelecida de 40 Newtons, sendo realizadas três medições com intervalo entre as medições de um minuto.

A temperatura da sala de coleta foi mantida em $21^{\circ} \mathrm{C}$ e iluminação controlada para evitar interferência na coleta dos sinais.

\section{3 - Posição dos voluntários durante a coleta}

A Sociedade Americana de Terapeutas da Mão (SATM) ou em inglês American Society Hand Therapy (ASHT) recomenda que todos os voluntários estejam em uma posição padronizada, adotando-se que os voluntários estejam sentados com o ombro aduzido e neutramente rodado, cotovelo flexionado a $90^{\circ}$, o antebraço em posição neutra, e o punho entre $0^{\circ}$ e $30^{\circ}$ de extensão e $0^{\circ}$ a $15^{\circ}$ de desvio ulnar, como ilustrado na Figura 1.

Figura 1- Posição recomendada pela SATM

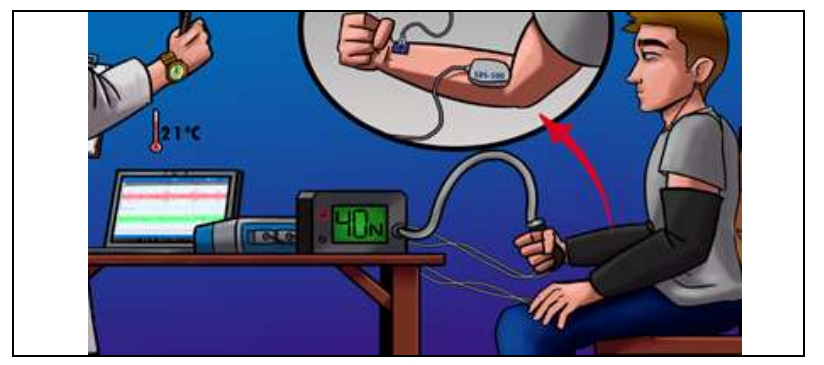

Fonte: Autores.

\section{4 - Protocolo}

Os voluntários foram recepcionados individualmente e encaminhados aleatoriamente para a sala de preparação onde era feito a perimetria com fita métrica e limpeza dos braços com álcool $70 \%$, sendo aplicados em seguida, os eletrodos bipolares, conforme demonstra a Figura 2.

Figura 2 - Medidas, limpeza e aplicação eletrodos

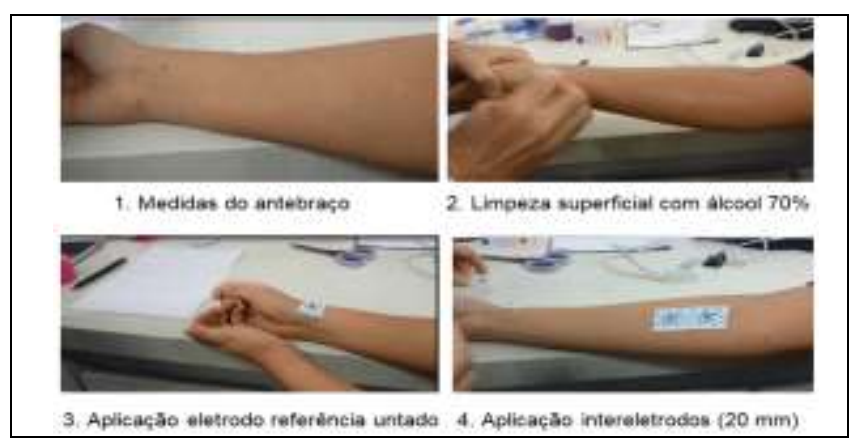

Fonte: Autores.

\section{5 - Pico máximo para comparação entre os voluntários}

O pico máximo foi a variável usada na comparação entre os sexos que são expressos em microvolts $(\mu \mathrm{V})$.
Pico máximo são os valores máximos da raiz quadrática média (RMS) encontrada na seleção realizada, ou seja, na análise e identificação do maior valor do sinal eletromiográfico (em $\mu \mathrm{V}$ ) durante dez segundos sob uma força isométrica pré-estabelecida de 40 Newtons, que pode ser calculado conforme a Equação 1:

$R M S=\sqrt[2]{\frac{1}{N} \sum_{i=1}^{N} x_{i}^{2}}$

\section{6 - Membro dominante e membro não dominante}

Membro dominante é o membro usado para função principal como manipular, montar ou movimentar um objeto.

Membro não dominante é o membro com função secundária, ou seja, fornece apoio postural e estabiliza o objeto e dessa forma assessorando o membro dominante.

\section{RESULTADOS}

\section{1 - Pico máximo do membro dominante}

O pico máximo do membro dominante feminino em relação ao pico máximo do membro dominante masculino na execução da mesma tarefa variou $(>110 \%)$ deduzindo que para executar a mesma força e atividade o sexo feminino recruta mais fibras que o grupo masculino, ou seja, se desgasta mais, conforme demostra os dados na Tabela 1.

Tabela 1- Pico máximo em $(\mu \mathrm{V})$ Membro Dominante

\begin{tabular}{l|cccc}
\hline Sexo & Feminino & Masculino & Diferença & Variaçào \\
Membro Dominante & MD & MD & MD & MD \\
Media $(\mu \mathrm{V})$ & 93.9 & 44.6 & 49,3 & $111 \%$ \\
Desvio Padrä̀ $(9)$ & 4,7 & 4,5 & & \\
\hline
\end{tabular}

Fonte: Autores.

\section{2 - Pico máximo do membro não dominante}

O pico máximo membro não dominante feminino em relação ao pico máximo do membro não dominante masculino variou (>94\%), confirmando que o sexo feminino para executar a mesma força e com a mesma duração demanda mais esforço, conforme demostra os dados da Tabela 2.

Tabela 2 - Pico máximo em $(\mu \mathrm{V})$ Membro não Dominante

\begin{tabular}{l|cccc}
\hline Sexo & Feminino & Masculino & Diferença & Variação \\
Membro não Dominautte & $\mathrm{MnD}$ & $\mathrm{MnD}$ & $\mathrm{MnD}$ & $\mathrm{MnD}$ \\
Média $(\mu \mathrm{V})$ & 94.2 & 48.4 & 45.8 & $95 \%$ \\
Desvio Padrăo $(\%)$ & 5.1 & 4.7 & & \\
\hline
\end{tabular}

Fonte: Autores.

\section{DISCUSSÃO}

Diante dos dados, é possível notar que as atividades de forma geral, são executadas para o perfil masculino, mesmo dentro dos princípios ergonômicos, pois, quando ambos os sexos executam a mesma tarefa ou atividade, o sexo 
masculino executa par ao membro dominante até $53 \%$ menos força que o sexo feminino e para o membro não dominante, esse esforço por parte do sexo masculino em relação ao sexo feminino pode ser de até $49 \%$ menor, ou seja, o desgaste é menor.

\section{CONCLUSÃO}

A força de preensão palmar é maior nos homens, comparada com a das mulheres e o lado dominante é mais forte do que o não dominante em ambos os sexos.

Os resultados demonstraram que há variação da intensidade de energia gerada entre os sexos masculino e feminino e assim, esta pesquisa contribuiu ao propor uma nova forma de avaliação seja nos exames admissionais ou periódicos e por sua vez, que seja incluído no programa de controle médico de saúde ocupacional das empresas, a verificação da preensão palmar objetiva e descontinuada a subjetiva.

Conclui-se que para a execução de uma atividade laboral, os ergonomistas necessitam ter uma visão ampliada do setor de trabalho e das atividades como, por exemplo, adequar na atividade a preensão palmar com o sexo que a executará e dessa forma prevenir e resguardar a saúde dos trabalhadores.

\section{REFERÊNCIAS}

BRASIL. Ministério do Trabalho e Emprego. Disponível em: http://trabalho.gov.br/seguranca-e-saude-notrabalho/normatizacao/normas-regulamentadoras. Acesso em 22 abr. 2019.

CHANG, H. O. Development of an integrated digital hand grip dynamometer and norm of hand grip strength. BioMedical Materials and Engineering, v. 26, n. s1, p. 611$617,2015$.

FERREIRA, C. V.; FERREIRA, C. G.; ESCOBAR, R. V.; Relação entre envelhecimento ativo e o risco de queda no perfil funcional de idosos. Revista Equilíbrio Corporal e Saúde, v. 4, n. 2, 2015.

HALL, S. J. Biomecânica Básica, $6^{\text {a }}$ edição, Rio de Janeiro: Guanabara Koogan, 2015.

IBGE. Instituto Brasileiro de Geografia e Estatística. Pesquisa Nacional por Amostra de Domicílios: pesquisa básica - 2001 a 2014. IBGE; 2013 [citado em 2015 maio 15]. Disponível em: http://bit.ly/29nCrxm. Acessado em: 23 mai. 2018.

IIDA I.; BUARQUE L. Ergonomia Projeto e Produção. São Paulo: Blucher, 2016.

MAGEE, D. J. Avaliação Musculoesquelética, ciências biológicas - saúde e medicina, Manole, Itália v.1, n.1, p.235,2010 .

MERLETTI, R., FARINA, D. Surface Electromyography: Physiology, Engineering, and Applications. ISBN: 978-1118-98702-5. May 2016. Editora Wiley - IEEE Press 592 Pages.

MIOTEC. Empresa especializada em equipamentos biomédicos. Manual. Disponível em: https://loja.miotec.com.br/produtos/miotool/. Acesso em 22 abr. 2019.
MOURA, R. A.; JESUS, N. M. R.; SOUZA, R. S. Antropometria e ergonomia como ferramentas de vanguarda produtivas nas indústrias do futuro. Revista Sodebras. Vol. 14. Ed. $\mathrm{n}^{\circ}$ 157. Jan/2019, p.109-112. ISSN. 1809-3957. DOI: https://doi.org/10.29367/issn.1809-3957.2019.157.

SOUZA, L. A.C.; Assessment of muscular strength with the modified sphygmomanometer test: what is the best method and source of outcome values? Brazilian journal of physical therapy, v. 18, n. 2, p. 191-200, 2014.

STARK, T.; WALKER, B.; PHILLIPS, J. K.; FEJER, R.; BECK, R. Hand-held dynamometry correlation with the gold standard isokinetic dynamometry: a systematic review. P M \& R. v. 3, n. 5, p. 472 - 9, 2013.

VIANNA, L. C.; OLIVEIRA, R. B.; ARAUJO, C. G. Agerelated decline in handgrip strength differs according to gender. J Strength Cond Res. 2013; 21(4): 1310-4.

WIDMAIER EP; RAFF H; STRANG K. Vander's Human Physiology: the mechanisms of body function, 14.ed, McGraw-Hill Higher Education, London, 2016.

\section{COPYRIGHT}

Direitos autorais: Os autores são os únicos responsáveis pelo material incluído no artigo.

Submetido em: 23/04/2019 Aprovado em: 13/05/2019 


\section{Área: Ciências Humanas e Sociais}

\begin{tabular}{|c|l|}
\hline $6-1$ & $\begin{array}{l}\text { A LIBERDADE CONCORRENCIAL MODELANDO O ESTADO: AS } \\
\text { INSTITUIÇÕES BRASILEIRAS À LUZ DA 4a REVOLUÇÃO INDUSTRIAL } \\
\text { THE CONCORRENTIAL FREEDOM MODELING THE STATE: THE BRAZILIAN } \\
\text { INSTITUTIONS IN THE LIGHT OF THE 4TH INDUSTRIAL REVOLUTION } \\
\text { lúri Daniel De Andrade Silva }\end{array}$ \\
\hline $6-2$ & $\begin{array}{l}\text { O SISTEMA MOODLE PODE SER CONSIDERADO UM MODELO DE GESTÃO DO } \\
\text { CONHECIMENTO? } \\
\text { CAN THE MOODLE SYSTEM BE CONSIDERED A KNOWLEDGE MANAGEMENT } \\
\text { MODEL? } \\
\text { Guilherme CaSSarotti Ferigato; José Aparecido Pereira }\end{array}$ \\
\hline $\begin{array}{l}\text { PERSPECTIVAS DO ENSINO DE MATEMÁTICA NA BASE NACIONAL } \\
\text { COMUM CURRICULAR DO ENSINO FUNDAMENTAL } \\
\text { PERSPECTIVES OF MATHEMATICS EDUCATION IN THE COMMON NATIONAL } \\
\text { BASE CURRICULAR OF FUNDAMENTAL TEACHING } \\
\text { Idemar Vizolli; Alexandre Oliveira Da Silva; WanesSa Cardoso Gomes Muniz }\end{array}$ \\
\hline
\end{tabular}




\author{
Revista SODEBRAS - Volume 14 \\ $\mathrm{N}^{\circ} 161-\mathrm{MAIO} / 2019$
}

\title{
A LIBERDADE CONCORRENCIAL MODELANDO O ESTADO: AS INSTITUIÇÕES BRASILEIRAS À LUZ DA $4^{\text {a }}$ REVOLUÇÃO INDUSTRIAL
}

\author{
THE CONCORRENTIAL FREEDOM MODELING THE STATE: THE \\ BRAZILIAN INSTITUTIONS IN THE LIGHT OF THE 4TH INDUSTRIAL \\ REVOLUTION
}

\author{
IÚRI DANIEL DE ANDRADE SILVA \\ UNIVERSIDADE PRESBITERIANA MACKENZIE E UNIVERSIDADE DE MOGI DAS CRUZES \\ iuridaniel84@gmail.com
}

\begin{abstract}
Resumo - O presente artigo analisa as instituições jurídicas brasileiras sob a ótica do desenvolvimento, da concorrência e da inovação, considerando a conjuntura da quarta revolução industrial, sob a premissa de que a tecnologia e o mercado, assim como são moldadas pelo fenômeno jurídico, também lhe servem de molde. Busca-se, através do método lógico-dedutivo, tratar o problema: "a configuração atual dos institutos jurídicos brasileiros está preparada para enfrentar a conjuntura econômica decorrente do progresso tecnológico que advém da quarta revolução industrial?”. No estado atual de inovações disruptivas - marcado pela interação tecnológica entre os domínios físicos, digitais e biológicos -, torna-se imperioso que o Estado e os institutos jurídicos brasileiros sejam remodelados, a fim de que a quarta revolução industrial seja vislumbrada como oportunidade.
\end{abstract}

\section{Palavras-chave: Inovação. Compliance. Teoria ordoliberal.}

Abstract - This article analyzes the Brazilian legal institutions from the point of view of development, competition and innovation, considering the conjuncture of the fourth industrial revolution, under the premise that technology and the market, as well as being shaped by the legal phenomenon, also serve as a template. The logical-deductive method seeks to address the problem: "The current configuration of Brazilian legal institutes is prepared to deal with the economic situation resulting from the technological progress that comes from the fourth industrial revolution?". The current state of disruptive innovations, marked by the technological interaction between the physical, digital and biological domains, implies that it is necessary for the State and Brazilian legal institutes to be remodeled, so that the fourth industrial revolution can be seen as an opportunity. In this process, efficiency must be seen as a means, the aim being the maintenance and strengthening of the competitive system.

Keywords: Inovation. Compliance. Ordoliberal Theory.

\section{INTRODUÇÃO}

A evolução tecnológica em curso consiste em fenômeno sem precedentes. A armadilha malthusiana parece ter sido desarmada pela crescente multiplicação da inovação, impulsionada pelos mecanismos decorrentes do sistema econômico capitalista.

O progresso alcançado, entretanto, traz consigo problemas de ordens variadas em todo o mundo, os quais carecem de tratamento adequado e, na área do direito, é necessário construir modelos que impulsionem o fenômeno jurídico de modo a adequá-lo à nova realidade dinâmica do desenvolvimento econômico.

Desde tempos remotos, já se percebera a dificuldade que o fenômeno jurídico demonstra para acompanhar as transformações da realidade. No caso brasileiro, se, no passado, o direito não foi capaz de acompanhar a evolução de uma sociedade predominantemente agrária que se industrializou nas últimas décadas, o desafio de adequação no contexto atual será imenso.

O presente artigo volta-se a analisar as instituições jurídicas brasileiras sob a ótica do desenvolvimento, da concorrência e da inovação, considerando-se a conjuntura da quarta revolução industrial, sob a premissa de que a tecnologia e o mercado, assim como são moldadas pelo fenômeno jurídico, também lhe servem de molde.

Busca-se, portanto, compreender se a moldura atual dos institutos jurídicos, bem como do Estado brasileiro, está preparada para enfrentar a conjuntura decorrente do progresso tecnológico, propondo-se diretivas a nortear a atuação, diante das novas roupagens de que se reveste o poder econômico e a concorrência.

A perspectiva metodológica assumida no presente trabalho é de cunho ordoliberal ${ }^{1}$. Considera a necessidade de construir mecanismos geradores de eficiência ${ }^{2}$, a fim de que o Brasil torne-se cada vez mais competitivo no cenário

1 Sobre a concepção ordoliberal, MUNHOZ, Carolina Pancotto Bohrer. Desenvolvimento e concorrência. In: Direito e Desenvolvimento. Org: BARRAL, Walber. São Paulo: Singular, 2005, p. 197: “A Escola de Freiburg caracteriza-se, desta forma, pela sua preocupação com o processo competitivo em si, ou com a possibilidade de efetiva competição, essencial para garantir o funcionamento de uma economia de mercado. Para tanto, propugna a criação de uma moldura institucional de mercado competitivo, o que tornaria desnecessária a intervenção excessiva do Estado no mercado".

2 Sobre a relação entre tecnologia, inovação e eficiência, conferir SILVA, Ernani Marques; AIHARA, Celia Hatsumi; SALVETTI, Nilson; FERNANDES, Tereza Cristina Maia; MAURO, Maria Helena. Modelando impactos das tecnologias de informação e comunicação na relação entre gestão do conhecimento, capacidade de inovação e eficiência organizacional. Revista Sodebras [on line]. v. 13, $\mathrm{n}^{\circ}$ 147, março/2018, p.124-128. ISSN. 1809-3957. Disponível em: <http://www.sodebras.com.br/edicoes/N147.pdf>. Acesso em: $20 \mathrm{de}$ novembro de 2017. 
mundial. A eficiência, contudo, não é aqui encarada como fim em si mesmo, mas como importante meio para o desenvolvimento, não se podendo olvidar mecanismos de distribuição de riqueza.

O ponto de partida do estudo corresponde à avaliação empreendida por Klaus Schwab (2016) acerca do que se tem denominado quarta revolução industrial. As conclusões do autor, sobretudo aquelas envolvendo aspectos relacionados às instituições, serão ponto de partida para as proposições ora formuladas.

Em seguida, analisar-se-á, tomando-se como referência os estudos de Luigi Zingales (2015), a conjuntura atual do capitalismo brasileiro, identificando-se premissas fundamentais para adequação do modelo ao cenário de fomento de inovações e de fortalecimento do mercado e da concorrência.

\section{1 - A Dimensão do Desafio: O Brasil no Contexto das Revoluções Industriais Pretéritas}

A conjuntura atual da inovação tecnológica conduz à constatação de que a humanidade atravessa período de verdadeira revolução, caracterizada pela ruptura e, portanto, pela descontinuidade no processo de inovação. Trata-se da quarta revolução industrial, também alcunhada "indústria $4.0 " 3$ ou "segunda era da máquina".

Antes de adentrar a análise do fenômeno, convém tecer algumas considerações acerca da participação brasileira nas revoluções industriais pretéritas. A primeira revolução industrial ocorreu em fins do século XVIII, tendo sido deflagrada pela invenção da máquina a vapor, a qual alavancou a produção mecânica, substituindo o modelo artesanal. A segunda revolução adveio ao final do século XIX, tendo decorrido do advento da eletricidade e das linhas de montagem, possibilitando a produção em massa, tal como se viu no fordismo. A terceira revolução industrial adveio a partir da década de 60 do século XX, tratando-se da revolução digital, impulsionada pela tecnologia dos semicondutores, pela computação em mainframe, pela computação pessoal e pela internet (SCHWAB, op. cit., p. 16).

Da ruptura decorrente de cada inovação não advieram alterações adstritas à ciência e ao desenvolvimento econômico, tendo sido a sociedade substancialmente modificada, assim como foram alteradas as estruturas de concorrência e do próprio sistema capitalista.

No Brasil, a modificação decorrente da evolução implicou sensíveis impactos na tessitura social, transformando um país agrário em industrial, com repercussões demográficas incalculáveis.

A industrialização brasileira remodelou os institutos jurídicos em seus diversos ramos dogmáticos. A título de exemplos, o Código Civil, primeiramente erigido para reger as relações típicas de uma sociedade agrária conservadora, foi reeditado em 2002; o Código Comercial, primeiramente concebido ainda à época imperial e sob nítida influência do Código napoleônico de 1808, veio a ser derrogado, promovendo-se a unificação formal do direito privado, incorporando-se as normas empresariais ao Código Civil de 2002; as preocupações centradas na dominação abusiva de mercado fizeram eclodir a Lei Antitruste na década de 90; o

\footnotetext{
${ }^{3} \mathrm{O}$ termo foi concebido em 2011, na feira de Hannover.

${ }^{4}$ A expressão foi alcunhada por Erik Brynjolfsson e Andrew McAfee, ambos professores do Massachussetts Institute of Technology (MIT), conforme mencionou Shwab (p. 16).
}

Código de Processo Civil de 1939, também atento aos anseios de uma sociedade agrária, foi substituído pelo Código de 1973 e, mais recentemente, pelo Código de 2015.

As inovações disruptivas foram, portanto, acompanhadas de ondas renovatórias em todos os segmentos jurídicos. No Brasil, ditas alterações jurídicas tem se mostrado, todavia, tardias, o que se pode constatar a partir dos exemplos acima mencionados. Quase 50 anos depois do eclodir do processo brasileiro de industrialização, advieram o novo Código Civil e o novo regramento empresarial, assim, como os ventos de modernização antitruste.

Em todas as revoluções anteriores, observa-se duploatraso brasileiro. O primeiro atraso é concernente ao próprio ingresso revolucionário. É que a economia pátria apenas adentra os estágios evolutivos revolucionários de forma muito tardia em relação a outras economias mundiais. $\mathrm{O}$ segundo atraso por sua vez, diz respeito à modernização do direito e das instituições.

A quarta revolução industrial, contudo, principia, trazendo consigo mais uma oportunidade histórica. Urge redirecionar os esforços para acompanhar as transformações decorrentes do progresso tecnológico.

\section{2 - A Quarta Revolução Industrial}

As tecnologias digitais, sobretudo o software e as redes, conquanto não sejam novas, tornam possível o advento de tecnologias de inteligência artificial e de aprendizagem automática que rompem os paradigmas até então estabelecidos.

A internet, por sua vez, tornou-se móvel e ubíqua, permitindo a profusão de informações de forma ainda mais veloz. Sobre as novas tecnologias e a inovação descontínua delas decorrente, Schwab aduz que "ainda precisamos compreender de forma mais abrangente a velocidade e a amplitude dessa revolução. (...) Imagine a assombrosa profusão de novidades tecnológicas que abrangem numerosas áreas: inteligência artificial (IA), robótica, a internet das coisas (IoT, na sigla em inglês), veículos autônomos, impressão em 3D, nanotecnologia, biotecnologia, ciência dos materiais, armazenamento de energia e computação quântica, para citar apenas algumas. Muitas dessas inovações estão apenas no início, mas já estão chegando a um ponto de inflexão de seu desenvolvimento, pois elas constroem e amplificam umas às outras, fundindo as tecnologias dos mundos físico, digital e biológico" (SCHWAB, 2016, p. 11).

O cerne da quarta revolução industrial a tornar disruptivo o contexto de inovações corresponde à fusão tecnológica e à interação entre os domínios físicos, digitais e biológicos.

Conquanto alguns estudiosos sustentem que as características acima descritas estejam inseridas no contexto da terceira revolução industrial, o mesmo Schwab enxerga com nitidez a ruptura revolucionária na velocidade, amplitude, profundidade e no impacto sistêmico das transformações (SCHWAB, 2016, p. 13).

De fato, as possibilidades e os prognósticos indicam uma guinada tecnológica sem igual que principia mudanças profundas nas relações sociais.

Alterações nos serviços - a partir de sistemas de plataforma, da robótica, da inteligência artificial e da internet das coisas -; nas transações e na moeda, a partir de tecnologias de blockchain; na produção, através da 
impressão 3D e, portanto, da personalização de mercadorias, são alguns prognósticos.

Haverá impacto fulcral nas relações sociais e remodelamento das estruturas de poder, inserindo-se aqui o poder econômico e a concorrência. As relações trabalhistas haverão de readequar-se, quiçá diante das novas realidades de prestação de serviços, como já se pode observar mediante a adoção de sistemas baseados em plataforma, a exemplo do Uber. Mercados inteiros serão afetados de forma letal pela disrupção tecnológica, abrindo-se espaço para novos ambientes de trabalho.

O sistema financeiro será moldado por novas tecnologias, com eliminação progressiva da moeda e adoção de blockchain. Os mecanismos de arrecadação tributária serão alicerçados por ferramentas cada vez mais poderosas de inteligência. $\mathrm{O}$ mesmo haverá de ocorrer em relação às técnicas de compliance e de inteligência criminal.

O direito tributário haverá de considerar outras formas de tributação, levando em conta, por exemplo, a possibilidade de produção pessoal de bens de consumo através da impressão 3D.

\section{MÉTODO}

Este trabalho é um estudo de revisão de literatura. Foram pesquisadas as palavras-chave em livros e artigos, nacionais e internacionais sobre o tema.

\section{RESULTADOS}

\section{1 - Economia e Direito na Quarta Revolução Industrial}

Os sistemas de plataforma podem implicar forte tendência à concentração de capitais. $\mathrm{O}$ fenômeno já se observa em relação ao mercado de informações dominado por empresas como Google e Facebook. Aplicativos como Netflix; Spotify e outros em seguimentos diversos conquistam cada vez maior fatia de mercado.

Eis uma das questões centrais a merecer tratamento. Com efeito, é da essência do sistema capitalista ser o mercado um espaço de liberdades e de exercício da própria democracia. A formação de oligopólios pode, se não houver controle adequado, corroer os fundamentos das instituições democráticas.

$\mathrm{O}$ conceito de desenvolvimento, vislumbrando sob enfoque ordoliberal preconizado pela escola de Freiburg, pressupõe relação intrínseca entre liberdade, democracia e mercado $^{5}$.

Assim, no cenário da quarta revolução industrial, definir com clareza uma perspectiva metodológica acerca do mercado, do desenvolvimento e da concorrência será fundamental para o delineamento da própria estrutura de poder e para a preservação das liberdades democráticas.

Não se pode olvidar que a eficiência é um importante norte a permear a tomada de decisões em matéria de mercado e de opções políticas. Neste ponto, a escola neoclássica de Chicago, cujos expoentes principais foram Robert Bork (1978) e Richard Posner (2006), forneceu importantes contribuições.

\footnotetext{
${ }^{5}$ Acerca da relação entre os conceitos supra, sob a perspectiva da escola de Freiburg, conferir MUNHOZ, Carolina Pancotto Bohrer. Desenvolvimento e concorrência. In: Direito e Desenvolvimento. Org: BARRAL, Walber. São Paulo: Singular, 2005, p. 202.
}

Daí exsurge maior entrelaçamento entre os estudos jurídicos e econômicos, sobrelevando-se a necessidade de análise consequencial do fenômeno jurídico, a fim de que se otimizem os recursos. Destaca-se no ponto, o enfoque de Law \& Economics, que recomenda a aproximação entre direito e economia, evitando-se a atual abordagem "no vácuo" de institutos jurídicos, passando as consequências e as externalidades econômicas a influenciar a hermenêutica e a aplicação de normas.

O contexto atual sugere, pois, a reorientação na mentalidade do operador do direito, a fim de abstraí-lo da pureza dogmática metodológica com que encara a realidade, aproximando-se direito e economia em um movimento dialético.

Não há dúvidas de que o consumidor foi beneficiado com os ganhos de eficiência decorrentes das últimas inovações. Não há como negar que a inovação tecnológica trouxe aumento na qualidade dos serviços e melhoria, em consequência, na qualidade de vida.

O problema que surge diz respeito ao poder de domínio de mercado que a remodelagem de serviços pode acarretar. É que, como aponta Luigi Zingales (2015), o capitalismo, na feição atual, tem se inclinado a uma lógica segundo a qual o "vencedor-leva-tudo".

Assim, a dinâmica de qualidade e preço que permeia a lógica utilitarista já não é o único critério de valoração da mercadoria ou do serviço. Quanto mais acessado determinado software ou aplicativo, maior valor terá e maior potencial para dominação de mercado, quiçá considerandose que a multiplicação de acessos é estimulada pelas empresas através de mecanismos de gratuidade.

Tal comportamento pode acarretar aniquilação da concorrência e causar danos à liberdade de mercado. Ora, sendo a liberdade pressuposto do desenvolvimento, a formação de monopólios, por implicar perda da liberdade de escolha entre consumidores e destruição da livreconcorrência real, pode acarretar sério atraso no desenvolvimento, desestimulando-se a inovação, a qual é a força que move a revolução em curso. O que está em jogo também é a liberdade e, portanto, o conteúdo substancial da democracia.

Sendo assim, não é a eficiência o único critério a ser considerado quando se pensa em modelar direito e instituições à luz do contexto tecnológico e da conjuntura atual do progresso.

A manutenção da concorrência deve ser um fim a ser perquirido, sendo a eficiência o meio. Eis a perspectiva assumida no presente trabalho.

As preocupações não podem olvidar igualmente aspectos distributivos, sob pena de ter-se sistema eficiente, mas injusto. Os benefícios da revolução industrial 4.0 devem ser compartilhados.

A vertente ordoliberal de análise de mercado propugna a elaboração de uma matriz mínima de organização do Estado, a partir da qual o mercado deve ser moldado ${ }^{6}$. Nota-

${ }^{6}$ Expondo o eixo central do pensamento ordoliberal, Eduardo Barros Mariutti (2018) explicita que o ordoliberalismo econômico aduz que "uma economia de mercado orientada pelos preços e pela concorrência só poderia ser construída mediante a criação de um amplo quadro institucional que, ancorado no poder do Estado, fosse capaz de se projetar para as diversas dimensões da vida social" (MARIUTTI, Eduardo Barros. Liberdade, justiça, concorrência e mercado: as tensões no pensamento liberal contemporâneo. Texto para Discussão Unicamp. IE. Campinas No. 285 mar/2018). 
se, portanto, que, assim como o mercado molda as instituições, são estas igualmente moldadas pelo fenômeno jurídico. Atento a tal realidade, Schwab enxerga na cooperação entre múltiplos stakeholders a chave para moldar a quarta revolução industrial, dela extraindo benefícios para a sociedade (SCHWAB, 2016, p. 14).

Modelar instituições e direito é etapa decisiva para que se extraia da revolução industrial o efetivo desenvolvimento, assim, a quarta revolução industrial pode ser enxergada sob perspectiva pessimista ou encarada como oportunidade. Este é o viés claramente proposto por Schwab, ora acolhido.

O Brasil encontra-se, portanto, diante de mais uma oportunidade para ingressar no cenário mundial da inovação tecnológica e do desenvolvimento. É mister adotar uma moldura institucional mínima que torne competitivo o país, fomentando-se a eficiência e o desenvolvimento tecnológico. Não se pode desprezar, contudo, o aspecto distributivo, sob pena de poucos serem os beneficiários da revolução, em prejuízo do potencial inovador.

Repensar as estruturas políticas e concorrenciais do Estado brasileiro deve ser prioridade. É fundamental, assim, que as formatações jurídicas, políticas e econômicas estejam alinhadas - tendo a concepção ordoliberal ${ }^{7}$ como centro de convergência - para que a $4^{\mathrm{a}}$ revolução industrial seja vislumbrada como fator de impulso ao desenvolvimento.

\section{2 - Moldura Mínima do Estado Brasileiro no Contexto da Quarta Revolução Industrial}

Analisando a conjuntura atual do capitalismo norteamericano, Luigi Zingales (2015) destaca que o compadrio, a lógica do "vencedor-leva-tudo" e a economia de "superastros" têm desvirtuado as estruturas essenciais que permearam o capitalismo americano, gerando sensação de injustiça e reduzindo a confiança do cidadão.

O compadrio acarreta corrosão da meritocracia, a partir da simbiose entre o Estado e o poder econômico, desequilibrando-se a concorrência. É evidenciado, sobretudo, na captura do Estado e, em muitas vezes, na captura recíproca.

Segundo a lógica do "vencedor-leva-tudo", nas novas estruturas de mercado, impulsionadas pelo software, "aquele que produzir o melhor aplicativo numa determinada categoria vai conquistar o mercado inteiro - não apenas o americano, mas o global" (ZINGALES, 2015, p. 113).

A obra, conquanto voltada principalmente a analisar os aspectos do capitalismo norte-americano, possui inequívoca aplicação em relação às estruturas capitalistas brasileiras e aos impactos que a quarta revolução industrial pode acarretar.

Diante do quadro atual da economia estadunidense, o autor aponta que a utilização da tributação como mecanismo distributivo; a hipertrofia da regulação e a simples rejeição das novas tecnologias não são as soluções adequadas. Nos dois primeiros casos, aduz que o incremento do papel do Estado pode fomentar o desenvolvimento do compadrio, acarretando captura.

\footnotetext{
7 “Os objetivos do ordoliberalismo são: moldar a economia por meio da formulação das regras do jogo, seguido da sua preocupação de que forças do mercado livre podem dar origem a instituições indesejáveis em forma de cartéis" (KLEIN, Caroline Rippe de Mello. Origens do pensamento liberal: uma pequena leitura da liberdade. Revista Convergência Crítica, $n^{\circ} 4,2014$ ).
}

Quanto ao terceiro aspecto, é natural que as inovações disruptivas tornem obsoletas certas profissões, alterando espectros sociais. Foi o que ocorreu com o mensageiro, quando da introdução da máquina a vapor; e com o livreiro, antes da introdução dos livros digitais, conforme exemplifica Zingales (2015). A tendência histórica, contudo, é que tais profissões sejam esquecidas pelas gerações que se seguem, abrindo-se novos mercados profissionais.

Os caminhos apontados por Zingales (2015) são nortes fundamentais para que o modelo brasileiro esteja adequado à realidade revolucionária descrita por Schwab (2016).

$\mathrm{O}$ autor italiano propõe um retorno do capitalismo norte-americano às suas origens, cujas características fundamentais consistiam na igualdade de oportunidades e de mercado e na desconcentração de poder político, decorrente do sistema federativo, possibilitando o que denominou "voto com os pés".

De fato, o compadrio corrói as estruturas de mercado, gerando desvirtuamento do sistema capitalista, em prejuízo do mérito e em desestímulo à inovação e ao empreendedorismo. O resultado final é a sensação generalizada de injustiça e o pessimismo, em prejuízo ao ambiente saudável de negócios.

$\mathrm{Na}$ mesma esteira, o modelo de fomento estatal a criação de "superastros" econômicos deve ser evitado, sob pena de desequilíbrio concorrencial que haverá de corroer as estruturas do livre-mercado.

A obra está em sintonia com a realidade brasileira. Aqui, o modelo de "superastros", por meio de subsídio ao desenvolvimento de campeões de mercado, conquanto lastreado na busca de eficiência, pecou em olvidar a competição, transformando a eficiência em fim em si mesmo.

Os prejuízos ao regular funcionamento de mercado foram notórios, em prejuízo à inovação e, portanto, à eficiência dinâmica e ao desenvolvimento.

A matriz mínima institucional proposta no presente artigo, à luz das lições econômicas de Zingales (2015), deve direcionar os institutos jurídicos e políticos, sobretudo os concorrenciais, ao fortalecimento do mercado - não apenas dos negócios. O modelo pro market, ao invés daquele pro business é essencial à preservação da liberdade concorrencial e, em consequência, das liberdades democráticas.

Somente o fortalecimento real dos mecanismos concorrenciais - por meio da adoção de um modelo econômico de cunho ordoliberal, através do qual o Estado assegure a eficiência dos processos competitivos - é capaz de assegurar liberdade, preservando os alicerces do desenvolvimento da democracia brasileira.

A necessidade de formação de uma matriz institucional e jurídica adequada ao norte econômico ordoliberal exsurge como meio para que a quarta revolução industrial seja, de fato, oportunidade de alavancar o desenvolvimento do Estado brasileiro.

Nessa moldura jurídico-institucional concebida para acomodar a quarta revolução industrial, impulsionando-a, é necessário:

a) prestígio à segurança jurídica;

b) fomento à inovação;

c) colaboração entre empresas e cooperação imparcial entre o Estado e as empresas. 
De fato, para que os players do mercado sejam estimulados a empreender, é mister o fortalecimento de um ambiente negocial seguro.

Ocorre que o cenário brasileiro carrega forte insegurança jurídica para o mercado, sobretudo quando se observa um modelo de tratamento de conflitos ainda arraigado no Poder Judiciário, cujas decisões fundam-se em leis norteadas pelo dirigismo contratual, a exemplo das normas sobre Direito de Empresa. Não contribui para a segurança, outrossim, a hipertrofia da jurisdição constitucional e o movimento de "judicialização da vida", o qual sinaliza ao mercado um forte intervencionismo sem sincronia.

Um importante passo rumo à eliminação da "jurisprudência lotérica" foi dado nos últimos tempos, a partir do início de formatação de um sistema de precedentes, por meio do Código de Processo Civil de 2015.

Outro passo fulcral está na possibilidade de utilização da arbitragem, inclusive em questões que envolvem direito público, otimizando-se a produção de decisões em matérias que envolvem alto grau de complexidade técnica. Neste ponto, no entanto, ainda há muito a avançar, discutindo-se, ainda em fase inicial, por exemplo, a possibilidade de extensão da arbitragem às cercanias do direito tributário.

Avanço louvável adveio com a Lei $n^{\circ} 12.529$, de 30 de novembro de 2011, a qual reformou o Conselho Administrativo de Defesa Econômica (CADE), reduzindo o tempo para prolação de decisões concorrenciais, aumentando a independência da autarquia e, sobretudo, prevendo o controle prévio dos atos de concentração. $\mathrm{O}$ CADE, aliás, já tem empreendido importantes estudos acerca de questões que se inserem no contexto da quarta revolução industrial, citando-se, por exemplo, estudo datado de abril de 2018, desenvolvido pelo Departamento de Estudos Econômicos (DEE), em que analisados os efeitos concorrenciais do aplicativo Uber $^{8}$.

Contribui igualmente para insegurança jurídica a perspectiva segundo a qual o aplicador do direito interpreta as normas. O viés puramente retrospectivo e punitivista sobre estruturas de mercado, desprezando análises que tomem em consideração aspectos econômicos e consequenciais, gera igualmente notória insegurança.

Neste sentido, o artigo 20 da Lei de Introdução às Normas do Direito Brasileiro, introduzido após a edição da Lei $n^{\circ} 13.655$, de 25 de abril de $2018^{9}$ - fruto dos estudos administrativistas de Carlos Ari Sundfeld - demanda uma virada de mentalidade para que o direito seja igualmente alvo de perscrutações consequenciais.

Não se está a sustentar que se devam desprezar os mecanismos de punição empresarial. Longe disto.

No entanto, a lógica utilitarista que permeia o mercado e o homo economicus é diferente da lógica do homo medius do direito sancionatório, sendo necessário preservar as estruturas econômicas, sem embargo de expurgar as máculas do sistema.

Quanto ao fomento à inovação, é certo que o compadrio e o risco da captura são problemas que precisam

\footnotetext{
${ }^{8} \mathrm{http}: / /$ www.cade.gov.br/noticias/dee-analisa-efeitos-

concorrenciais-da-entrada-da-uber-sobre-mercado-de-aplicativosde-taxi.

${ }^{9}$ Inclui no Decreto-Lei ${ }^{\circ}$ 4.657, de 4 de setembro de 1942 (Lei de Introdução às Normas do Direito Brasileiro), disposições sobre segurança jurídica e eficiência na criação e na aplicação do direito público.
}

ser encarados com seriedade. Não há estímulo à inovação se o mercado funciona através de estruturas corroídas. Onde não impera o mérito, não há confiança tampouco estímulo à inovação e ao empreendedorismo.

O modelo gerencial de administração pública, neste sentido, já proposto desde o advento da Emenda Constitucional $\mathrm{n}^{\mathrm{o}} 19$, de 04 de junho de 1998, deve ser fortalecido, com a ressalva metodológica ora sustentada de que a eficiência não é um fim em si mesmo, nem o valor supremo a ser alcançado, tratando-se de meio para que a concorrência e a liberdade de mercado possam ser experimentadas por todos os participantes do jogo capitalista.

A inovação deve exsurgir igualmente na criação de novas tecnologias jurídicas que se voltem a reger os efeitos da revolução industrial 4.0. Fundamental, ademais, é construir uma plataforma educacional que se volte ao desenvolvimento de novas tecnologias e ao estudo de novos materiais, incentivando-se o empreendedorismo.

O modelo que se deve buscar é pautado no fortalecimento da concorrência, a fim de que o poder econômico não capture o Estado. É preciso, aliás, que se construam mecanismos de cooperação utilitaristas, a fim de que os agentes econômicos sintam-se estimulados a perceber que são parte de um todo que deve funcionar de forma harmoniosa para o desenvolvimento comum.

Neste ponto, os instrumentos de justiça fiscal e os órgãos de fiscalização de condutas predatórias devem ter efetividade $^{10}$, para que se crie um jogo saudável que conduza ao incentivo utilitário de parceria empresarial.

Estado e Empresas devem ser igualmente parceiros jamais compadres - incentivando-se as parcerias públicoprivadas e utilizando-se a competição real como um dos critérios norteadores das aquisições públicas mediante licitação. Também aqui, o fortalecimento do controle dos mecanismos de combate à cartelização se faz necessário para que se tenha saudável ambiente de negócios.

\section{CONCLUSÃO}

A quarta revolução industrial é uma oportunidade real de desenvolvimento do Brasil. A partir das constatações de Klaus Schwab e de Luigi Zingales, analisadas sob o prisma capitalista concorrencial ordoliberal, conclui-se ser necessária a formulação de um molde institucional e jurídico mínimo que permita ao Brasil acompanhar as novas dinâmicas de mercado, impulsionando o desenvolvimento, a inovação e o empreendedorismo.

O resultado a ser alcançado não deve olvidar o norte da eficiência. Não se pode, contudo, erigir a eficiência ao patamar de fim em si mesmo, devendo-se priorizar a busca pelo equilíbrio concorrencial, mediante mecanismos que obstem a captura do Estado.

A quarta revolução industrial deverá moldar as estruturas jurídicas brasileiras, sendo igualmente por elas moldada. Nos moldes institucionais exsurgem como vetores a segurança jurídica, o fomento à inovação e a colaboração.

${ }^{10}$ Neste sentido, conferir ARAÚJO, Alan Kilson Ribeiro; LEITE, Fábio de Araújo; NASCIMENTO, Danilo Alves; GONÇALVES, Rodrigo Franco. Internet das coisas: uma avaliação comparativa de instrumentos relatórios. Revista Sodebras [on line]. v. 11, $\mathrm{n}^{\circ}$ 123, março/2016, p.222-225. ISSN. 1809-3957. Disponível em: <http://www.sodebras.com.br/edicoes/N123.pdf>. Acesso em: 02 de dezembro de 2015. 
Se o duplo-atraso outrora descrito caracterizou o percurso do Brasil pelas revoluções industriais pretéritas, o momento é tempestivo para que não se percam as oportunidades de desenvolvimento que advirão com a revolução em curso.

\section{REFERÊNCIAS}

ARAÚJO, Alan Kilson Ribeiro; LEITE, Fábio de Araújo; NASCIMENTO, Danilo Alves; GONÇALVES, Rodrigo Franco. Internet das coisas: uma avaliação comparativa de instrumentos relatórios. Revista Sodebras [on line]. v. 11, $\mathrm{n}^{\mathrm{o}}$ 123, março/2016, p.222-225. ISSN. 1809-3957. Disponível em: <http://www.sodebras.com.br/edicoes/N123.pdf>. Acesso em: 02 de dezembro de 2015.

AZEVEDO, Paulo Furquim. Análise econômica da defesa da concorrência. In: TIMM, Luciano Benetti (org.). Direito e Economia no Brasil. 2. ed. São Paulo: Atlas, 2014.

BAGNOLI, Vicente. Direito Econômico. 6.ed. São Paulo: Atlas, 2013.

BAGNOLI, Vicente. Direito e Poder Econômico. Os Limites Jurídicos do Imperialismo frente aos Limites Econômicos da Soberania. Rio de Janeiro: Elsevier, 2009.

BORK, Robert H. The antitruste paradox. New York: The Free Press, 1993.

BRASIL. Lei no 10.406, de 10 de janeiro de 2002 (Código Civil). Brasília: Distrito Federal, jan. 2002.

BRASIL. Lei $n^{\circ}$ 12.529, de 30 de novembro de 2011. Brasília: Distrito Federal, nov. 2011.

COOTER, Robert; ULEN, Thomas. Law \& economics. 6.ed. Boston: Pearson/Addison Wesley, c2012.

GICO JÚNIOR, Ivo. Introdução ao Direito e Economia. In: TIMM, Luciano Benetti (org.). Direito e Economia no Brasil. 2. ed. São Paulo: Atlas, 2014.

KLEIN, Caroline Rippe de Mello. Origens do pensamento liberal: uma pequena leitura da liberdade. Revista Convergência Crítica, nº 4014.

MACKAAY, Ejan; ROUSSEAU, Stéphane. Análise Econômica do Direito. Tradução de Rachel Sztjan. 2.ed. São Paulo: Atlas, 2015.

MARIUTTI, Eduardo Barros. Liberdade, justiça, concorrência e mercado: as tensões no pensamento liberal contemporâneo. Texto para Discussão Unicamp. IE. Campinas No. 285 mar $/ 2018$.

MUNHOZ, Carolina Pancotto Bohrer. Desenvolvimento e concorrência. In: Direito e Desenvolvimento. Org: BARRAL, Walber. São Paulo: Singular, 2005.

POSNER, Richard. Economic analysis of law. 9.ed. New York: Wolters Kluwer Law \& Business, 2014.

Para além do direito. Tradução de Evandro Ferreira e Silva. São Paulo: Martins Fontes, 2009.

SALOMÃO FILHO, Calixto. Direito Concorrencial. São Paulo: Malheiros, 2013.

SCHWAB, Klaus. A quarta revolução industrial. Tradução de Daniel Moreira Miranda. São Paulo: Edipro, 2016.
SILVA, Ernani Marques; AIHARA, Celia Hatsumi; SALVETTI, Nilson; FERNANDES, Tereza Cristina Maia; MAURO, Maria Helena. Modelando impactos das tecnologias de informação e comunicação na relação entre gestão do conhecimento, capacidade de inovação e eficiência organizacional. Revista Sodebras [on line]. v. 13, no 147, março/2018, p.124-128. ISSN. 1809-3957. Disponível em: <http://www.sodebras.com.br/edicoes/N147.pdf >. Acesso em: 20 de novembro de 2017.

WOLKART, Erik Navarro. Análise econômica do processo civil. São Paulo: Revista dos Tribunais, 2019.

ZYLBERSZTJN, Decio; SZTAJN, Rachel. Análise Econômica do Direito e das Organizações. In: Direito e Economia. Organizadores: ZYLBERSZTJN, Decio; SZTAJN, Rachel. Rio de Janeiro: Elservier, 2005.

ZINGALES, Luigi. Um capitalismo para o povo: reencontrando a chave da prosperidade americana. São Paulo: BEI Comunicação, 2015.

\section{COPYRIGHT}

Direitos autorais: O autor é o único responsável pelo material publicado nesta revista.

Submetido em: 26/02/2019 Aprovado em: 15/04/2019 


\author{
Revista SODEBRAS - Volume 14 \\ $\mathrm{N}^{\circ} 161-\mathrm{MAIO} / 2019$
}

\title{
O SISTEMA MOODLE PODE SER CONSIDERADO UM MODELO DE GESTÃO DO CONHECIMENTO?
}

\author{
CAN THE MOODLE SYSTEM BE CONSIDERED A KNOWLEDGE \\ MANAGEMENT MODEL?
}

\author{
GUILHERME CASSAROTTI FERIGATO ${ }^{1}$; JOSÉ APARECIDO PEREIRA ${ }^{2}$ \\ 1- MESTRE EM GESTÃO DO CONHECIMENTO - UNICESUMAR; 2- DOUTOR EM FILOSOFIA. \\ PROFESSOR NA PONTIFÍCIA UNIVERSIDADE CATÓLICA DO PARANÁ E NO PROGRAMA DE PÓS- \\ GRADUAÇÃO EM GESTÃO DO CONHECIMENTO NAS ORGANIZAÇÕES DA UNICESUMAR. \\ PESQUISADOR DO INSTITUTO CESUMAR DE CIÊNCIA, TECNOLOGIA E INOVAÇÃO (ICETI). \\ guilhermeferigatto@gmail.com; pzez@bol.com.br
}

\begin{abstract}
Resumo - No presente artigo o objetivo consiste em estabelecer relaçõesentre duas áreas importantes do saber humano, quais sejam, a gestão do conhecimento e a educação a distância. Nesse sentido, o intuito é realizar conexões entre a espiral do conhecimento proposta por Takeuchi e Nonaka e o moodle como ferramenta de ensino e aprendizagem em ambientes virtuais, a partir da seguinte questão: comparado com a espiral do conhecimento, o Moodle pode ser considerado um modelo de gestão do conhecimento? O artigo está dividido em três partes: a) a espiral do conhecimento na ótica de Nonaka e Takeuchi; b) $O$ sistema moodle como ambiente de ensino e de aprendizagem; Da possibilidade do sistema Moodle ser considerado um modelo de gestão do conhecimento. Os procedimentos adotados para a discussão em torno do problema se orientaram pela leitura, análise e interpretação dos textos que abordam o assunto definido neste texto.
\end{abstract}

Palavras-chave: Espiral do Conhecimento. Moodle. Gestão.

\begin{abstract}
In this article the objective is to establish relations between two important areas of human knowledge, namely, knowledge management and distance education. In this sense, the intention is to make connections between the based on the following question: compared to the knowledge spiral, Moodle can be considered a model of knowledge management? The paper is divided into three parts: a) the knowledge spiral from Nonaka and Takeuchi; b) The moodle system as a teaching and learning environment; The possibility of the Moodle system being considered a model of knowledge management. The procedures adopted for the discussion around the problem were guided by the reading, analysis and interpretation of the texts that approach the subject defined in this text.
\end{abstract}

Keywords: Knowledge Spiral. Moodle. Management.

\section{INTRODUÇÃO}

$\mathrm{Na}$ contemporaneidade, o conhecimento constitui a mola propulsora no processo de gestão nas organizações. É por meio dele que essas entidades podem adquirir, organizar e processar informações com o intuito de ampliar os conhecimentos já perpetuados. Conforme (ANDREATTO et al, 2018, p. 25), "a gestão desse conhecimento exige esforço, determinação e autonomia no processo de geração de mudança que subsidiará a organização no direcionamento de suas frentes".
Também no âmbito da educação a distância, o conhecimento constitui-se como elemento fundamental nas relações de ensino e aprendizagem. Por isso, faz-se necessário o desenvolvimento de ambientes virtuais de ensino e de aprendizagem, provindos e geridos por meio de plataformas e ferramentas de construção de ambientes, como por exemplo, o moodle.

A investigação que pretendemos desenvolver nesse artigo encontra-se relacionada a duas áreas importantes, tanto no âmbito da gestão quanto no contexto da educação a distância. Assim, a nossa abordagem procurará estabelecer relações entre a espiral do conhecimento proposta por Takeuchi e Nonaka e o moodle como ferramenta de ensino e aprendizagem em ambientes virtuais. Tendo em vista isso, o seguinte problema norteará a nossa reflexão: comparado com a espiral do conhecimento proposta por Nonaka e Takeuchi, o Moodle pode ser considerado um modelo de gestão do conhecimento? Partimos da hipótese que, pelas suas características, ele pode, seguramente, ser interpretado como um modelo de gestão de conhecimento.

\section{MÉTODO}

Os procedimentos metodológicos adotados para a discussão em torno do problema se orientaram pela leitura, análise e interpretação dos textos que abordam o assunto definido neste texto, ou seja, foi priorizado o método qualitativo. $\mathrm{O}$ texto em seu desenvolvimento está organizado em três partes: a) a espiral do conhecimento na ótica de Nonaka e Takeuchi; b) O sistema moodle como ambiente de ensino e de aprendizagem e c) Da possibilidade do sistema Moodle ser considerado um modelo de gestão do conhecimento.

\section{RESULTADOS}

3.1 - A espiral do conhecimento na perspectiva de Takeuchi e Nonaka

Para Nonaka (2008), o conhecimento está vinculado a exploração dos insights, ou seja, o conhecimento tácito, ideias pessoais e expertise de cada indivíduo são utilizadas constantemente e podem ser testados e utilizados pelas 
organizações. Neste sentido, acredita-se que para acontecer a socialização do conhecimento tácito é necessário um ambiente favorável para a construção do conhecimento e que os indivíduos se sintam confortáveis e seguros para compartilhar suas ideias e pensamentos. Outro ponto fundamental em relação às organizações japonesas, apresentado por Nonaka (2008, p. 41) é que “a empresa não é uma máquina, mas um organismo vivo. Da mesma forma que um indivíduo, ela pode ter um sentido coletivo de identidade e de finalidade fundamental. Este é o equivalente organizacional ao autoconhecimento". Ou seja, o entendimento de todos os caminhos a serem seguidos pela organização.

Para Takeuchi e Nonaka (2008) o novo conhecimento tem sua origem no indivíduo, ou seja, inicia-se a partir do conhecimento tácito que ao longo do tempo foi construído e se torna sua parte intrínseca. Quando ele contribui com algo novo: "o conhecimento pessoal de um indivíduo é transformado em conhecimento organizacional para a empresa como um todo" (TAKEUCHI; NONAKA, 2008, p. 41). Assim, o conhecimento ao ser transformado em organizacional pode ser utilizado em massa, sendo o novo conhecimento utilizado por toda a organização e em todos os níveis hierárquicos. Com relação a gestão do conhecimento, os autores concluíram que a construção do conhecimento possui o seguinte pressuposto: "o conhecimento é criado através da interação entre o conhecimento tácito e o explícito" (TAKEUCHI; NONAKA, 2008, p. 60). Por isso, segundo os autores, o conhecimento pode ser convertido através de quatro formas: socialização, externalização, combinação e internalização.

Para Takeuchi e Nonaka (2008. p. 60) "o indivíduo pode adquirir conhecimento tácito diretamente dos outros sem usar a linguagem". No processo de socialização, um ponto importante salientado pelos autores está ligado à experiência do indivíduo como fator fundamental para a aquisição do conhecimento tácito. Nessa etapa da espiral, o conhecimento encontrado é o chamado conhecimento tácito que, por sua vez, é transmitido para outros indivíduos. Assim, segundo Torres et al (2009, p. 1), "na socialização ocorre a construção e compartilhamento do conhecimento tácito através da interação entre as pessoas, sendo que existe a conversão do conhecimento tácito para o tácito". Também há convergências de ideias com Fresta (2011, p. 28) quando afirma que a socialização é oriunda de ralações e interação de conhecimentos intrínsecos dos indivíduos, ou seja, conhecimento tácito disseminado entre pessoas. Portanto, a socialização está vinculada a vivências, experiências e técnicas são compartilhadas informalmente e não tendo a obrigatoriedade de meios padronizados para tal.

Em relação à externalização, Takeuchi e Nonaka (2008, p. 62) salientam que "é um processo de articulação do conhecimento tácito em conceitos explícitos". Isso é fruto reflexivo do diálogo. Processo que acontece de modo organizado, planejado, articulado e definido de modo a converter o conhecimento tácito em conhecimento articulável, ou seja, identifica-se o conhecimento tácito, aplica-lhe deduções e induções de modo a sistematizá-lo a ponto de ser um conceito explícito formal. Soares (2012, p. 48) refere-se à externalização nos seguintes termos: “Através da interação mútua e de diálogos há articulação do conhecimento tácito em explícito. Acontece através de códigos, linguagem estimulando a utilização do conhecimento tácito por meio de analogias, metáforas ou modelos".

A próxima etapa descrita por Takeuchi e Nonaka na espiral é a combinação na qual se encontra o conhecimento sistêmico que se deu através da combinação de vários conhecimentos explícitos. Para Silva et al (2011, p. 5) "o conhecimento passa do grupo para a organização sob a forma de documentos, formalizações e conversas". Por sua vez, Para Oliveira et al. (2010, p. 157), "a combinação tem como objetivo sistematizar o conhecimento explícito, ocorrendo a conversão de explícito para explícito. Nesse caso o conhecimento passa do grupo para a organização". Logo, a combinação nada mais é do que, nas palavras de Fresta (2011, p. 32) "diferentes conhecimentos explícitos em um novo conhecimento explícito, num processo de sistematização de conceitos". Ainda nesse sentido, Soares (2012, p. 48) afirma que: "É o processo de sistematizar conceitos em um sistema de conhecimento, cria conhecimento explícito ao combinar diferentes conhecimentos explícitos por meio de processos sociais".

Por fim, a internalização encerra as etapas de conversão do conhecimento de modo que o conhecimento explícito se torne algo intrínseco do indivíduo, ou seja, o conhecimento passou pela socialização, externalização, combinação passa a ser know-how, expertise do indivíduo transformando-o no valioso capital intelectual. Desse modo, o modelo de espiral do conhecimento defendido pelos autores está atrelado à premissa segundo a qual o conhecimento humano é construído e disseminado por meio da interação social. Dessa maneira, a conversão do conhecimento pode acontecer percorrendo o seguinte itinerário: "1. Socialização: Compartilhar e criar conhecimento tácito através de experiência direta; 2 . Externalização: Articular conhecimento tácito através do diálogo e da reflexão; 3. Combinação: Sistematizar e aplicar o conhecimento explícito e a informação; 4. Internalização: Aprender e adquirir novo conhecimento tácito na prática" (NONAKA; TAKEUCHI, 2008, p. 23).

Mas para haver harmonia nos fluxos da espiral do conhecimento os autores indicam serem necessários alguns meios de promoção de condições para criação do conhecimento organizacional, tais como: a) intenção, Takeuchi e Nonaka (2008, p. 71) definem como "a aspiração da organização às suas metas". Para atingir a intenção, é necessário que os esforços aconteçam de forma planejada e se tornem parte do planejamento do negócio; b) a autonomia: " [...] aumenta a possibilidade de motivação dos indivíduos para a criação de novos conhecimentos. Além disso, as pessoas autônomas funcionam como parte de uma estrutura holográfica, na qual o todo e cada parte compartilham as mesmas informações". (NONAKA, 2008, p.75); c) flutuação e caos criativos: nela acontece a interação da organização com o ambiente externo. Nesta etapa, ocorre a chamada decomposição: "Uma flutuação ambiental frequentemente desencadeia uma decomposição na organização, a partir da qual novo conhecimento pode ser criado" (NONAKA, TAKEUCHI, 2008, p. 76). Por outro lado, o caos criativo é concebido de modo natural. A organização se depara com uma crise, como por exemplo, mudanças no contexto econômico-político de um país ou pode ser gerado propositalmente para que haja movimentação e criação de metas e objetivos inovadores criando, assim, uma espécie de desafio ou uma crise simulada. Ele pode contribuir com o aumento do 
comprometimento dos indivíduos com os objetivos diários e suas tarefas.

Tendo apresentado as etapas constituintes da espiral do conhecimento na ótica de Nonaka e Takeuchi, nas linhas seguintes, o propósito consiste em explicitar os componentes fundamentais do sistema Moodle para, posteriormente, demonstrar em que sentido ele pode ser considerado um modelo de gestão de conhecimento a partir das etapas da referida espiral.

\section{2 - O sistema moodle como ambiente de ensino $e$ de aprendizagem}

Para (LEMOS et al, 2018, p. 6) "A utilização de ambientes computacionais na educação auxilia a condução do processo de ensino em direção a melhorias e avanços no processo de ensino aprendizagem". Nesse sentido, o Moodle constitui uma ferramenta fundamental. A palavra moodle é a junção de Modular Object-Oriented Dynamic Learning Environment, ou seja, Ambiente de Aprendizagem Dinâmica Modular Orientado a Objeto. Almeida (2014, p. 41) salienta que "O sistema moodle é um sistema de gestão de ensino e aprendizagem que permite a criação de cursos on-line, aplicações de uma série de atividades, aulas, sequências didáticas e tudo isso possibilitando a criação de um ambiente de aprendizagem virtual". Várias e novas atualizações e versões foram melhoradas e à medida que o moodle ganhou espaço e foi utilizado, outras aplicabilidades foram surgindo, como por exemplo, utilizado por escolas de nível primário a fim de auxiliar os pais a ensinarem os filhos em suas próprias casas. Ele também é utilizado como meio de promover o ensino e a aprendizagem na educação a distância. Carvalho Junior et al. (2012, p. 42) afirmam que "o moodle é uma ferramenta de apoio à aprendizagem amplamente utilizada por instituições de ensino que fazem uso de metodologia de ensino a distância". Por outro lado, Castro (2012, p. 26) destaca que o "moodle é adequado para atividades a distância, mas nada o impede de ser uma ferramenta para apoiar e complementar as atividades do ensino presencial".

A ferramenta moodle foi pensada e concebida por cientista da computação ao perceber que poderia possibilitar novos horizontes educacionais e ampliação da usabilidade dos sistemas de engenharia utilizados pelos educadores dessa área e, principalmente, aos estudantes a fim de minimizar possíveis distorções no processo de ensino e de aprendizagem: "Moodle foi criado por Martin Dougiamas, cientista da computação e educador que passou um tempo apoiar um CMS em uma universidade em Perth, Austrália. (COLE; FOSTER, 2008, p. ix).O moodle está vinculado ao sítio na internet moodle.org, o qual centraliza informações, discussões colaborativas entre os usuários da ferramenta de modo que eles possam socializar suas dificuldades e casos de sucesso a fim de auxiliar a empresa provedora do moodle a aprimorar sua ferramenta de maneira mais harmoniosa com os interesses dos usuários. Convêm destacar que em 2003, uma empresa foi criada com objetivo de oferecer e dar suporte na usabilidade, hospedagem, consultoria e parametrização dos ambientes, a empresa moodle.com.

Ao entrar em contato com a história do moodle, podemos vislumbrar um ambiente virtual de aprendizagem. Esse pode ser considerado como um importante recurso que aproxima o professor e o estudante que por algum motivo não tem a oportunidade de estar fisicamente em sala de aula, distância da sala de aula dentre outros fatores. Nesse sentido, Valenzuela e Villalobos (2013, p. 73) afirmam que: "Os administradores têm todos os privilégios e sua principal função é gerenciar as informações no banco de dados e controle de acesso. Finalmente, os professores estão desenvolvendo atividades e materiais para os sujeitos, com base na aplicação de princípios pedagógicos".

Se planejados e controlados, então os ambientes virtuais de aprendizagem possibilitam a construção tanto do conhecimento tácito quanto do explícito igualmente como acontece em sala de aulas presenciais. O moodle foi inicialmente construído com apoio pedagógico ao processo de ensino e de aprendizagem online ou ensino a distância, mas que hoje pode assumir muitas caraterísticas peculiares da educação a distância, tais como, comunicação, repositório de informação, rede de trabalho colaborativo etc. Isso tem proximidade com a afirmação de Burnham et al. (2012) para o qual o moodle surge com destaque em relação a outros ambientes virtuais. Além disso, possui especificidades que atendem diretamente as necessidades pedagógicas, flexibilizando e proporcionando autonomia aos professores. Assim, o Moodle é um conjunto de softwares utilizados para produção de cursos na internet, o que converge para o pensamento de Cole e Foster (2008) ao afirmarem que o moodle pode ser entendido como um sistema de gerenciamento de cursos utilizados por escolas, faculdades e, até mesmo, empresas para instrução individual e/ou coletiva, mas para tal é necessária a utilização de tecnologia e navegadores da web.

O moodle, apesar de ser protegido por direito autoral, é fornecido gratuitamente e com as funcionalidades e usabilidades básicas onde o usuário é autorizado. Para Dougiamas e Taylor (2009, p. 20): "O Moodle foi desenhado para ser compatível, flexível, e fácil de ser modificado. Foi escrito usando-se a linguagem popular e poderosa do PHP, que faz funcionar qualquer plataforma de computador com um mínimo de esforço, permitindo que professores montem seus próprios servidores usando suas máquinas desktop (computador de mesa)".

Em sua concepção inicial, o moodle foi pensado para que o professor pudesse facilmente manipulá-lo adequadamente no âmbito do ambiente virtual de aprendizagem. Outra característica destacável é a possibilidade de integração e compatibilidade do moodle com outras plataformas de sistemas que podem contribuir, como por exemplo, com o gerenciamento acadêmico. Mas é possível identificar outros recursos que foram implantados devido a demandas institucionais e educacionais das instituições de ensino superior, tais como: a) Material Extra: recurso de livre acesso ao professor da disciplina do curso que é utilizado para a disponibilização de alguns materiais, tais como, artigos, imagens, planilhas, vídeos; b) Sala do Café: recurso disponibilizado para que estudantes e professores possam criar seus próprios tópicos de discussão. Este recurso acreditamos ter proximidade com o conceito de $b a$ do conhecimento, ou seja, é um ambiente propenso, motivador e facilitador onde haverá socialização, compartilhamento de conhecimento entre os indivíduos. De modo geral é um local físico, um espaço no qual as pessoas se encontram e trocam experiências, mas que poderá ser um ambiente virtual para ampliação do $b a$ físico; c) Mural de Avisos: recurso que é alimentado com cronogramas, informações do andamento do curso e orientações gerais; d) Atividades: recurso que direciona o estudante diretamente para a atividade que deve ser realizada no momento. 
Existem ainda outros recursos como fórum, chat, escolha, glossário, diário, questionário, tarefa, wiki (LEITE, 2016).

Além das características tecnológicas e facilitadoras do processo de ensino e de aprendizagem o moodle pode contribuir com o fluxo de comunicação entre os participantes dos ambientes e, principalmente, como maximizador do processo de aprendizagem cooperativa. Diante dessa perspectiva Piccolo e Santana (2010, p. 6) salientam que o "moodle como meio de suporte para ser uma ferramenta não só de comunicação, mas também de colaboração e cooperação entre todos os atores envolvidos nos projetos e programas educacionais do Instituto". Como podemos observar, omoodle propicia uma gama de recursos e atividades que são parametrizadas pelos gestores, de modo geral pela área de tecnologia da informação, as quais estão baseadas nos objetivos pedagógicos e nos objetivos institucionais e organizacionais. Tais parametrizações permitem aos usuários a flexibilizaçãocontribuindo com um ambiente adaptativo às necessidades e passível de possíveis melhorias ao longo do seu uso. Através dessas parametrizações e flexibilizações este ambiente poderá ser um local não somente utilizado com repositório de materiais, mas também como um bavirtual do conhecimento, proporcionando, em nossa visão, uma ampliação e perpetuação do conhecimento, seja na forma tácita ou explicita.

Quanto à sua filosofia, o formato do moodle apresentase como aprendizagem especial, focando-se na pedagogia sócio construtivista. Esta filosofia é descrita por Moodle (2016, p. 1) a partir de quatro conceitos: a) Construtivismo: apresenta o conhecimento construído a partir da interação do indivíduo com o seu ambiente. Tudo o que acontece ao redor do indivíduo poderá ser aliado às experiências passadas constituindo um novo conhecimento. Se usado sucessivamente, então o ambiente do indivíduo poderá ser ampliado e fortalecido; b) Construcionismo: a aprendizagem só terá seu efeito quando causa impacto nas experiências de outrem. $\mathrm{O}$ que socializamos interfere no outro modificando seu modo de pensar e reproduzir a informação compartilhada; c) Construtivismo Social: um grupo social construindo algo para os outros, de modo compartilhado e agrupado dividindo os mesmos objetivos; d) Comportamento Conectado e Separado: analisa com mais profundidade as motivações dos indivíduos diante de uma discussão. O comportamento separado apresenta o indivíduo defendendo suas ideias de modo lógico buscando a identificação de pontos falhos nas ideias dos outros. Por outro lado, o comportamento conectado, é a compreensão das ideias de todos havendo a empatia entre as pessoas. No tópico seguinte, tem-se como objetivo fundamental responder a seguinte questão: considerando as etapas da espiral do conhecimento o Moodle pode ser considerado um modelo de gestão do conhecimento?

\section{3 - Da possibilidade do sistema Moodle ser considerado um modelo de gestão do conhecimento}

Quanto à espiral do conhecimento, mais conhecida como modelo SECI, anteriormente observamos quatro etapas predominantes pelas as quais ocorrem as conversões do conhecimento: a socialização, a externalização, a combinação e, por fim, a internalização. Em relação a essa espiral na perspectiva de Takeuchi e Nonaka, fica claro que o recurso fórum do Moodle está relacionado com a socialização, uma vez que o recurso foi parametrizado para proporcionar aos usuários um meio ou canal de compartilhamento de informações e de conhecimento. Nesse sentido, Coutinho et al. (2007, p. 3) afirmam que "O fórum possui o gerenciamento de conhecimento atrelado à sua essência, já que naturalmente oferece as quatro etapas do gerenciamento de conhecimento [...] e fornece suporte aos modos de criação de conhecimento definidos por Nonaka". Assim, podemos afirmar que existe no moodle a conversão de conhecimento tácito para tácito na medida em que o estudante e o professor mantenham o relacionamento e a comunicação.

Há no Moodle vários recursos e fluxos de trabalho que, em conexão e trabalho colaborativo os quais podemos identificar como um processo de externalização. Dalmau (2010, p. 3) descreve o processo de externalização da seguinte maneira: "É o processo no qual o conhecimento tácito é expresso através de metáforas, analogias, conceitos, hipóteses e modelos, tornando-se explícito. A escrita, neste contexto, pode ser considerada como uma forma de conversão do conhecimento [...]". No contexto do ensino e da aprendizagem, é oportuno destacar que muitos dos recursos do moodle têm premissas de comunicação, registro e controle de histórico de etapas cumpridas. Além disso, é utilizado para troca de mensagens entre os participantes juntamente com o recurso de anexar arquivos, com o desenvolvimento do artigo pelo estudante e as devidas recomendações dos professores. A externalização pode ser algo ainda mais amplo, na medida em que outros possam absorver o conhecimento transmitido em artigos científicos, por exemplo.

A combinação, como etapa da espiral do conhecimento, no Moodle, é observada nas relações de trabalho, no gerenciamento e, principalmente, na organização, planejamento e parametrização do ambiente virtual, uma vez que nem todos os participantes possuem o conhecimento técnico para tal. Ela é visível no processo de desenvolvimento do moodle e, sobretudo, sua parametrização tendo como norte os objetivos das organizações, da sociedade e do processo de ensino e de aprendizagem. Toda esta combinação une-se quando áreas distintas trabalham em coesão uma com as outras, equiparando o conhecimento para o desenvolvimento conjunto do ambiente virtual. Nesse sentido, por se tratar de um ambiente virtual no qual há um grande número de pessoas envolvidas, podemos observar que há sim a combinação de conhecimento para o planejamento, a organização e o controle dos fluxos de trabalho empregados e estipulados para cada participante. No Moodle, combinação está presente, por exemplo, no desenvolvimento de manuais para as orientações nos quais são apresentadas as regras, os passose as normas para os estudantes e os professores.

Quanto à internalização, Dalmau et al. (2010, p. 1 e 2) destacam que ela "é o processo de incorporação do conhecimento explícito ao tácito, sendo a aprendizagem uma maneira de efetuar esta conversão". No contexto do ambiente de orientação de trabalho de conclusão de curso na modalidade a distância a internalização acontece, por exemplo, no momento em que o estudante desenvolve o artigo para o professor, e esse, observa que já não há mais falhas quanto as normas e regras que ele deveria seguir, bem como a aderência com as linhas de pesquisa de cada curso. Enfim, uma análise criteriosa de um recurso presente no Moodle qual seja, o fórum, mostrará que somente nele se 
encontram todas etapas da espiral do conhecimento propostas por Nonaka e Takeuchi.

Enfim, quanto às possíveis contribuições, o caráter interdisciplinar pode ser concebido como um dos principais aspectos relevantes desse estudo, visto que ele pretendeu estabelecer relações entre temas de campos distintos, mas conectados a um problema comum. No que tange às limitações, destacamos a impossibilidade de aprofundar algumas questões, como por exemplo, o processo de avaliação da aprendizagem no sistema moodle e a sua relação com a espiral do conhecimento, a fim de diagnosticar se os aspectos dessa espiral estão presentes no referido processo avaliativo e quais são as suas contribuições.

\section{CONCLUSÃO}

O presente artigo procurou desenvolver uma reflexão sobre a seguinte questão: comparado com a espiral do conhecimento proposta por Nonaka e Takeuchi, o sistema Moodle pode ser considerado um modelo de gestão do conhecimento? Considerando os resultados da pesquisa em torno dessa problemática, conclui-se que o moodle pode, sim, ser considerado um modelo de gestão do conhecimento. Não existem recursos únicos e específicos que possam ter exclusivamente relação com a espiral, mesmo o fórum que possui todas as etapas é amparado por outros recursos, atividades e fluxos de trabalho que corroboram para que ele seja assumido como um modelo de gestão. Assim, o moodle pode ser considerado um modelo de gestão do conhecimento por apresentar vários elementos colaborativos que se auxiliam para que as entradas sejam processadas, obtendo como resultado a aprendizagem. O moodle é uma ferramenta que reúne diversos elementos que contribuem com a identificação de conhecimento tácito, sua decodificação, seu armazenamento. A partir disso, outros conhecimentos podem ser originados e construídos mutuamente. Ele se destaca pela amplitude de possibilidades na construção de conhecimento e, principalmente, como provedor dos ciclos da gestão do conhecimento.

\section{REFERÊNCIAS}

ANDREATTO, Luciana Bovo et al. O diagnóstico de clima organizacional e a adoção de práticas de gestão do conhecimento no contexto escolar. Revista Sodebras [online]. v. 13, n. 156, Dez./ 2018, p. 25-30. ISSN 18093957. https://doi.org/10.29367/issn.1809-3957.2018.156.

ALMEIDA, Altair Portes: Estudo de funções utilizando geogebra e moodle. Dissertação, Universidade Federal de São Carlos. 2014.

BURNHAM, Teresinha Fróes et al. Ambientes virtuais de aprendizagem o Moodle com espaço multirreferencial de aprendizagem. Programa de Pós-graduação em Educação Universidade Federal de Bahia, UFBA. In: SILVA, Marco (org.). Formação de professores para docência online. São Paulo: Edições Loyola, 2012. Vários Autores.

CASTRO, Tássia Portela Serrão.Construção automática de redes sociais móveis no ambiente moodle. Dissertação, Universidade do Vale do Rio dos Sinos, São Leopoldo, 2012.
COLE, Jason; FOSTER, Helen. Using moodle: teaching with popular open source course management system. O’Reilly - EUA, 2008.

CARVALHO JUNIOR, Joelson; CARVALHO OLIVEIRA, Cíntia Simões, BORIM, Andrea Carla Alves. Ferramenta moodle como recuso para gerenciamento e orientação de TCC, Anuário da Produção Acadêmica Docente, vol. 5, n ${ }^{\circ}$ 10, Anhanguera Educacional Ltda., 2012

DALMAU, Marcos Baptista Lopez et al. O Processo de Gestão do Conhecimento em uma Instituição de Ensino Superior: Um Estudo de Caso Considerando a Oferta de um Curso de Graduação a Distância. Revista Digital da CVA Ricesu, ISSN 1519-8529. Volume 6, Número 22, fevereiro de 2010 .

DOUGIAMAS, Martin e TAYLOR, Peter C. Moodle: Usando Comunidades de Aprendizes para Criar um Sistema de Fonte Aberta de Gerenciamento de Curso. Capítulo 15: ALVES, Lynn Daniela e OKADA, Barros Alexandra (Org): MOODLE Estratégias Pedagógicas e Estudos de Caso, 2009.

FRESTA, Alcina Maria Rodrigues.Condições para a Criação do Conhecimento Organizacional FPTI Fundação Parque Tecnológico de Itaipu: Um estudo de caso, UFPR, 2011.

LEITE, Maria Teresa Meirelles.O ambiente virtual de aprendizagem Moodle na prática docente: conteúdos pedagógicos. 2008. Disponível em: http://www.pucrs.br/famat/viali/tic_literatura/artigos/ava/tex tomoodlevvirtual.pdf. Acesso em: 10/03/19.

LEMOS, Karina Dutra de Carvalho et al. O uso de softwares como apoio ao processo de aprendizagem em uma instituição de ensino público federal. Revista Sodebras [online]. v. 13, n. 156, Dez./2018, p. 6-13. ISSN 1809-3957. https://doi.org/10.29367/issn.1809-3957.2018.156

NONAKA; TAKEUCHI, H. Empresa Criadora do Conhecimento. In: Hirotaka Takeuchi e Ikujiro Nonaka (Org.). Gestão do Conhecimento. Bookman. Trad. Thorell A. 2008

OLIVEIRA, Mírian; BECKER, Grace Vieira; PEDRON, Cristiane Drebes; DALL'IGNA, Felipe. Espiral do conhecimento em frameworks de gestão do conhecimento: ocaso de duas organizações em Portugal. Perspectivas em Ciência da Informação, v.15, n.3, p.155-175, set./dez. 2010.

SILVA, Fernanda Tavares et al: A Apropriação do Modelo de Espiral do Conhecimento de Takeuchi e Nonaka: uma análise dos anais do EnANPAD de 2005 a 2009. III Encontro de Administração da Informação EnADI/ ANPAD, 2011.

SOARES, Aline Pereira: Gestão do conhecimento e conflitos interorganizacionais na EAD: construção de uma teoria substantiva (tese de doutorado). Universidade Federal de Santa Catarina, 2012.

TORRES, Cristina et al. Relação dos mecanismos de Gestão do Conhecimento com a Espiral do conhecimento. X Salão de Iniciação Científica - PUCRS, 2009. 
VALENZUELA, Zambrano, B., y VILLALOBOS, Pérez, M. V. Aprendizaje autorregulado a través de lá plataforma virtual Moodle. Educ. 2013. Educ. Vol. 16, No. 1, pp. 66-79.

\section{COPYRIGHT}

Direitos autorais: Os autores são os únicos responsáveis pelo material incluído no artigo.

Submetido em: 19/03/2019

Aprovado em: 09/05/2019 


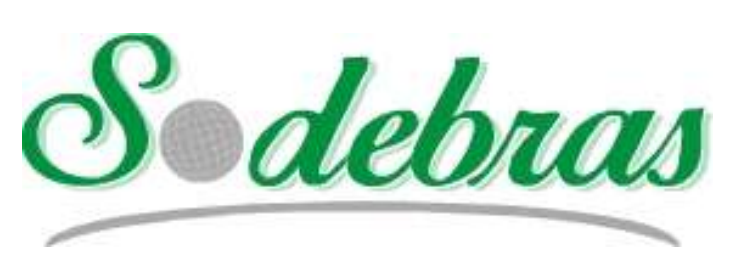

Revista SODEBRAS - Volume 14

$\mathrm{N}^{\circ} 161-\mathrm{MAIO} / 2019$

\title{
PERSPECTIVAS DO ENSINO DE MATEMÁTICA NA BASE NACIONAL COMUM CURRICULAR DO ENSINO FUNDAMENTAL
}

\author{
PERSPECTIVES OF MATHEMATICS EDUCATION IN THE COMMON \\ NATIONAL BASE CURRICULAR OF FUNDAMENTAL TEACHING
}

\author{
IDEMAR VIZOLLI'; ALEXANDRE OLIVEIRA DA SILVA²; WANESSA CARDOSO GOMES MUNIZ; \\ $1 ; 2 ; 3$ - UNIVERSIDADE FEDERAL DO TOCANTINS \\ idemar@mail.uft.edu.br; alexandreos231533@gmail.com; wanessa.cardoso@uft.edu.br
}

\begin{abstract}
Resumo - A Base Nacional Comum Curricular (BNCC) tem como fundamento a determinação dos conhecimentos fundamentais que todos os estudantes brasileiros têm o direito ao acesso $e$ à apropriação durante sua trajetória na educação básica. A BNCC considera a matemática como fruto da produção de diferentes culturas e etnias, o que permite uma reflexão sobre a construção do conhecimento matemático $e$ do processo de ensino $e$ aprendizagem desta ciência. Este estudo tem como objetivo identificar as perspectivas que a BNCC estabelece para o processo de ensino e aprendizagem da matemática no Ensino Fundamental. Trata-se de um estudo documental, cujos resultados indicam que o processo de ensino e aprendizagem de matemática devem considerar tanto os aspectos da própria ciência matemática como aqueles presentes no contexto social dos estudantes.
\end{abstract}

Palavras-chave: BNCC. Ensino e Aprendizagem de Matemática. Ensino Fundamental.

\begin{abstract}
The National Curricular Common Base (BNCC) is based on determining the fundamental knowledge that all Brazilian students have the right to access and appropriation during their trajectory in basic education. BNCC considers mathematics as the fruit of the production of different cultures and ethnicities, which allows a reflection on the construction of mathematical knowledge and the teaching and learning process of this science. This study aims to identify the perspectives that the BNCC establishes for the teaching and learning process of mathematics in Elementary School. It is a documentary study whose results indicate that the process of teaching and learning mathematics must consider both the aspects of mathematical science itself and those present in the students' social context.
\end{abstract}

Keywords: BNCC. Teaching and Learning of Mathematics. Elementary School.

\section{INTRODUÇÃO}

$\mathrm{O}$ presente artigo tem como objetivo identificar as perspectivas que a Base Nacional Comum Curricular (BNCC) estabelece para o processo de ensino e aprendizagem da matemática no Ensino Fundamental. Observa-se que a BNCC visa mudar a forma de ensinar matemática, propondo aos professores metodologias diferenciadas que possam mostrar aos estudantes que a matemática está presente em diversas situações da vida cotidiana, dando significado à aprendizagem e fazendo uma interligação dos conhecimentos adquiridos na sala de aula com os saberes e fazeres das comunidades onde a escola está inserida.
A Base Nacional Comum Curricular (2017) foi estabelecida pelo Ministério da Educação, em parceria com o CONSEDE (Conselho Nacional de Secretários Estaduais de Educação) e UNDIME (União Nacional dos Dirigentes Municipais de Educação), e contou com a participação de instituições de ensino públicas e privadas, da sociedade civil, por meio de consultas públicas, fóruns e seminários realizados em todo território brasileiro. Ela é um documento de caráter normativo e tem como objetivo promover mudanças na educação do país, especialmente no currículo e avaliação, consequentemente, na formação docente, uma vez que:

\begin{abstract}
"define o conjunto orgânico e progressivo de aprendizagens essenciais que todos os alunos devem desenvolver ao longo das etapas e modalidades da Educação Básica, de modo a que tenham assegurados seus direitos de aprendizagem e desenvolvimento, em conformidade com o que preceitua o Plano Nacional de Educação (PNE) (BRASIL, 2017, p.8)."
\end{abstract}

Ela ainda propõe aos professores formas diferentes de lidar com o ensino de matemática, por meio de uma proposta de aprendizagem que promova o envolvimento dos estudantes na exploração de situações que ocorrem no cotidiano, inovando e discutindo alternativas essenciais para o ensino e aprendizagem. Posição esta que corrobora com os estudos de Vizolli; Barros e Pinho (2017), ao destacarem que a metodologia adotada por professores se constitui como elemento essencial ao processo de aprendizagem de matemática.

Esse panorama nos conduz a elaborar a seguinte pergunta de pesquisa: que perspectivas a Base Nacional Comum Curricular (BNCC) apresenta para o processo de ensino e aprendizagem da matemática?

\section{MÉTODOS}

Adotamos a metodologia de pesquisa de natureza qualitativa e documental. Segundo Ludke e André (1986) a análise documental é uma técnica valiosa de abordagem de dados qualitativos. Em uma pesquisa qualitativa pode-se utilizar vários procedimentos e instrumentos de composição e análise de dados, entre estes a pesquisa documental.

$\mathrm{Na}$ análise documental utilizam-se documentos que não sofreram tratamento analítico. O desafio a esta técnica de pesquisa é a capacidade que o pesquisador tem de selecionar, 
tratar e interpretar a informação, visando compreender a interação com sua fonte. A pesquisa documental é entendida por Lakatos e Marconi (1992) como:

"coleta de dados em fontes primárias, como documentos escritos ou não, pertencentes a arquivos públicos, arquivos particulares de instituições e domicílios, e fontes estatísticas para a construção de um determinado panorama."

\section{ASPECTOS HISTÓRICOS E LEGAIS QUE NORTEIAM A BNCC}

Na perspectiva de refletir sobre o processo de ensino a aprendizagem de matemática no Ensino Fundamental, a partir da BNCC, se faz necessária uma contextualização histórica retratando o pensamento inicial até a sua homologação em 20 de dezembro de 2017.

Com a Constituição Federal de 1988 observa-se que é preconizada a criação de uma base comum à educação brasileira como mostra os artigos 210 e 2011:

"Art. 210: serão fixados conteúdos mínimos para o ensino fundamental, de maneira a assegurar formação básica comum e o respeito aos valores culturais e artísticos, nacionais e regionais."

"Art. 211: A União, os Estados, o Distrito Federal e os Municípios organizarão em regime de colaboração seus sistemas de ensino (BRASIL, 1998)."

Consensualmente ligada a CF de 1988, a Lei de Diretrizes e Bases da Educação - LDB, n9.394/96 também estabelece que os currículos da educação básica devem ter uma base comum. De acordo com o Art. 26:

"Os currículos da educação infantil, do ensino fundamental e do ensino médio devem ter base nacional comum, a ser complementada, em cada sistema de ensino e em cada estabelecimento escolar, por uma parte diversificada, exigida pelas características regionais e locais da sociedade, da cultura, da economia e dos educandos (BRASIL, 2015, p.19).”

A LDB ainda define que os entes federados terão que nortear os currículos e seus conteúdos mínimos, para assegurar a formação básica comum a todos. Em seu Art. $9^{\circ}$ destaca que a União incumbir-se-á de:

"IV - estabelecer, em colaboração com os estados, o Distrito Federal e os municípios, competências e diretrizes para a educação infantil, ensino fundamental e o ensino médio, que nortearão os currículos e seus conteúdos mínimos, de modo a assegurar formação básica comum (BRASIL, 2015, p. 12-13)."

A construção da BNCC tem sua inspiração e sua organização baseada nas Diretrizes Curriculares Nacionais, que são normas obrigatórias para a Educação Básica e que orientam o planejamento curricular das escolas e dos sistemas de ensino. Em seus artigos 14 e 15, encontra-se a forma que deve ser organizada a base comum:

“Art. 14. A base nacional comum na Educação Básica constitui-se de conhecimentos, saberes e valores produzidos culturalmente, expressos nas políticas públicas e gerados nas instituições produtoras do conhecimento cientifico e tecnológicos; no mundo do trabalho; no desenvolvimento das linguagens; nas atividades desportivas e corporais; na produção artística; nas formas diversas de exercício da cidadania e nos movimentos sociais."

"Art. 15. A parte diversificada enriquece e complementa a base nacional comum, prevendo o estudo das características regionais e locais da sociedade, da cultura, da economia e da comunidade escolar, perpassando todos os tempos e espaços curriculares constituintes do Ensino Fundamental e do Ensino Médio, independentemente do ciclo da vida no qual os sujeitos tenham acesso à escola (BRASIL, 2010, p. 67-68)."

Relevante para a criação da BNCC foi a Conferência Nacional de Educação (CONAE - 2014), na qual se debateu sobre a importância da necessidade de uma base comum curricular e bem como a garantia a participação da sociedade nas discussões sobre a melhoria da educação nacional. Destaca-se também o Plano Nacional de Educação, Lei ${ }^{\circ}$ $13.005 / 2014$, que na sua meta 7 , especialmente na estratégia 7.1, está determinada a criação e implementação da BNCC mediante a pactuação federativa em regime de colaboração.

Nesse sentido em junho de 2015 foi criado o grupo de redação responsável pela primeira versão da BNCC, sendo que após várias reuniões de estudos a primeira versão foi disponibilizada, de setembro de 2015 até março de 2016, pela Secretaria de Educação Básica do Ministério de Educação (SEB/MEC) no portal da base, para consulta pública. Segundo o site do MEC (http://movimentopelabase.org.br/), Movimento pela Base Nacional Comum (2018):

"A consulta online da primeira versão é encerrada com mais de 12 milhões de contribuições da sociedade civil, professores, escolas, organizações do terceiro setor e entidades científicas."

A partir dos resultados colhidos na consulta pública, nos meses de março e maio, pesquisadores da Universidade de Brasília (UNB) sistematizaram as contribuições e encaminham para o grupo de redatores da BNCC.

Desse modo, ainda no início de maio, o MEC divulga a segunda versão redigida a partir das contribuições da consulta pública. Já nos meses de junho a agosto de 2016, segundo o site Movimento Pela Base Nacional Comum (2018):

"A segunda versão da BNCC roda o país em seminários estaduais organizados pelo Consed e pela Undime, com a participação de mais de 9 mil participantes, entre professores, gestores e alunos."

Com o término dos seminários, no mês de setembro de 2016, o Consed e a Undime entregam ao MEC o relatório com as contribuições dos seminários que serviram de insumo para a redação da terceira versão. Porem somente em março de 2017 é que o MEC entrega ao Conselho Nacional de Educação (CNE) a terceira versão da BNCC, com as partes da Educação Infantil e do Ensino Fundamental.

A terceira versão da BNCC traz como proposta que durante a Educação Básica "os alunos devem desenvolver dez competências gerais que pretendem assegurar, como resultado do seu processo de aprendizagem e desenvolvimento, uma formação humana integral que visa à construção de uma sociedade justa, democrática e inclusiva" (BRASIL, 2017, p. 25).

Para dar mais transparência e credibilidade ao documento, de junho a dezembro de 2017, o CNE realizou 
consultas públicas em todo país para ouvir a sociedade sobre a terceira versão. Após todo esse processo de diálogos e contribuições, em 15 de dezembro de 2017 o CNE aprovou a Base por 20 votos a 3, sendo que sua homologação pelo MEC ocorreu em 20 de dezembro de 2017, o que se deu por meio da Portaria $\mathrm{N}^{\circ} 1570$. Assim, com a homologação, a BNCC passou a valer em todo território brasileiro.

\section{ENSINO E APRENDIZAGEM DE MATEMÁTICA NO CONTEXTO DA BNCC}

O ensino e a aprendizagem são processos que vem desde o homem primitivo, onde a educação é transmitida das gerações mais velhas as gerações mais novas. Desse modo para falar sobre o ensino e aprendizagem de matemática é necessário destacar que é algo complexo e que necessita de uma análise de como o ser humano desenvolve e processa a cognição, uma vez que no próprio desenvolvimento humano estamos em um processo de constante aprendizagem.

Partindo dessa perspectiva, José e Coelho (2003, p.11) enfatizam que:

"Para que a aprendizagem provoque uma efetiva mudança de comportamento e amplie cada vez mais o potencial do educando, é necessário que ele perceba a relação entre o que está aprendendo e a vida."

Já Carraher, Carraher e Schlieman (1995, p.12) afirmam que:

“A aprendizagem de matemática na sala de aula é um momento de interação entre a matemática organizada pela comunidade cientifica, ou seja, a matemática formal, e a matemática como atividade humana."

Ainda nessa perspectiva Freire (1997, p. 81), destaca que "o ato de ensinar -...-$]$ não é a simples transmissão do conhecimento em torno do objeto ou do conteúdo". Transmissão que se faz muito mais através da pura descrição do conceito do objeto a ser mecanicamente memorizando pelos alunos. Não se ensinam saberes prontos, acabados, mas transformam-se aprendizados através de interações com a realidade, levando em consideração a influência de toda bagagem de saberes que o alunado carrega. Assim:

“[...] exige o ensino de uma matemática que permita à criança lidar com o mundo à sua volta, além disso, permite a capacidade do aluno de solucionar problemas, cálculos, capacidades intelectuais e de desenvolvimento do pensamento e do conhecimento (D’AMBROSIO, 2003, p.1)."

Nessa perspectiva a aprendizagem acontece de maneiras diversificadas dependendo das estruturas motivacionais e cognitivas, destacando-se então a importância de se usar diferentes metodologias no processo de ensino e aprendizagem. Desse modo D'Ambrosio (1986, p.49) enfatiza que a "Aprendizagem é uma relação dialética reflexão-ação, cujo resultado é um permanente modificar da realidade".

Ainda observa-se que a Base Nacional Comum Curricular destaca que ao longo da Educação Básica, as aprendizagens devem concorrer para assegurar aos estudantes o desenvolvimento de dez competências gerais, que consubstanciam, no âmbito pedagógico, os direitos de aprendizagem e desenvolvimento das habilidades.
Diante desse contexto com a implementação da BNCC o ensino passa a ter um letramento mais reflexivo e uma maior variedade de contextos, trazendo os conceitos teóricos para a vida real e isso é visível quando analisamos as dez competências gerais. Relacionado ao componente curricular de Matemática observa-se que a BNCC visa mudar a forma de ensinar matemática, mostrando para os alunos uma matemática que está em tudo, como no mercado, padaria, na feira e nas demais coisas do dia a dia. A base preconiza que, muito mais do que apenas absorver os conteúdos das disciplinas, os estudantes deverão sair da rotina para assumir uma postura mais participativa na sociedade.

Nessa perspectiva a BNCC preza por uma articulação dos diversos campos do componente de matemática para que consigamos ter uma aprendizagem de qualidade. Essa articulação deve acontecer entre a Aritmética, Álgebra, Geometria, Estatística e Probabilidade, para que seja garantido que os alunos relacionem as observações das suas vivências e consigam representá-las e consequentemente possam associá-las a uma atividade matemática fazendo induções e conjecturas.

Desse modo espera-se que eles desenvolvam a capacidade de identificar oportunidades de utilização da matemática para resolver problemas, aplicando conceitos, procedimentos e resultados para obter soluções e interpretálas segundo os contextos das situações. Para que isso aconteça no Ensino Fundamental será necessário ter compromisso com o desenvolvimento do letramento matemático, definido como as competências e habilidades de raciocinar, representar, comunicar e argumentar matematicamente, de modo a favorecer o estabelecimento de conjecturas, a formulação e a resolução de problemas em uma variedade de contextos, utilizando conceitos, procedimentos, fatos e ferramentas matemáticas.

\begin{abstract}
"É também o letramento matemático que assegura aos alunos reconhecer que os conhecimentos matemáticos são fundamentais para a compreensão e a atuação no mundo e perceber o caráter de jogo intelectual da matemática, como aspecto que favorece o desenvolvimento do raciocínio lógico e crítico, estimula a investigação e pode ser prazeroso (fruição) (BRASIL, 2017, p. 264)."
\end{abstract}

O desenvolvimento dessas habilidades está intrinsecamente relacionado a algumas formas de organização da aprendizagem matemática, com base na análise de situações da vida cotidiana, de outras áreas do conhecimento e da própria Matemática. Ainda segundo a BNCC:

"Os processos matemáticos de resolução de
problemas, de investigação, de desenvolvimento de
projetos e da modelagem podem ser citados como
formas privilegiadas da atividade matemática,
motivo pelo qual são, ao mesmo tempo, objeto e
estratégia para a aprendizagem ao longo de todo o
Ensino Fundamental. Esses processos de
aprendizagem são potencialmente ricos para o
desenvolvimento de competências fundamentais
para o letramento matemático (raciocínio,
representação, comunicação e argumentação) e para
o desenvolvimento do pensamento computacional
(BRASIL, 2017, p. 264).”

Ao delimitar as competências específicas da disciplina, que indicam como as competências gerais da Base devem ser expressas naquele componente, a Matemática é conceituada 
como "ciência humana, fruto das necessidades e preocupações de diferentes culturas, em diferentes momentos históricos" e, ainda, "uma ciência viva, que contribui para solucionar problemas científicos e tecnológicos e para alicerçar descobertas e construções" (NOVA ESCOLA, 2019). A Base foca no que o aluno precisa desenvolver, para que o conhecimento matemático seja uma ferramenta para ler, compreender e transformar a realidade.

Nessa perspectiva, para que sejam garantidas aos alunos o desenvolvimento dessas competências a escola deverá criar um espaço de socialização dos conhecimentos historicamente acumulados e a construção de novos saberes. Logo os conteúdos precisam ser interligados à realidade da sala de aula e essa adequação está também relacionada ao professor.

\section{O PROCESSO DE ENSINO E APRENDIZAGEM DE MATEMÁTICA A PARTIR DE CONHECIMENTOS PRESENTES EM SABERES E FAZERES DAS COMUNIDADES ONDE OS ESTUDANTES ESTÃO INSERIDOS}

Falar do processo de ensino e aprendizagem de matemática com foco na BNCC é deixar claro que será necessário rever as práticas e tentar interligar os conhecimentos da sala de aula com os saberes e fazeres das comunidades onde esses alunos estão inseridos. Logo é necessário destacar que o componente de matemática sofreu algumas mudanças visando o desenvolvimento de habilidades com base na análise de situações da vida cotidiana.

Nesse sentido as habilidades de matemática visam à garantia do acesso e à apropriação do conhecimento de todas as crianças e jovens, além de se construir uma sociedade mais justa e solidária. Partindo desse viés, destacamos o papel que a escola terá para conseguir desenvolver as habilidades alinhadas a vida cotidiana dos alunos. Desse modo a escola deverá incentivar os alunos em situações que promovam a reflexão, a investigação e a pesquisa, o letramento matemático e a resolução de problemas e espaços onde eles possam representar e vivenciar suas experiências e ressignificá-las a partir da construção de novos conhecimentos.

Partindo desse pressuposto, o ensinar e aprender Matemática, nos dias atuais com a BNCC, leva em conta o que o estudante já conhece, ou seja, os conhecimentos prévios e as experiências que possui fora da escola. À escola cabe articular esses tipos de conhecimento e experiência que o estudante já possui, àqueles que irá aprender, de forma que possa alcançar os objetivos de aprendizagem e desenvolvimento propostos para cada ano de escolaridade.

Um item de extrema importância no desenvolvimento do processo de ensino e aprendizagem de matemática e que está presente na BNCC é a utilização da Modelagem Matemática, uma vez que ela proporciona um ambiente de aprendizagem problematizador que se distancia do ensino tradicional, onde os temas, as perguntas e os procedimentos para encontrar a solução dos problemas serão feitos pelos estudantes, que podem pensar em estratégias nem sempre indicadas ou sugeridas pelo professor, mas mediadas por ele.

Nesse sentido, a modelagem se diferencia das tarefas investigativas, pois estas se relacionam a contextos intramatemáticos e a modelagem se refere a contextos extramatemáticos. Ela também se difere da resolução de problemas, pois na modelagem os temas e as questões, no geral, são feitos pelos estudantes, o que não acontece com os problemas.

De acordo com Barbosa (2001):

\begin{abstract}
"A modelagem pode ser entendida como uma oportunidade de os estudantes identificarem questões ou problemas oriundos de uma problemática do cotidiano relativa a um contexto real e que possam ser resolvidos por meio da Matemática, sem a fixação de procedimentos prévios para a sua resolução (BARBOSA, 2001).”
\end{abstract}

Assim, a modelagem permite estabelecer relações da Matemática com outras áreas de conhecimento para que os problemas possam ser resolvidos. Como acontece com a utilização de outras estratégias, o trabalho com a modelagem envolve uma mudança de postura por parte do professor, uma vez que ele levará em conta os interesses dos estudantes, podendo assumir três configurações diferentes para o seu desenvolvimento (BARBOSA, 2001).

Ainda pode-se destacar que a modelagem matemática é uma forma de tentar romper com a dicotomia existente entre a matemática escolar, vista como formal, e a sua utilidade na vida cotidiana. Ela ainda é considerada como uma forma de compreender os saberes e fazeres presentes no dia a dia dos educandos, possibilitando, assim, transformar situações reais em modelos matemáticos favorecendo, assim, o interesse, o dinamismo e a motivação por parte dos alunos. Logo segundo D’Ambrosio (1986, p. 25):

\begin{abstract}
"A criação de Modelos Matemáticos vem ao encontro da necessidade de que se desenvolva uma técnica de acesso ao conhecimento e, tal conhecimento, acumulado e depositado, deverá ser acessível a vários níveis de necessidade. E que haja uma forma de ensino mais dinâmica, mais realista e menos formal, mesmo no ensino tradicional, permitindo atingir objetivos mais adequados a nossa realidade."
\end{abstract}

\section{CONCLUSÕES}

Analisando as principais mudanças no componente de matemática fica evidente que a BNCC tem como foco principal a utilização de situações do cotidiano para mostrar ao aluno que a Matemática é aplicada em diversas situações fora e dentro da escola. Nesse sentido o professor terá um papel fundamental nesse processo, que só será viável com o desenvolvimento de um planejamento que consiga desenvolver as competências e habilidades com foco nos conhecimentos da vida cotidiana dos alunos.

Os professores deverão ter consciência da importância da utilização dos recursos didáticos para dinamizar o processo ensino aprendizagem de matemática, sendo necessário utilizar uma variedade de recursos lúdicos, jogos e brincadeiras que facilitam o ensino e a aprendizagem de matemática na resolução de problemas, auxiliando assim no processo do letramento matemático.

O uso dos materiais didáticos só será viável e significativo em sua prática pedagógica quando ele se constituir um elemento de apoio na construção do conhecimento matemático. Para isso será necessário fazer uma ligação com os saberes e fazeres dos estudantes, ou seja, a sua vida cotidiana deve ser foco nesse processo.

Outro ponto que é necessário destacar é a importância de investimentos na formação inicial e continuada dos professores no sentido de buscarem inovações e estudos 
atuais no ensino de matemática no sentido de reorientar a sua atuação docente, por que sabemos que profissionais qualificados desempenham sua função com qualidade. Desse modo os programas de formação constituem-se espaços para a reflexão sobre sua ação pedagógica e a abertura para novas possibilidades didáticas com foco no aluno que segundo a BNCC é o centro do processo e precisa desenvolver uma postura mais ativa.

Assim o presente trabalho traz essas possíveis conclusões até o momento, uma vez que se acredita que o Brasil está passando por uma grande transformação com a implementação da BNCC, necessitando assim de uma política de formação mais eficaz voltada para os docentes. Tal fato faz-se necessário, haja vista que o próprio documento preza por uma mudança nas práticas dos professores com foco em um ensino pautado na vivência dos alunos, ou seja, os saberes e fazeres que os alunos adquirem no meio em que estão inseridos.

\section{REFERÊNCIAS}

BARBOSA, Jonei Cerqueira. Modelagem Matemática e os professores: a questão da formação. Bolema, Rio Claro, SP, V. 14, n. 15, p. 5-23, 2001.

BRASIL. Congresso Nacional. Lei 13.005/14, de 25 de junho de 2014. Aprova o Plano Nacional de Educação e dá outras providências. Congresso Nacional. Diário Oficial da União, Brasília, 2014.

BRASIL. Constituição 1988. Constituição da República Federativa do Brasil. Brasília, DF: Senado Federal, 1988.

BRASIL. Lei 9.394, de 20 de dezembro de 1996. Estabelece as Diretrizes e Bases da Educação Nacional. Diário Oficial da União, Brasília, DF, v. 11, 2015.

BRASIL. Ministério da Educação. Base Nacional Comum Curricular - BNCC. Disponível em: http://basenacionalcomum.mec.gov.br. Acesso em: 13 de jun. de 2018.

CARRAHER. Terezinha Nunes; CARRAHER. David William; SCHLIEMANN. Ana Lúcia Dias. Na vida dez na escola zero. São Paulo: Cortez, 1995.

D' AMBROSIO. Ubiratan. Disponível em: <http://etnomatematica.org/articulos/boletin.pdf>. Sextafeira, 31 de outubro de 2003. Acessado dia 24/02/2019.

D'AMBROSIO, Ubiratan. Da realidade à Ação: Reflexões sobre Educação e Matemática. Campinas. SP: Summus/UNICAMP, 1996.

FREIRE,P. Pedagogia da esperança: um reencontro com a pedagogia do oprimido. 4. ed. Rio de Janeiro: Paz e Terra, 1997.

JOSÉ. Elisabete da Assunção; COELHO. Maria Teresa. Problemas de Aprendizagem. São Paulo: Ática, 2003.

LAKATOS, Eva Maria; MARCONI, Marina de Andrade. Metodologia do trabalho científico. $4^{\mathrm{a}}$ ed. São Paulo: Atlas, 1992.

LÜDKE, Menga e ANDRÉ, Marli E. D. A. Pesquisa em educação: abordagens qualitativas. São Paulo: EPU, 1986.

Nova Escola: Novos Temas e Reorganização das Áreas São as Principais Novidades em Matemática. São Paulo:
2018. Disponível em: https://novaescola.org.br/bncc/conteudo/32/novos-temas-ereorganizacao-das-areas-sao-as-principais-novidades-emmatematica>. Acesso em: 20 de jan. 2019.

VIZOLLI, Idemar; BARROS, Marcos José Pereira; PINHO, Maria José de. Formação inicial de professores para ensinar matemática na Educação Básica: um estudo nos projetos pedagógicos dos cursos ofertados pela Universidade Federal do Tocantins. Revista Sodebras [on line]. v. 12, n. 139, julho/ 2017, p. 77-84. ISSN 1809-3957. Disponível em: <http://www.sodebras.com.br/edicoes/N139.pdf>. Acesso em: 20 de jan. 2019.

\section{COPYRIGHT}

Direitos autorais: Os autores são os únicos responsáveis pelo material incluído no artigo

Submetido em: 05/03/2019 Aprovado em: 16/04/2019 


\section{Área: Ciências Agrárias e Biológicas}

\begin{tabular}{|c|l|}
\hline $4-1$ & EFEITOS DO FORMALDEÍDO EM ESTUDANTES DE MEDICINA \\
& $\begin{array}{l}\text { EFFECTS OF FORMALDEHYDE ON MEDICAL STUDENTS } \\
\text { Gabriela Lopes Do Carmo; Juliana Bertuci Pereira; Isabela Uchôa De Oliveira; } \\
\text { Mariana Tamashiro Uezato; Wagner Alves De Souza Judice }\end{array}$ \\
\hline 4-6 & $\begin{array}{l}\text { EVOLUTION OF CHRONIC NON-CUMMUNICABLE DISEASES (NCDs) IN THE } \\
\text { STATE OF SÃO PAULO, BRAZIL - 2007 TO 2016 } \\
\text { Rodolpho Telarolli Júnior; Leonor De Castro Monteiro Loffredo }\end{array}$ \\
\hline
\end{tabular}




\title{
7 Revista SODEBRAS - Volume 14 $\mathrm{N}^{\circ} 161$ - MAIO/ 2019 \\ EFEITOS DO FORMALDEÍDO EM ESTUDANTES DE MEDICINA
}

\author{
EFFECTS OF FORMALDEHYDE ON MEDICAL STUDENTS
}

\author{
GABRIELA LOPES DO CARMO $^{1}$; JULIANA BERTUCI PEREIRA ${ }^{2}$; ISABELA UCHÔA DE OLIVEIRA ${ }^{3}$; \\ MARIANA TAMASHIRO UEZATO ${ }^{4}$; WAGNER ALVES DE SOUZA JUDICE 5 \\ 1; 2; 3; 4 - DISCENTES DA FACULDADE DE MEDICINA DA UNIVERSIDADE DE MOGI DAS CRUZES, \\ MOGI DAS CRUZES, SÃO PAULO, BRASIL; 5 - CENTRO INTERDISCIPLINAR DE INVESTIGAÇÃO \\ BIOQUÍMICA DA UNIVERSIDADE DE MOGI DAS CRUZES, MOGI DAS CRUZES, SÃO PAULO, BRASIL \\ gabi_ldc@yahoo.com.br; ju.bp@hotmail.com; Isabela.uchoa.o@gmail.com; marehtams@gmail.com; \\ wagnerjudice@gmail.com
}

\begin{abstract}
Resumo - Peças anatômicas e cadáveres são frequentemente conservados em formaldeído o qual pode ser prejudicial saúde. Nesse estudo avaliamos os efeitos do formaldeído em estudantes de medicina expostos a essa substância e o uso de equipamento de proteção individual (EPIs) e possíveis alterações na saúde. Realizamos estudo descritivo-exploratório, com abordagem quantitativa com aplicação de questionário a 169 estudantes de medicina. Verificou-se que $100 \%$ dos estudantes desconheciam a concentração do formaldeído nas peças; $62 \%$ utilizavam luvas e avental, e 3\% não utilizavam EPIs; $4 \%$ apresentaram rinite, destes, 66,7\% frequentaram o laboratório de 2-3vezes/semana. Concluímos que o uso dos EPIs é fundamental; aplicações de novos métodos de conservação devem ser avaliados. Os casos de rinite observados podem não estar relacionados ao fornaldeído, uma vez que $5 \%$ da população apresenta rinite não alérgica.
\end{abstract}

Palavras-chave: Formaldeído. Peças Anatômicas. Estudantes de Medicina. Rinite.

\begin{abstract}
Anatomical pieces and corpses are often preserved in formaldehyde which can be detrimental to health. In this study we evaluated the effects of formaldehyde in medical students exposed to this substance and the use of personal protective equipment (PPE) and possible changes in health. We conducted a descriptive-exploratory study, with a quantitative approach with application of a questionnaire to 169 medical students. It was verified that $100 \%$ of the students did not know the concentration of the formaldehyde in the pieces; $62 \%$ used gloves and aprons, and 3\% did not use PPE; 4\% had rhinitis, $66.7 \%$ of them attended the laboratory 2-3 times/week. We conclude that the use of PPE is fundamental; applications of new conservation methods should be evaluated. The cases of rhinitis observed may not be related to the formaldehyde, since $5 \%$ of the population presents non-allergic rhinitis.
\end{abstract}

Keywords: Formaldehyde. Anatomical Pieces. Medical Students. Rhinitis.

\section{INTRODUÇÃO}

Peças anatômicas são essenciais para o estudo na área da saúde, pois o conhecimento das estruturas e órgãos que compõem o corpo humano, assim como a função e localização de cada um, são indispensáveis para a prática clínica, diagnóstica e cirúrgica (TORTORA, 2006).

Peças e cadáveres a fresco, apesar de oferecerem maior fidelidade na reprodução das estruturas in vivo, são de difícil obtenção e possuem durabilidade bastante limitada para o estudo, sendo inviável a constante reposição exigida por esse método. Portanto, para possibilitar seu estudo por tempo superior ao de autólise e sem a ação de microorganismos, é necessário o uso de métodos de fixação e preservação. São usados como fixadores: a glicerinação, resina de poliéster, o álcool etílico, o fenol e o formaldeído (OLIVEIRA, et al, 2013).

Das Faculdades de Medicina brasileiras, 96\% utilizam cadáveres humanos em anatomia prática. Dessas, 83,3\% utilizam formolização e 56,4\% glicerinação, estando a formolização predominante em todas as regições, exceto na Centro-Oeste. Contudo, $60,7 \%$ das faculdades que empregam formolização intencionam substituir devido à insalubridade do formaldeido (SILVA, et al, 2016), pois possui uma alta toxicidade, que provoca irritação no bulbo ocular, nas vias aéreas superiores, desconforto respiratório e efeito carcinogênico (SOUSA, et al, 2015). Outra técnica em estudo é a preservação por solução aquosa de cloreto de sódio (OLIVEIRA, 2014).

O formaldeído é muito usado para embalsamento e conservação de cadáveres, favorecendo a preservação e desinfecção de peças anatômicas para estudos de anatomia (SAOWAKON, et al, 2015)

Fornaldeído é classificado pela Agência Internacional de Pesquisas em Câncer (IARC, 2012), e pelo Programa Nacional de Toxicologia dos Estados Unidos (NTP, 2016) como agente cancerígeno; além disso, Wei et al (2017) identifiou efeito leucêmico. Formaldeído reduz o número de células sanguíneas periféricas e induz modificações cromossómicas específicas de leucemia em células mielóides progenitoras (LAN, et al, 2015).

Formaldeído apresenta efeitos deletérios no DNA (CARVALHO, 2009). Em função disso, necessita ser substituído para preservar a saúde de todos que frequentam os laboratórios.

Segundo Viegas et al (2010), mais de $90 \%$ do formaldeído inalado por humanos é absorvido no trato respiratório superior. Ele é tóxico quando ingerido, inalado ou quando entra em contato com a pele; também é tóxico se administrado por via intravenosa, intraperitoneal ou subcutânea. Os efeitos na maioria das pessoas a este composto são bem conhecidos: irritação nos olhos e no trato 
respiratório superior, dor de cabeça, náuseas, sonolência e reações alérgicas na pele (SILVA, 2010).

Exposição aguda ao formaldeído pode causar irritação nos olhos, nariz, garganta e pele, enquanto a exposição em longo prazo tem sido associada a certos tipos de câncer nasal e asma (ERICH, 2014; NESLIHAN, et al, 2016).

Normalmente, os alunos que frequentam os laboratórios de anatomia são transitórios, porém, pesquisadores, docentes e técnicos estão expostos por longos períodos de tempo ao formol e são mais prejudicados. Dessa forma o tempo de exposição ao formol é um fator a se considerar (VIEGAS, et al, 2010).

Portanto, diante dessas informações nosso objetivo foi avaliar os efeitos do formaldeído em estudantes de medicina expostos a essa substância em função da utilização do laboratório de anatomia e averiguar o uso de equipamento de proteção individual pelos frequentadores e a possível ocorrência de alterações de saúde.

\section{MÉTODOS}

Trata-se de um estudo descritivo-exploratório, com abordagem quantitativa em que foram avaliados 169 estudantes do primeiro ao terceiro ano de um curso de medicina que frequentaram o laboratório de anatomia por um período de 12 meses. Todos os participantes assinaram o termo de consentimento livre e esclarecido (TCLE). O questionário foi elaborado pelos pesquisadores a fim de avaliar possíveis complicações respiratórias com a exposição ao formaldeído. O estudo foi avaliado por Comitê de Ética em Pesquisa vinculado ao Ministério da Saúde sob número CAAE 79225117.0.0000.54.97 e parecer de aprovação 2.398.642.

\section{RESULTADOS E DISCUSSÃO}

Sabe-se que os principais efeitos provocados pela inalação de vapores de formaldeído são dores de cabeça, tosse, náuseas, lacrimejamento nos olhos, além de depressão do sistema nervoso central. O contato prolongado a ele pode intensificar esses sinais e sintomas. Visto isso, a necessidade de utilização de equipamentos de proteção é de suma importância (BERTAZZI, et al, 1989).

Figura 1 - Distribuição do número absoluto de alunos em relação à frequência de utilização do laboratório de anatomia
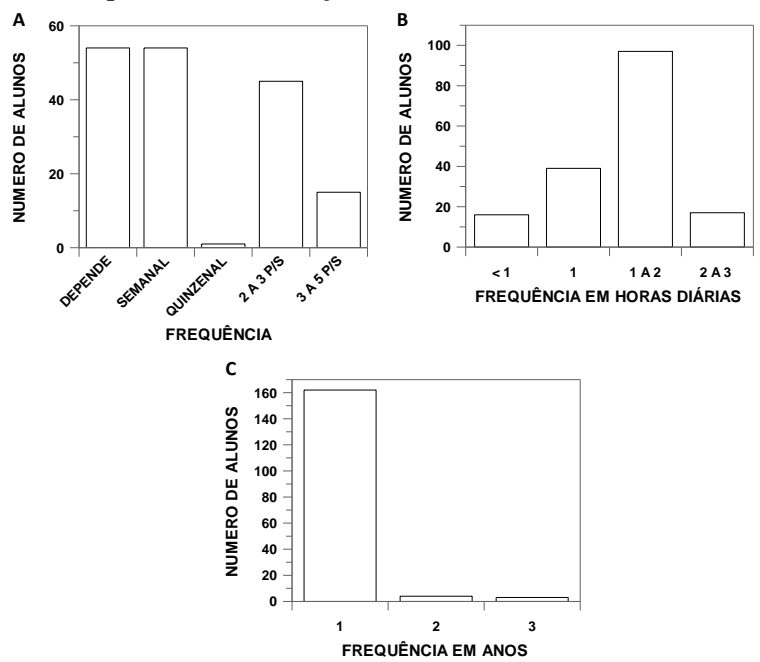

Fonte: Autores, 2019.

A) P/S $\rightarrow$ por semana; B) Frequência em horas diárias; C) 1, 2 e 3 correspondem ao número de anos.
Observamos que a frequência ao laboratório de anatomia dependia da ocorrência das provas e esse dado se equiparava à frequência semanal. A frequência quinzenal era baixa, sendo que a frequência de 2 a 3 vezes foi de $26,6 \%$ dos alunos (Figura 1A), e que 57,4\% dos alunos permaneciam entre 1 a 2 horas no laboratório (Figura 1B). Além disso, verificamos que as frequências se concentraram em um único ano (Figura 1C), correspondendo ao período das aulas de anatomia.

No contexto da segurança pessoal por meio da utilização de EPIs pelos alunos, 62,1\% deles faziam uso frequente de avental e luvas, sendo que apenas $3,6 \%$ não apresentavam uso de EPIs e que 2,4\% utilizavam luvas, avental e máscara (Figura 2). Contudo, as máscaras utilizadas eram apenas cirúrgicas e não apresentam proteção contra os vapores do formaldeído implicando nenhuma proteção contra esse agente volátil, pois se trata de filtros mecânicos e não químicos.

Figura 2 - Distribuição do número absoluto de alunos em relação ao uso de EPIs no laboratório de anatomia

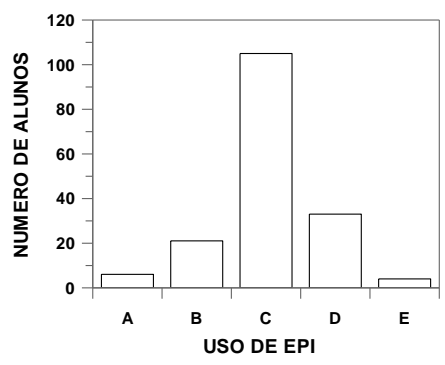

Fonte: Autores, 2019.

A) não usam EPIs; B) apenas usam avental; C) luva e avental com uso frequente; d) luva e avental com uso não frequente; E) usam luva, avental e máscara.

O uso de EPIs é fundamental à biossegurança a qual é definida como o conjunto de ações voltadas para a prevenção, minimização ou eliminação de riscos inerentes às atividades de pesquisa, produção e ensino visando à saúde do homem e a qualidade dos resultados (TEIXEIRA e VALLE, 1996).

Os alunos foram questionados sobre a ocorrência de doenças respiratórias crônicas bem como se desenvolveu alguma doença respiratória em função da utilização do laboratório de anatomia.

Verificamos que 56,8\% dos alunos relataram não possuir doença crônica respiratória e 43,2\% relataram possuir (Figura 3A). Esse dado está bem acima da população em geral que é cerca de 20 a $25 \%$ (BAGATIN e COSTA, 2006).

Figura 3 - Distribuição do número absoluto de alunos em relação à existência de doença crônica alérgica e desenvolvimento de doença respiratória em função do formaldeído do laboratório de anatomia
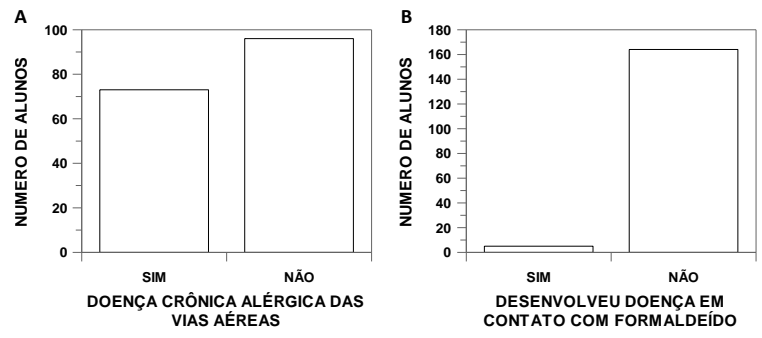

Fonte: Autores, 2019. 
Por outro lado, uma pesquisa mostrou que $44 \%$ dos brasileiros apresentam sintomas de doenças respiratórias asma e bronquite crônica em sua maioria (IBOPE, 2016).

Constatamos que aproximadamente $3 \%$ dos estudantes reportaram apresentar desenvolvimento de doença respiratória em função do contato com o formaldeído (Figura 3B).

Estudos mostram que a incidência de sintomas rinoconjuntivais relacionados ao trabalho é maior nos primeiros 12 a 20 meses de atividade profissional e aumenta com a duração da exposição até um período de 24 meses (GAUTRIN, et al, 2006).

Dentre os alunos que reportaram desenvolvimento de doença $(n=5)$, quatro mencionaram surgimento de rinite ou agravamento, um relato sobre aparecimento de alergia (com uso frequente de luvas, avental e máscara), e somente um não usava avental e luvas com frequência. Dessa forma, os eventos relacionados à rinite corroboram a ineficácia da máscara cirúrgica na prevenção dos efeitos do formaldeído, pois essas não foram desenvolvidas para vapores e sim bloqueio de material particulado.

As queixas rinológicas frequentes nos trabalhadores de laboratórios de anatomia patológica expostos ao formaldeído são as rinites (HAYES, 1986), e a prevalência mundial de rinite na idade adulta está por volta de $10 \%$ (SNOW Jr. e WACKYM, 2009), sendo divididas em alérgicas e não alérgicas com prevalências semelhantes e a rinite ocupacional comum a esses dois grupos (DYKEWICZ, 1998). Contudo, estima-se na população em geral que $20 \%$ tenham rinite alérgica e $5 \%$ não alérgica (BAGATIN e COSTA, 2006).

É essencial a avaliação da patologia rinológica em trabalhadores expostos ao formaldeído (LEITE e UVA, 2012), pois as vias aéreas são mais sensíveis a este químico tanto para efeitos agudos quanto crônicos, tornando-se um "irritante" nasal em concentrações de 0,06 a 1,15 ppm (OMS, 1984). Concentrações de formaldeído entre 0,1-5 ppm em laboratórios de anatomia tem sido mostrado acarretar irritação das vias aéreas superiores, tosse, queimação ocular e lacrimejamento em alunos, professores e técnicos (WHO, 2016) e dados de estudos de citologia nasal revelou condição inflamatória crônica não alérgica em grupo exposto ao formaldeído (BRUNO, et al, 2018)

Uma vez que em baixas concentrações o formaldeído é um agente químico irritante das vias aéreas, sua substituição nos laboratórios de anatomia deva ser levada em consideração. Nesse contexto verificamos que apenas $2,4 \%$ dos alunos (Figura 4A) abordaram a pauta de substituição deste químico.

Um dos importantes efeitos toxicológicos dos poluentes ambientais pode envolver danos oxidativos induzidos por Espécies Reativas de Oxigênio (SMITH, et al, 2015). Nesse contexto, estudos já relataram estresse oxidativo exacerbado e diminuição da capacidade antioxidante após contato prolongado com formaldeído (MEI, et al, 2016). Além disso, exposição ocupacional ao formaldeído pode promover alterações de comportamentos como agressividade, depressão, ansiedade, distúrbios do sono e, em particular, deficiências cognitivas (MEI, et al, 2016). Foraldeído também apresenta certos efeitos sinérgicos na citotoxicidade induzida pelo benzeno no sangue periférico promovendo redução no número de algumas células do sistema imunológico (WEN, et al, 2016).
Mesmo sabendo dos efeitos adversos da exposição ao formaldeído, somente 1,2\% dos alunos (Figura 4B) se preocuparam em fazer exames de rotina. Provavelmente esse comportamento esteja associado à baixa frequência e curto tempo de exposição, levando ao aluno interpretar a não ocorrência de efeitos colaterais uma vez que verificamos baixo número de casos de desenvolvimento de problemas respiratórios (Figura 3B) que poderiam estar associados à inalação do formaldeído.

Estudos tem mostrado o comprometimento da eficiência do reparo de DNA o que aumenta a possibilidade que exposição frequente da pele e membranas mucoides ao formaldeído representando um fator de risco adicional ao câncer cutâneo em combinação à radiação UV ou químicos carcinogênicos (LUCH, et al, 2014; ZENDEHDEL, et al, 2018).

Em função dos efeitos deletérios do formaldeído, fazse mister a realização de campanhas de segurança no trabalho esclarecendo trabalhadores e estudantes expostos a este agente (LACERDA, et al, 2015).

Figura 4 - Distribuição dos alunos em relação à discussão da substituição do formaldeído e realização de exames médicos de rotina
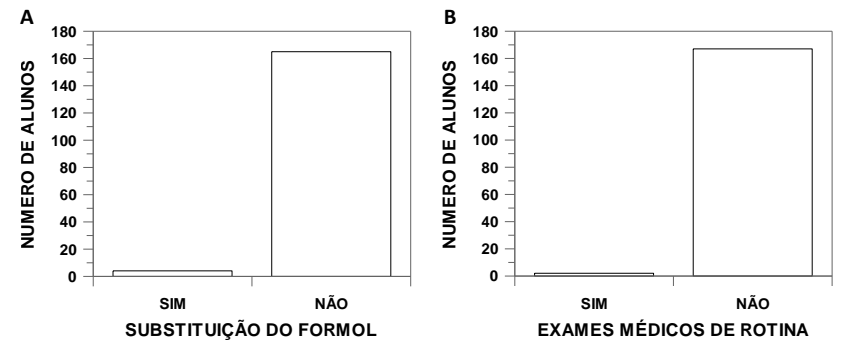

Fonte: Autores, 2019.

Dentre as possibilidades de substituição do formaldeído nos laboratórios de anatomia encontra-se a técnica de glicerinação. A glicerina tem a capacidade de desidratação celular, atuando como fungicida e bactericida. Além disso, a glicerina é uma substância inodora, não irrita as mucosas, não é carcinogênica e não possui um risco de contaminação ambiental tão elevado se comparado ao formol (AN, et al, 2012; KRUG, et al, 2011).

\section{CONCLUSÃO}

No tocante aos efeitos do folmandeído é fato tratar-se de um fator de risco à saúde do estudante e que o tempo de exposição implica em menor ou maior gravidade das ocorrências. Contudo, em função do período de tempo avaliado, não foi possível correlacionar os efeitos do formaldeído aos relatos dos eventos de desenvolvimento de doença, principalmente aos casos rinite uma vez que $5 \%$ da população apresenta rinite não alérgica. Nesse contexto, um avanço no estudo implica acompanhar os alunos por um maior período de tempo de exposição.

Independentemente de nesse estudo não ter sido possivel correlacionar os casos de alterações das vias aéreas superiores com o formaldeído, isso não estabelece a desobrigação do uso dos EPIs uma vez que os riscos de irritação e ou lesão de pele, mucosa e tecidos moles é elevada podendo ocasionar ulcerações. Além disso, os vapores podem acarretarr dores de cabeça, tosse, náuseas, lacrimejamento e depressão do sistema nervoso central. Dessa forma, a utilização dos EPIs devem ser normas a 
serem seguidas rigorosamente e os riscos do contato e inalação claramente expostos aos alunos e constar no manual de utilização dos laboratórios.

Em função dos riscos inerentes do contato ao formaldeído tanto a curto quanto em longo prazo, deve ser levado em consideração pelas universidades as aplicações de novos métodos de conservação apesar dos custos serem mais elevados, como a glicerinação.

\section{REFERÊNCIAS}

AN, X.; YUE, B.; LEE, J.H.; LIN, C.; HAN, S.H. Arterial anatomy of the gracilis muscle as determined by latex injection and glycerin transparency. Clin. Anat., V. 25, p. 231-234, 2012.

BAGATIN, E.; COSTA EA. Doenças das vias aéreas superiores. J. Bras. Pneumol., v. 32, suppl.2, São Paulo, 2006.

BRUNO, E.; SOMMA, G.; RUSSO, C.; POROZAJ, D.; PIETROIUSTI, A.; ALESSANDRINI, M.; MAGRINI, A. Nasal cytology as a screening tool in formaldehyde-exposed workers. Occup Med (Lond). v. 68, n. 5, p. 307-313, 2018.

CARVALHO, K.S. Influência do formol utilizado para conservação de cadáveres na obtenção de DNA nuclear em tecido muscular. Dissertação de mestrado. Faculdade de Odontologia de Piracicaba, Universidade Estadual de Campinas. Piracicaba, SP, Brasil, 2009.

BERTAZZI, P.A.; PESATORI, A.; GUERCILENA, S.; $e t$ al. Rischio cancerogeno per I produttori di resine esposti a formaldeide: Estensione del follow-up. Med Lav., V.80, p. 111-122, 1989.

DYKEWICZ, M. et al. - Diagnosis and management of rhinitis: Complete guidelines of the Joint Task Force on Practice Parameters on Allergy, Asthma and Immunology. Annals of Allergy, Asthma and Immunology, v. 81, n. 11, p. $478-518,1998$.

ERICH, B. Human body preservation - old and new techniques. J Anat., v. 224, n. 3, p. 316-344, 2014.

GAUTRIN, D.; DESROSIERS, M.; CASTANO, R. Occupational rhinitis. Curr Opin Allergy Clin Immunol. V. 6, p. 77-84, 2006.

HAYES, R.B. et al. Cancer of the nasal cavity and paranasal sinuses and formaldehyde exposure. International Journal of Cancer, v. 37, n. 4, p. 487-492, 1986.

IARC (International Agency for Research on Cancer). IARC Monographs on the Evaluation of Carcinogenic Risks to Humans. Chemical Agents and Related Occupations. FORMALDEHYDE. Lyon, France v. 100F, p. 401-435, 2012.

IBOPE PESQUISA. 55\% dos brasileiros dizem não saber nada a respeito da Doença Pulmonar Obstrutiva Crônica. 2016. Disponível em: <http://www.ibopeinteligencia.com/noticias-e-pesquisas/55dos-brasileiros-dizem-nao-saber-nada-a-respeito-da-doencapulmonar-obstrutiva-cronica/>. Acesso em: 11/03/2019.

KRUG, L.; PAPPEN, F.; ZIMMERMANN, F.; DEZEN, D.; RAUBER, L.; SEMMELMANN, C.; ROMAN, L.I.; BARRETA, M.H. Conservação de Peças Anatômicas com Glicerina Loira. Instituto Federal Catarinense, Concórdia,
SC, p.1-6. 2011. (Resumo) Disponível em: <http://mic.ifcconcordia.edu.br/wpcontent/uploads/2011/09/MIC109_Conserva\%C3\%A7\%C3 $\%$ A3o_de_pe $\%$ C3\%A7as_anat\%C3\%B4micas_com_gliceri na_loira.pdf>. Acesso em: 11/03/2019.

LACERDA, L.P.; DANTAS, E.B.S.; CERQUEIRA, G.S.; PERON, A.P.; SOUSA, J.M.C. Occupational toxicology study emphasizing the cytotoxic and mutagenic activity among workers exposed to gasoline. Biotemas, v. 28, n. 3, p. 135-141, 2015.

LAN, Q.; SMITH, M.T.; TANG, X.; GUO, W.; VERMEULEN, R.; JI, Z.; HU, W.; ET AL. Chromosomewide aneuploidy study of cultured circulating myeloid progenitor cells from workers occupationally exposed to formaldehyde. Carcinogenesis, v. 36, p. 160-167, 2015.

LEITE, E.S.; UVA, A.D.S. Exposição a formaldeído num laboratório de anatomia patológica: prevalência de rinite ocupacional e de outros sintomas. Saúde \& Trabalho, v. 8, p. 67-85, 2012.

LUCH, A.; FREY, F.C.; MEIER, R.; FEI, J.; NAEGELI, H. Low-dose formaldehyde delays DNA damage recognition and DNA excision repair in human cells. PLoS One, v. 9, n. 4, p. e94149, 2014.

MEI, Y.; DUAN. C.; LI, X.; ZHAO, Y.; CAO, F.; SHANG, S.; DING, S.; YUE, X.; GAO, G.; YANG, H.; SHEN, L.; FENG, X.; JIA, J.; TONG, Z.; YANG, X. Reduction of endogenous melatonin accelerates cognitive decline in mice in a simulated occupational formaldehyde exposure environment. Int. J. Environ. Res. Public Health. v. 13, n. 3, pii E258, 2016.

NESLIHAN, G.; ZAFER, K.C.; FEZA, A.L.; AFTAP, A.; HASAN, B.T. The Evaluation of Formaldehyde Exposure in the Anatomy Laboratories and the Preventive Measures. Gazi Med J. v. 27, n. 2, p. 98-103, 2016.

NTP-National Toxicology Program. U.S. Department of Health and Human Services (HHS)Formaldehyde (14th Report on Carcinogens). from <https://ntp.niehs.nih.gov/ntp/roc/content/profiles/formaldeh yde.pdf>, 2016. Acesso em: 27/03/2019.

OLIVEIRA, I. M.; MINDELLO, M. M. A.; MARTINS, Y. O.; FILHO, A.R.S. Análise de peças anatômicas preservadas com resina de poliéster para estudo em anatomia. Rev. Col. Bras. Cir. v. 40, n. 1, p. 76-80, 2013.

OLIVEIRA, F. S. Assessing the effectiveness of $30 \%$ sodium chloride aqueous solution for the preservation of fixed anatomical specimens: a 5-year follow-up study. Journal Anatomy. v. 225, n. 1, p. 118-121, 2014.

OMS-Organização Mubndial da Saúde. Exposition aux substances irritants pour les voies respiratoires. Limites recommandees d'exposition profssionelle a visee sanitaire. Rapport d'un group de etude de l'OMS. Serie Rapports Techniques (Genève) v. 707, p. 5-25, 1984.

SAOWAKON, N.; NGERNSOUNGNERN, P.; WATCHARAVITOON, P.; NGERNSOUNGNERN, A.; KOSANLAVIT R. Formaldehyde exposure in gross anatomy laboratory of Suranaree University of Technology: a comparison of area and personal sampling. Environ Sci Pollut. Res. v. 22, n, 23, p. 19002-19012, 2015. 
SILVA, G.R.; CORTEZ, P.O.B.C.; LOPES， I.S.L.; TEIXEIRA, B.A.C.B.; LEAL, N.M.S. Métodos de conservação de cadáveres humanos utilizados nas faculdades de medicina do Brasil. Revista de Medicina, v. 95, n. 4, p. 156, 2016.

SILVA, M.Z.M. A importância da biossegurança nos laboratórios de anatomia patológica dos hospitais públicos diante do manuseio do formol. Monografia. Programa de Pós-Graduação da Faculdade de Economia, Administração, Contabilidade e Ciências da Informação e Documentação (FACE), da Universidade de Brasília. 2010. Disponivel em: <http://www.bdm.unb.br/bitstream/10483/1356/1/2010_Mar iaZeliadaMotaSilva/>. Acesso em: 11/03/2019.

SOUSA, A.M.; CARVALHO, L.D.; MAIA, L.S.; SOARES, R.M.O.; AUDI, S.G. Formaldeído: grau de percepção de professores e técnicos de laboratórios universitários de anatomia, quanto aos riscos ocupacionais e uso de EPI'S. FIEP Bull Online. v. 85, n. 1, 2015. DOI: 10.16887/85.a2.93.

SMITH M.T.; DE LA ROSA, R.; DANIELS, S.I. Using exposomics to assess cumulative risks and promote health. Environ Mol Mutagen. v. 56, n. 9, p. 715-23, 2015.

SNOW JR, J.B.; WACKYM, PA. Allergic Rhinitis. Ballenger's Otorhinolaryngology Head and Neck Surgery, 17th Edition. v. 43, p. 531. 2009.

TEIXEIRA, P.; VALLE, S. Biossegurança: uma abordagem multidisciplinar. Rio de Janeiro: Fiocruz, $2^{a}$ edição (revista e ampliada): 2010.

TORTORA, G.J. Corpo Humano: Fundamentos de Anatomia e Fisiologia. 6a ed. Porto Alegre: Artmed, 2006.

VIEGAS, S.; LADEIRA, C.; NUNES, C.; MALTAVACAS, J.; GOMES, M.; BRITO, M.; MENDONCA, P.; PRISTA, J. Genotoxic effects in occupational exposure to formaldehyde: a study in anatomy and pathology laboratories and formaldehyde-resins production. J. Occup. Med.Toxicol. v. 5, n.1, p.25, 2010.

WEI, C.; CHEN, M.; YOU, H.; QIU, F.; WEN, H.; et al. Formaldehyde and co-exposure with benzene induce compensation of bone marrow and hematopoietic stem/progenitor cells in BALB/c mice during post-exposure period. Toxicol Appl Pharmacol. v. 324, p. 36-44, 2017.

WEN, H.; YUAN, L.; WEI, C.; ZHAO, Y.; QIAN, Y.; MA, P.; et al. Effects of combined exposure to formaldehyde and benzene on immune cells in the blood and spleen in Balb/c mice. Environ Toxicol Pharmacol, v. 45, p. 265-73, 2016.

WHO (World Health Organization). WHO guidelines for indoor air quality: selected pollutants. Switzerland, 2010. Retrieved April 9, 2016, from: <http://www.euro.who.int/_data/assets/pdf_fle/0009/12816 9/e94535.pdf>. Acesso em: 11/03/2019.

ZENDEHDEL, R.; ABDOLMALEKI, P.; JOUNI, F.J.; MAZINANI, M. Genetic variation and risk of DNA damage in peripheral blood lymphocytes of Iranian formaldehydeexposed workers. Hum Exp Toxicol. v. 37, n. 7, p. 690696, 2018.

\section{COPYRIGHT}

Direitos autorais: Os autores são os únicos responsáveis pelo material incluído no artigo.

Submetido em: 20/03/2019

Aprovado em: 11/04/2019 


\author{
Revista SODEBRAS - Volume 14 \\ $\mathrm{N}^{\circ} 161$ - MAIO/ 2019
}

\title{
EVOLUTION OF CHRONIC NON-CUMMUNICABLE DISEASES (NCDS) IN THE STATE OF SÃO PAULO, BRAZIL - 2007 TO 2016
}

\author{
RODOLPHO TELAROLLI JÚNIOR ${ }^{1}$; LEONOR DE CASTRO MONTEIRO LOFFREDO ${ }^{2}$ \\ 1 - DEPARTMENT OF BIOLOGICAL SCIENCES, UNIVERSIDADE ESTADUAL PAULISTA- UNESP, \\ ARARAQUARA, SP, BRAZIL (HTTPS://ORCID.ORG/0000-0002-9070-4778); 2 - DEPARTMENT OF \\ BIOESTATISTICS, UNIVERSIDADE ESTADUAL PAULISTA- UNESP, ARARAQUARA, SP, BRAZIL \\ AND SCHOOL OF MEDICINE, UNIVERSITY OF ARARAQUARA-UNIARA, ARARAQUARA, SP, \\ BRAZIL (HTTPS://ORCID.ORG/0000-0002-9070-4778) \\ rtjr@terra.com.br; lcmloffredo@uol.com.br
}

\begin{abstract}
Non-communicable chornic diseases (NCDs) are today the leading cause of death in most parts of the world, representin $g$ more than $70 \%$ of them. This is an epidemiological study with d escriptive purpose, of ecological type. The objective of this researc $h$ is to describe a historical series (2007 to 2016) of mortality from NCDs excluding external causes in São Paulo, the most thriving $s$ tate in Brazil. The data were retrieved from Brazilian official pub lic databases. In the average, along the studied period, 189.8 deat hs/100,000 were caused by circulatory system diseases, 115.2 by $n$ eoplasms, 80.1 by diseases of the respiratory tract, 38.3 by disease $s$ of the digestive system and 29.2 by endocrine, nutritional and $m$ etabolic diseases. The 60 years old and above males were the pred ominant victims of all causes, except endocrine and metabolic dis eases, especially diabetes. NCDs represent a financial burden to $i$ ndividuals and for the society. A reduction in their incidence relie $s$ actions towards declining behavioral and risk factors.
\end{abstract}

Keywords: Noncommunicable Diseases Epidemiology. Cardiovascular Diseases.

\section{INTRODUCTION}

Non-communicable chronic diseases are characterized by the absence of microorganisms at their origins and are also called non-infectious diseases and chronic degenerative diseases. According to the World Health Organization (WHO), in 2008, 36 million deaths worldwide were caused by coronary diseases and strokes (GRAYLEY, 2011), as well as lung infections, cancer and diabetes (ALWAN et al., 2010).

The prevalence of NCDs is being observed throughout the world and integrates the process known as the epidemiological transition (SCHMIDT et al., 2011). Between 2000 and 2012 this group of diseases raised from $46 \%$ to $55 \%$ of the world's total causes of death, while communicable diseases dropped from $43 \%$ to $34 \%$. In Brazil, over the same period, the records of NCDs increased from $62 \%$ to $70 \%$ of total deaths, and the communicable ones dropped from $24 \%$ to $15 \%$ (REIS \& PIMENTEL, 2016).

External causes, which are not the object of this study, appear as the first cause of deaths among Brazilian adult population aged 15 to 59 years old, and the State of São Paulo is no exception (SEADE, 2016; SEADE, 2017). In descending order, diseases of the circulatory system, neoplasms, diseases of the digestive and respiratory follow the rank. Among the population aged 60 and above, endocrine, nutritional and metabolic diseases, especially diabetes, appear as the fifth group of NCDs considered relevant in mortality statistics (SEADE, 2014).

These diseases present multi-causal origins and can be controlled or postponed by actions lifestyle in order to stimulate changes in habits and reduce risk factors, such as sedentariness, smoking, obesity and overweight, as well as unhealthy dietary habits. They top the rank of causes for premature deaths, compromising the quality of life in patients, limiting their work capacity or causing disabilities, incurring, thus, in high costs for the society (WHO, 2013; OPAS, 2015).

The process of populational aging in the world represents a major factor of increse in the presence of NCDs among mortality causes, and this is also true in Brazil. However, as the aging process, known as demographic transition, has occurred more slowly in European countries, starting in the first half of the 19th century, in Brazil this process was observed ialong the second half of the 20th century. While France was allowed 150 years to see its elderly population double, Brazil will face this two-fold growth within only 30 years, until 2030 (REIS \& PIMENTEL, 2016).

This rapid process of epidemiological transition makes it imperative to better study the characteristics of mortality due to NCDs in the country. The study of NCDs in São Paulo is specially interesting because the state presents a higher HDI compared to other states in the country, thus, anticipating trends that will only be present in the nationwide decades later. Information is fundamental for the design of governmental and social strategies that may lead to a better management of morbidity and mortality by NCDs (DUNCAN et al., 2012; WHO, 2011).

The objective of this study is to analyze the trends of mortality by NCDs in the State of São Paulo, from 2007 to 2016 , by age groups and by causes of death groups along the 2007-2011 and 2012-2016 quinquenia.

\section{METHODS}

This is an epidemiological study with descriptive purpose, of time series, of ecological type. The total number of annual deaths by NCDs between 2007 and 2016 in the State of São Paulo was analyzed. Because it is an 
ecological study, characterized by the presence of "groups of people" as observation units, public domain secondary population data were used (ALMEIDA \& BARRETO, 2011).

Mortality numbers were retrieved from the Foundation State System of Data Analysis (SEADE), observing the Civil Registry - Microdata Tabulations for the State of São Paulo, according to the annual observation of its occurrence between 2007 and 2016 (SEADE, 2018). The studied age groups were: $<1$ year old, 1 to 4,5 to 9 , 10 to 19,20 to 59,60 years old and above, as well as ignored age. The categories adopted for gender were: male, female and ignored. For populational assessment, information from Brazilian Institute for Geography and Statistics (IBGE) was used (IBGE, 2018).

The causes of death by NCDs were studied according to the chapters of the WHO International Classification of Diseases and Related Health Problems, in its tenth version (ICD-10) (WHO, 2007), and the five main death cause groups (ICD chapters) were selected.

In order to analyze the trend of mortality by cause in the State of São Paulo, the calculation was carried out by using the formula:

\section{Mortality $(\mathrm{NCD})=\mathrm{x} 100,000$}

The database was built up in an Excel spreadsheet in order to calculate the mortality coefficients for the State of São Paulo as well as its temporal trends for the second year of the period ranging from 2007 to 2016, and, also, for the quinquennia that composes the period. Significance tests were performed in order to find the ratio between the quinquennia coefficients (2012-2016 and 2007-2011) per point (R) and $95 \%$ confidence interval $(95 \% \mathrm{CI})$, making it possible to verify if there was a statistically significant difference between these coefficients or whether such difference was caused random effects only (DEVER, 198).

Since secondary data were retrieved from the available public official databases, where information does not identify individuals, the study was not required to be submitted to the Research Ethics Committee.

\section{RESULTS}

The State of São Paulo presented the following groups of NCDs that compounded the five main causes of death of this nature from 2007 to 2016 :

1. Diseases of the Circulatory System - Chapter IX ICD

2. Neoplasms - Chapter II ICD

3. Diseases of the Respiratory Tract - Chapter X ICD

4. Diseases of the Digestive System - Chapter XI ICD

5. Endocrine, Nutritional and Metabolic Diseases Chapter IV ICD.

The coefficients of mortality from the abovementioned causes in the studied period can be observed in Figure 1.
Figure 1 - Mortality coefficients (per 100,000 inhabitants) from NCD causes SP, 2007 to 2016

\section{Coef.x 100.000}

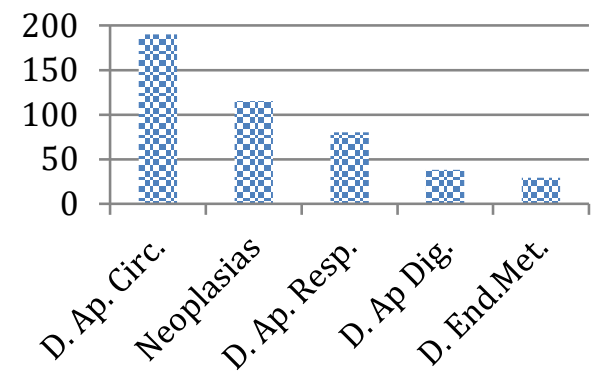

Source: SEADE, 2018.

The highest coefficient of mortality per cause was due to diseases of the circulatory system (189.8 per 100,000 inhabitants), the main cause of mortality in São Paulo state. High mortality rates (per 100,000 inhabitants) were observed for neoplasms (115.2), diseases of the respiratory tract $(80,1)$, diseases of the digestive system $(38,3)$ and endocrine, nutritional and metabolic diseases $(29,2)$.

The behavior of each of these causes of death during the period can be visualized in Figure 2:

Figure 2 - Mortality coefficients (per 100,000 inhabitants) from NCD causes SP, 2007 to 2016

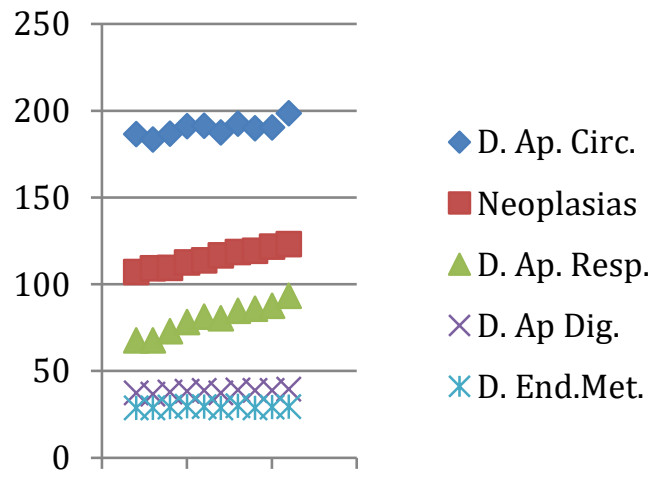

2005201020152020

Source: SEADE, 2018.

The incidence of mortality due to diseases of the circulatory system, neoplasias, respiratory tract and digestive system showed upward trend, whereas stability in mortality due to endocrine, metabolic and nutritional diseases was observed.

When comparing the quinquennia 2012-2016 and $2007-$ 2011, it was verified that mortality by:

- diseases of the circulatory system presented $\mathrm{R}=1.02$ (95\% CI: 1,010-1,030), showed significant increase.

- neoplasms have raised significantly, since $\mathrm{R}=1.09$ (95\% CI: 1.080-1.100).

- diseases of the respiratory tract have shown important growth, where $\mathrm{R}=1.17$ (95\% CI: 1.160-1.180),

- endocrine, metabolic and nutritional diseases remained stable from 29.20 to $29.02(\mathrm{R}=1.01)$, being considered non-significant and

- diseases of the digestive system have descended significantly, $\mathrm{R}=1.02$ (1.019-1.021). 
Concerning gender, there was a predominance of deaths in males from diseases of the circulatory system (52\%), neoplasms (54\%), diseases of the respiratory tract (52\%), and diseases of the digestive system $(63 \%)$. The female gender deaths consisted had their causes in endocrine, metabolic and nutritional diseases $(54 \%)$.

Regarding age-related deaths, the percentual distribution can be visualized as follows (Figure 3):

Figure 3 - Percentual distribution of the main causes of NCD deaths according to age groups. SP, 2007 to 2016

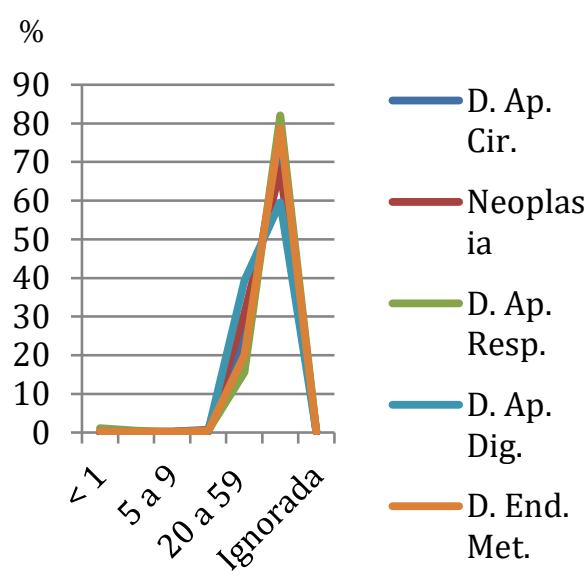

Source: SEADE, 2018.

As shown in Figure 3, all causes had the highest percentage of deaths in the age group of $60+$ years old, preceded by the age ranging from 20 to 59 . On the other hand, diseases of the digestive system presented $40 \%$ of mortality between 20 and 59 year-olds, being followed in frequency by the neoplasms; in this age group, NCDs less frequent causes of death were diseases of the respiratory tract.

\section{CONCLUSION}

What determines the use of health services is defined by the existence of a cause, either by its severity or by the urgency of the treatment. Such requirements are fulfilled by patients presenting NCDs, and thus, this group is the one which demands health services most, 13 reinforcing the need for studies on the subject (TRAVASSOS \& MARTINS, 2004; GOLDSTEEN et al., 2015).

In the State of São Paulo, between 2007 and 2016, the cardiovascular diseases group represented the main cause of mortality (189.8 per 100,000 inhabitants), especially hypertensive diseases, ischemic heart diseases, cerebrovascular diseases and other disorders of the circulatory system. The occurrence of the above is associated to an equation in which behaviors and risk factors: sedentary lifestyle, smoking, overweight or obesity, high cholesterol levels and unhealthy eating habits, such as excessive consumption of salt and saturated fats, stand out. They also become more frequent as the average age of the population raises, which is a reality in Brazil, resulting from the rapid demographic transition process over the last 50 years.

Following those, in descending order of frequency, appear the groups of neoplasms (115.2 per 100,000 inhabitants), diseases of the respiratory tract (80.1 per 100,000 inhabitants), diseases of the digestive system $(38.3 \%$ per 100,000 inhabitants) and endocrine, nutritional and metabolic (29.2 per 100,000 inhabitants). As a whole, this pattern is the same observed for the Brazilian average, with some reservations.

NCDs are, by definition, avoidable causes of death, the origin of many premature deaths that could be avoided through the use of a set of prophylactic measures aimed at health guarantee and the control of risk factors related to its genesis. Their control is also closely related to the improvement of the medical care system and the incorporation of new therapeutic technologies (MALTA et al., 2018).

In 2011 the Ministry of Health launched a plan for the control of NCDs, a set of strategic actions to address these diseases, in accordance with the global goals defined by WHO in 2011 for the agenda until 2025 (WHO, 2012).

Male mortality predominated in all causes, with the exception of those associated with endocrine, metabolic and nutritional diseases, and NCDs had a greater participation in the age group of 60 years old and above. The greater participation of NCDs in the mortality of the elderly is mainly due to two classes of factors: a) the fact that these diseases are of a chronic nature and their genesis is associated with exposure to risk factors and behaviors, which are added alonglife, favoring its development; (b) the increase, over the last 80 years, in the number of deaths of young adults, due to external causes, and deaths due to violent causes, especially for homicides and accidents. This seems fairly clear when we observe the inexistence of male overmortality among young adults in the year 1940. This phenomenon is typical in regions and countries that have undergone rapid urbanization processes, such as Brazil (IBGE, 2016).

The general pattern of mortality with predominance of NCDs observed in the State of São Paulo is the same that has been observed for some time in Brazil as a whole (IBGE, 2016). In 2012, NCDs accounted for $74 \%$ of deaths countrywide, external causes for $12 \%$ and communicable diseases for the remaining $14 \%$. The expectation is that this pattern might spread out over the country as a whole. The only causes of infectious deaths present among the 10 main causes of mortality in Brazil are lower respiratory tract infections (REIS et al., 2016). These changes integrate the process of epidemiological transition, which is ongoing in the country including the State of São Paulo (REIS \& PIMENTEL, 2016). São Paulo showed a decreasing trend in mortality from external causes from 2007 to 2016, while countrywide, the deaths from violent causes increased by $3 \%$ between 2011 and 2016, reaching a figure of 30.8 per 100,000 inhabitants.

NCDs are today one of the greatest public health issues since they cause economic and social impact on patients, their families and the society. ${ }^{19}$ These diseases lead to a diminishment in the quality of life and individual autonomy, incurring in their dependence on others, as well as a high family and social financial burden. On the other hand, such diseases show high avoidability rates, either through low complexity measures, such as the fight against risk factors and behaviors, smoking and poor eating habits, or through investment in medium and high complexity hospital care. The reduction in mortality by NCDs presents itself as one of the main poles of investment in the public and private health industry in the coming decades.

However, as a result of the difficulties and high costs to implement these measures (increament in medium and high complexity hospital care), as well as to promote changes in risk behaviors of the population considerad harmful to health, 
we shal not expect changes in short or mid term in the broad prevalence trends of NCDs as the main causes of death in the country, neither in the State of São Paulo.

The data sources of the research were reliable and top quality public databases (IBGE and SEADE). Nevertheless, it is worth mentioning that such sources are usually somehow out of date in relation to the present days due to the institutions' difficulties in aggregating data from remote and deprived regions of the country to the ones retrieved in São Paulo state. This limitation is beyond the reserchers' control, and they shall be considered as intrinsic to the methodology adopted in the research.

\section{REFERENCES}

ALMEIDA F N, BARRETO M. Epidemiologia e Saúde: fundamentos, métodos e aplicações. Guanabara Koogan; 2011.

ALWAN A, MACLEAN DR, RILEY LM et al. Monitoring and surveillance of chronic non-communicable diseases: Progress and capacity in high-burden countries. Lancet. 2010; 376(9755):1861-8. doi:10.1016/SO140-6736(10)61853-3. PMID: 21074258.

IBGE. Instituto Brasileiro de Geografia e Estatística (IBGE). Pesquisa Nacional de Saúde 2013 - Indicadores de Saúde e Mercado de Trabalho. Available from: https://biblioteca.ibge.gov.br/visualizacao/livros/liv97329.pdf. Accessed in 2019 (Apr 14).

DEVER G E A. A Epidemiologia na Administração dos Serviços de Saúde. Pioneira; 1988.

DUNCAN BB, CHOR D, AQUINO EML et al. Chronic noncommunicable diseases in Brazil: priorities for disease management and research. Rev Saúde Pública. 2012; 46 (supl 1):126-34. doi: 10.1590/S0034-89102012000700017. PMID: 23532314

GOLDSTEEN R L, GOLDESTEEN K, DWELLE T L. Introduction to Public Health - Promises and Practices. Springer Publishing; 2015.

GRAYLEY MV. Doenças crônicas mataram mais de 36 milhões em 2008. ONU: News. 27 abr 2011. Available from: Available from: https://news.un.org/pt/story/2011/04/1373311doencas-cronicas-mataram-mais-de-36-milhoes-em-2008.

Accessed in 2018 (May 28).

IBGE. Instituto Brasileiro de Geografia e Estatística (IBGE). Projeção da população do Brasil por sexo e idade para o período de 2000-2060. Available from: http://tabnet.datasus.gov.br/cgi/Ibge/projpopbr.pdf. Accessed in 2018 (Apr 27).

IBGE. Instituto Brasileiro de Geografia e Estatística. Tábua completa de mortalidade para o Brasil - 2015 - Breve análise da evolução da mortalidade no Brasil. 2016. Available from: ftp://ftp.ibge.gov.br/Tabuas_Completas_de_Mortalidade/Tabua s_Completas_de_Mortalidade_2014/notastecnicas.pdf.

Accessed in 2018 (May 25).

MALTA D C, SALTARELLI R M F, PRADO R R, MONTEIRO R A, ALMEIDA, M F. Preventable deaths within Brazil's Public Health System in a population from 5 to 69 years old, 2000 - 2013. Rev. bras. epidemiol. 2018; 21:1-15. doi: 10.1590/1980-549720180008. PMID: 30088593
OPAS Organização Pan-Americana da Saúde. Doenças crônicas- não transmissíveis causam 16 milhões de mortes prematuras todos os anos. 2015. Available from: https://www.paho.org/bra/index.php?option=com_content\&vie $\mathrm{w}=$ article\&id=4766 Accessed in 2018 (May 25).

REIS C, BARBOSA L, PIMENTEL V. O desafio do envelhecimento populacional na perspectiva sistêmica da saúde. BNDES Setorial. 2016; 14:87-124. Available from: https://web.bndes.gov.br/bib/jspui/handle/1408/9955. Accessed in 2018 (May 25).

SCHMIDT MI, DUNCAN BB, E SILVA GA et al. Chronic non-communicable diseases in Brazil: Burden and current challenges. Lancet. 2011; 377(9781):1949-61. doi: 10.1016/S0140-6736(11)60135-9 PMID: 21561658.

SEADE. Perfil da mortalidade da população no Estado de São Paulo. SP Demográfico. 2014; 14(3):1-11. Available from: http://www.seade.gov.br/produtos/midia/2018/08/SPDemografi co_Num-03_jul2014.pdf. Accessed in 2019 (Feb 17).

SEADE. Mortalidade por suicídio no Estado de São Paulo. SP demográfico. 2016; 16(3):1-14. Available from: http://www.seade.gov.br/produtos/midia/2016/09/SeadeSPDem o-Suic\%C3\%ADdios.pdf. Accessed in 2019 (Feb 17).

SEADE. EM 2015, o Estado de São Paulo atingiu a menor taxa de acidentes de transporte dos últimos 35 anos. SP Demográfico. 2017; 17(3):1-18. Available from: http://www.seade.gov.br/produtos/midia/2017/09/SPDemografi co_Num-03_2017.pdf. Accessed in 2019 (Feb 17).

SEADE. Informações dos Municípios Paulistas. Available from:

http://produtos.seade.gov.br/produtos/imp/index.php?page=wel come. Accessed in 2018 (Apr 27).

TRAVASSOS C, MARTINS M. A review of concepts in health services access and utilization. Cad Saude Publ. 2004; 20(Sup 2):190-8. doi: S0102-311X2004000800014. PMID: 15608933

WHO World Health Organization. Classificação Estatística Internacional de Doenças e Problemas Relacionados à Saúde - CID-10. EDUSP; 2007.

WHO World Health Organization. Resolution adopted by the General Assembly. 2012. Available from: Available from: http://www.who.int/nmh/events/un_ncd_summit2011/political _declaration_en.pdf. Accessed in 2018 (May 25).

WHO World Health Organization. World Health Assembly. Global action plan for the prevention and control of noncommunicable diseases. 2013. Available from: Available from:

http://apps.who.int/iris/bitstream/10665/94384/1/97892415062 36_eng.pdfhttp://apps.who.int/iris/bitstream/10665/94384/1/97 89241506236_eng.pdf. Accessed in 2018 (May 25).

\section{COPYRIGHT}

Direitos autorais: Os autores são os únicos responsáveis pelo material incluído no artigo.

Submetido em: 23/03/2019 Aprovado em: 15/04/2019 


\section{Área: Ciências Exatas e Engenharias}

\begin{tabular}{|c|c|}
\hline $1-3$ & $\begin{array}{l}\text { IMPLEMENTAÇÃO DE CANAL SEGURO PARA TRANSMISSÃO DE DADOS } \\
\text { MÉDICOS } \\
\text { SECURE CHANNEL IMPLEMENTATION FOR MEDICAL DATA TRANSMISSION } \\
\text { Samuel Henrique França Leite; Dalton Matsuo Tavares; Stella Jacyszyn } \\
\text { Bachega; Olávio Gonçalves De Almeida }\end{array}$ \\
\hline $1-7$ & $\begin{array}{l}\text { A EDUCAÇÃO E PRESERVAÇÃO AMBIENTAL NUMA TURMA DE 5 ANO } \\
\text { DO ENSINO FUNDAMENTAL L - BOA ESPERANÇA - ES } \\
\text { THE EDUCATION AND ENVIRONMENTAL PRESERVATION IN A CLASS OF } 5 \\
\text { YEARS OF ELEMENTARY SCHOOL L - BOA ESPERANÇA - ES } \\
\text { Marcos Daher Oliveira; Marcus Antonius Da Costa Nunes }\end{array}$ \\
\hline 3-4 & $\begin{array}{l}\text { APLICAÇÕES DE SOFTWARES LIVRES PARA ANÁLISES DE SISTEMAS } \\
\text { ENERGÉTICOS E OS RESPECTIVOS ESTUDOS DE EFICIEENCIA ENERGÉTICA } \\
\text { APPLICATIONS OF FREE SOFTWARE FOR ENERGY SYSTEM ANALYSIS } \\
\text { AND THEIR ENERGY EFFICIENCY STUDIES } \\
\text { Rafael Ayres Soares; Marcio Zamboti Fortes; Angelo Cesar Colombini }\end{array}$ \\
\hline $3-8$ & $\begin{array}{l}\text { OTIMIZAÇÃO DO TEMPO DE VIDA ÚTIL DE ELETRODOS UTILIZADOS } \\
\text { EM UM PROCESSO DE SOLDA NA CARROCERIA EM UMA EMPRESA } \\
\text { AUTOMOBILÍSTICA } \\
\text { OPTIMIZING THE USEFUL LIFE TIME OF ELECTRODES USED IN A } \\
\text { WELDING PROCESS IN THE BODY IN AN AUTOMOBILE COMPANY } \\
\text { Nilo Antonio De Souza Sampaio; Alzira Ramalho Pinheiro De Assumpção; Helena } \\
\text { Maria Perim De Almeida; Jéssica Crystina Ramos Medon De Oliveira; Luma Britto } \\
\text { Pinto }\end{array}$ \\
\hline
\end{tabular}




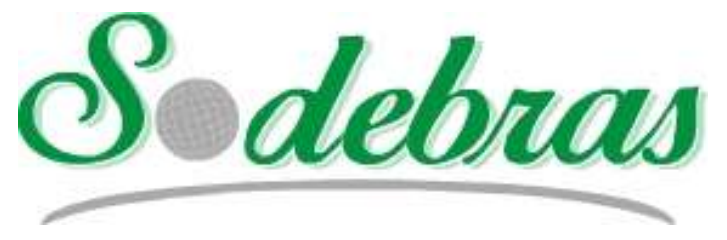

Revista SODEBRAS - Volume 14

$\mathrm{N}^{\circ} 161-\mathrm{MAIO} / 2019$

\title{
IMPLEMENTAÇÃO DE CANAL SEGURO PARA TRANSMISSÃO DE DADOS MÉDICOS
}

\author{
SECURE CHANNEL IMPLEMENTATION FOR MEDICAL DATA \\ TRANSMISSION
}

\author{
SAMUEL HENRIQUE FRANÇA LEITE ${ }^{1}$; DALTON MATSUO TAVARES ${ }^{1}$; STELLA JACYSZYN \\ BACHEGA $^{2}$; OLÁVIO GONÇALVES DE ALMEIDA ${ }^{1}$ \\ 1 - UNIVERSIDADE FEDERAL DE GOIÁS - REGIONAL CATALÃO (IBIOTEC); 2 - UNIVERSIDADE \\ FEDERAL DE GOIÁS - REGIONAL CATALÃO (FENG) \\ samuelfranca@discente.ufg.br;dalton_tavares@ufg.br; stella@ufg.br; olaviogoncalves@discente.ufg.br
}

\begin{abstract}
Resumo - O monitoramento remoto de pacientes auxilia os serviços de saúde, pois estes podem ser utilizados para acompanhar pacientes que não têm condições de se locomover até um centro médico. Há inúmeros protocolos disponíveis que possibilitam a transmissão segura de dados. Tal transmissão é de vital importância para qualquer aplicação que utilize sensores. $O$ objetivo deste artigo foi analisar $e$ avaliar os principais protocolos $e$ ferramentas que possibilitam a transmissão segura de dados, para determinar qual se enquadra melhor no contexto da área médica. Para tanto, foi utilizada uma metodologia de revisão de escopo (ou estudo de escopo), a qual permitiu elencar protocolos e ferramentas para a transmissão segura de dados. Como resultado, foi possível realizar um comparativo entre os protocolos e ferramentas levantados, e concluir qual protocolo e ferramenta é o mais indicado para o referido cenário.
\end{abstract}

Palavras-chave: Transmissão Segura de Dados. Protocolos para Transmissão Segura. Ferramentas para Transmissão Segura.

\begin{abstract}
Remote patients' monitoring helps health services as they can be used to observe patients who are unable to move to a medical facility. There are numerous protocols available that enable secure data transmission. Such transmission is of vital importance to any application that uses sensors. The objective of this article was to analyze and evaluate the main protocols and tools that allow the secure transmission of data, to determine which fits best in the medical context. In order to do so, a scoping review (or scoping study) methodology was used, which allowed to catalog protocols and tools for the secure transmission of data. As a result, it was possible to perform a comparison between the protocols and tools gathered, and to conclude which protocol and tool is best suited for the aforementioned scenario.
\end{abstract}

Keywords: Secure Data Transmission. Protocols for Secure Transmission. Secure Transmission Tools.

\section{INTRODUÇÃO}

Redes de Sensores Sem Fio (RSSF) consistem em um grupo de sensores sem fio que podem se comunicar uns com os outros, utilizando protocolos de comunicação padrão. Esses sensores podem ser usados para medir parâmetros físicos diferentes (como pressão, temperatura, quantidade de diferentes gases no ambiente etc.) (PAI;
POOJARY; PAI, 2014). Os dados coletados por esses sensores precisam ser passados para um local principal através da rede (YI et al., 2016).

Campos promissores para RSSF são as aplicações em saúde, onde os pacientes podem ser monitorados em casa ou em hospitais (YI et al., 2016). No contexto de transmissão de dados, muitos estudos concentram-se na entrega confiável e eficiente desses dados. A transmissão segura de dados é importante em qualquer área de aplicação de sensores. Mais especificamente, na área médica, torna-se importante devido a ameaças como o acesso indevido aos dados do paciente, ou falsificação de dados monitorados e geração de alarmes falsos ou modificação de dados transmitidos (YI et al., 2016). Dessa forma, como objetivo deste artigo, foram analisados quais protocolos e ferramentas possibilitam a implementação de um canal seguro para transmissão de dados médicos. Essa pesquisa é incremental ao estudo realizado em Sousa et al. (2017), o qual considerava apenas a transmissão dos dados biométricos capturados usando uma placa Arduino, utilizando módulos de comunicação especializados para uma rede Wi-Fi, porém sem levar em consideração questões relativas a segurança.

O presente artigo está estruturado como segue: na próxima seção estão os procedimentos metodológicos; na seção três estão os conteúdos teóricos identificados durante o estudo de escopo realizado; na seção quatro estão os resultados obtidos quanto a comparação dos protocolos e ferramentas levantados na pesquisa; por fim, a seção cinco apresenta a conclusão.

\section{PROCEDIMENTOS METODOLÓGICOS}

A explicação científica desta pesquisa é hipotéticodedutiva. Esta consiste em três etapas: identificação do problema, formulação das hipóteses e a refutação das mesmas (falseamento). Esta última etapa tem como objetivo validar as novas teorias levantadas (MARCONI; LAKATOS, 2017).

O procedimento de pesquisa utilizado foi o estudo de escopo. Para conduzir o estudo de escopo, as recomendações de Arksey e O’Malley (2005) e Levac, Colquhoun e O’Brien (2010) foram seguidas. Mais 
especificamente, as seguintes etapas propostas por Arksey e O’Malley (2005) foram empregadas, a saber: (1) identificação da questão de pesquisa; (2) identificação de estudos relevantes; (3) seleção de estudos; (4) extração dos dados a partir dos estudos selecionados; (5) síntese e relato dos resultados. Autores como Bachega e Tavares (2015; 2017) também advogam o uso desses passos.

A hipótese norteadora para essa pesquisa é a possibilidade da criação/utilização de mecanismos para a transmissão segura de sinais vitais, os quais serão coletados por uma RSSF. Mais especificamente, trata-se de uma rede de sensores corporais (do termo em inglês Wireless Body Area Networks ou WBAN). Nesse contexto, WBAN é uma RSSF que incorpora diferentes redes e dispositivos sem fio para permitir o monitoramento remoto. Uma das aplicações direcionadas de WBAN é em ambientes médicos, onde as situações de pacientes podem ser continuamente monitoradas (YUCE, 2010).

\section{1 - Identificação da questão de pesquisa}

No primeiro estágio foi constatada a importância de um sistema para a transmissão segura de dados que utilize, idealmente, mecanismos baseados em código aberto (open source) e que seja de baixo custo. A questão de pesquisa estabelecida diz respeito a "quais ferramentas permitem a criação de canais de comunicação seguros para a transmissão de dados via Internet?".

\section{2 - Identificação de estudos relevantes}

No segundo estágio decidimos utilizar o Portal de Periódicos Capes/MEC como fonte do levantamento bibliográfico. Inicialmente, foram definidos os critérios de exclusão para os trabalhos selecionados. O primeiro critério foi em relação a data de publicação. Neste caso, foi definido um período com no máximo 10 anos de diferença em relação ao início da pesquisa, em agosto de 2017 (exceções somente para documentos considerados relevantes, observando-se o seu impacto na área). O segundo critério foi em relação ao idioma. Foram selecionados apenas textos escritos em inglês, português e espanhol para facilitar a tradução e compreensão dos documentos. $\mathrm{O}$ terceiro critério foi em relação a qualidade dos documentos (foram utilizados apenas textos que foram revisados por pares)

\section{3 - Seleção de estudos}

No terceiro estágio, definimos os termos de busca que estão de acordo com a questão de pesquisa estabelecida no estágio 1. Ao todo foram determinados 6 (seis) termos de busca: (1) secure channels; (2) tools for secure data transfer; (3) private computer networks; (4) VPN implementations; e (5) secure cloud architectures. Foram selecionados apenas termos em inglês, tendo em vista que as pesquisas mais relevantes e abrangentes para a área de computação tradicionalmente são publicadas nesse idioma.

A Tabela 1 mostra o aspecto quantitativo em relação as buscas na ferramenta online do Portal de Periódicos Capes/MEC, utilizando os seguintes filtros: (1) Periódicos revisados por pares; (2) Data de publicação: 2007 até 2017; (3) Idioma: Português, Inglês e Espanhol. Os documentos retornados são aqueles que o Portal Capes indicou como o total de documentos relativo àquele termo de busca (já com os filtros aplicados).
Tabela 1 - Quantitativo do levantamento bibliográfico após filtragem inicial

\begin{tabular}{cc}
\hline Termos de busca & $\begin{array}{c}\text { Quantidade de documentos } \\
\text { retornados }\end{array}$ \\
\hline Secure channels & 37588 \\
Tools for secure data & 19768 \\
transfer & 44243 \\
Private computer networks & 501 \\
VPN implementations & 2638 \\
Secure cloud architectures & \\
\hline
\end{tabular}

Em seguida, foi realizada a análise dos títulos dos documentos levantados conforme a Tabela 1, identificando os trabalhos que possuíam alinhamento com a hipótese ou a questão de pesquisa. $O$ resultado desta análise aparece registrado na Tabela 2 .

Tabela 2 - Quantitativo dos documentos após análise de títulos

\begin{tabular}{cc}
\hline Termos de busca & $\begin{array}{c}\text { Quantidade de documentos } \\
\text { analisados }\end{array}$ \\
\hline Secure channels & 315 \\
Tools for secure data & 140 \\
transfer & 80 \\
Private computer networks & 320 \\
VPN implementations & 80 \\
Secure cloud architectures & \\
\hline
\end{tabular}

Depois da análise de títulos, foram selecionados ao todo 135 documentos. Em seguida, foi realizada uma análise mais detalhada, baseada na leitura do resumo (abstract) de cada artigo selecionado. Usando novamente os critérios de inclusão e exclusão, foi reduzido ainda mais esse quantitativo, permanecendo um total de 27 artigos a serem analisados na próxima etapa.

\section{4 - Extração de dados, síntese e relato dos resultados}

No quarto e quintos estágios (aqui representados em conjunto), foram analisados e organizados todos os artigos selecionados no estágio anterior com o intuito de identificar qual protocolo/ferramenta seria o mais promissor para a transmissão de dados médicos. Os 27 artigos selecionados na etapa anterior foram lidos na íntegra. Destes, foram extraídas as informações relevantes para a pesquisa. Assim, todo o conteúdo selecionado foi registrado para compor este artigo científico.

\section{REVISÃO DE ESCOPO REALIZADA}

O objetivo desta seção é apresentar os protocolos e ferramentas levantados ao longo desta pesquisa, com o intuito de se estabelecer o melhor cenário possível para a criação de um canal seguro no contexto de transmissão de dados médicos.

\section{$3.1-$ Protocolos}

Tecnologias como Virtual Private Network (VPN), desfrutam de ampla aceitação e são exemplos do que hoje em dia é chamado de "segurança utilizável" para comunicação segura em redes (RASS et al., 2015). As tecnologias de VPN são diferentes em suas abordagens, significando que a escolha de qual tecnologia usar depende muito do cenário em que essa tecnologia será aplicada. Portanto é importante entender as similaridades, diferenças e 
capacidades de cada tecnologia antes de selecionar uma solução (ROWAN, 2007).

No estudo de Rossberg e Schaefer (2011) afirma-se que a VPN configurada manualmente oferece uma melhor segurança quando comparada a diversas abordagens que visam a autoconfiguração de VPN. Além disso, o grande número de abordagens de configuração automática que usam protocolos criptográficos inseguros é preocupante.

Com isso, serão discutidos os principais protocolos criptográficos para configurar uma VPN manualmente. Após a análise de todos os protocolos levantados, serão reunidos subsídios para determinar qual a melhor abordagem no contexto de transmissão segura de dados médicos.

\section{$3.1 .1-C o A P$}

O Constrained Application Protocol (CoAP) é uma variante do HTTP, padronizado para fornecer recursos da Web na Internet das coisas (Internet of Things ou IoT). O CoAP é executado sobre o User Datagram Protocol (UDP) e foi projetado especialmente para ser utilizado com dispositivos restritos de baixa potência (RAZA et al., 2017).

Em Van Den Abeele et al. (2015), os autores implementaram e avaliaram uma arquitetura de software baseada em nuvem que permite a integração de dispositivos com poucos recursos. Nesse trabalho, o CoAP foi escolhido porque é um protocolo leve, mas poderoso, sendo uma boa alternativa para integrar dispositivos mais simples à nuvem. $\mathrm{O}$ uso do CoAP possibilita uma solução leve, na qual um dispositivo virtual pode ser usado não só pelos serviços convencionais, mas também pelos próprios dispositivos com poucos recursos.

Em Raza et al. (2017), os autores apresentam uma arquitetura de comunicação totalmente baseada em protocolos padronizados, a qual garante a comunicação segura entre dispositivos de IoT. Nessa aplicação, foi implementado o CoAP seguro para dispositivos IoT restritos. A avaliação de desempenho e implementação da arquitetura foi realizada com todos os três modos de segurança do CoAP: Pre-Shared Key (PSK)-based, RawPublic Key (RPK)-based e X.509 certificate-based. Essa avaliação mostrou que a arquitetura de comunicação é uma solução de segurança de comunicação End-to-End (E2E) viável para a IoT conectada à nuvem, em termos de tempo, energia e sobrecarga de armazenamento.

Os autores poderiam utilizar o protocolo HTTP para a arquitetura de comunicação, mas afirmam que ele é pesado demais para dispositivos IoT. Sendo assim, utilizaram o UDP como protocolo de transporte, já que este fornece muitas das mesmas funcionalidades que o HTTP fornece.

\section{$3.1 .2-I P s e c$}

O IPsec é o protocolo de segurança mais utilizado para proteger as sessões de comunicação baseadas em IP em uma rede (LIYANAGE et al., 2017). O IPsec refere-se a vários protocolos intimamente vinculados, que operam na camada IP da pilha de rede. Toda a criptografia ocorre nessa camada, essencialmente protegendo elementos mais acima na pilha. Isso proporciona um alto grau de flexibilidade às VPNs baseadas no IPsec (ROWAN, 2007).

$\mathrm{O}$ acesso remoto com o IPsec geralmente requer a instalação de agentes de software ou clientes no computador do usuário. Os clientes estão disponíveis para uma variedade de dispositivos de computação (ex. PCs, Macs e smartphones) capazes de executar clientes IPsec. Do ponto de vista de segurança, isso melhora a situação, garantindo que apenas computadores com um cliente configurado corretamente consigam se conectar a VPN corporativa (ROWAN, 2007).

Como o IPsec é uma estrutura de protocolos, é possível ser flexível sobre quais protocolos de criptografia, autenticação e integridade de dados são usados. Por exemplo, é viável criar uma VPN com o algoritmo de criptografia Advanced Encryption Standard (AES) ou o algoritmo Blowfish. Nesse caso, a autenticação poderia utilizar, por exemplo, chaves pré-compartilhadas fornecidas por uma Infraestrutura de Chaves Públicas (ICP) de confiança múltipla (ROWAN, 2007).

Apesar do IPsec possuir vantagens, não é possível usar tunelamento IPsec nas Redes Móveis Definidas por Software (do termo em inglês Software-Defined Mobile Networks ou SDMN) devido a limitações, como por exemplo (LIYANAGE et al., 2017):

- mecanismos IPsec existentes suportam apenas túneis ponto-a-ponto. No entanto, as SDMN requerem túneis multiponto-a-multiponto para permitir recursos de rede;

- os mecanismos de troca de chaves do IPsec negociam uma chave de criptografia exclusiva por túnel. No entanto, as SDMN precisam encaminhar o mesmo tráfego para vários nós por meio de vários túneis;

- os mecanismos IPsec existentes não suportam o gerenciamento centralizado de políticas ou a coordenação centralizada durante o estabelecimento de túneis, pois estabelecem túneis de ponta a ponta de maneira distribuída.

\subsection{3 - Transport Layer Security (TLS)}

O Secure Sockets Layer (SSL) é um protocolo de nível de transporte. O SSL é mais comumente usado na Internet para fornecer HTTP seguro para acesso a páginas confidenciais. No SSL, o navegador da Web lida com o lado do cliente do túnel e a maioria dos navegadores da Web tem suporte ao protocolo SSL embutido. Sendo assim, não há necessidade de instalar software adicional no computador de um usuário, resolvendo o problema de gerenciamento e licenciamento de clientes (ROWAN, 2007). O uso de um navegador da Web para fornecer o lado do cliente do túnel da VPN significa que todos os aplicativos da Web baseados em HTTP funcionarão nativamente. Com isso, se garante o acesso a aplicativos de intranet e webmail (ROWAN, 2007).

Um dos conjuntos de segurança mais bem-sucedidos é o TLS, que foi originalmente baseado no protocolo SSL. Programas podem fornecer meios para criptografar o tráfego arbitrário de aplicativos usando SSL e TLS (ROSSBERG; SCHAEFER, 2011). Além do TLS, existem vários outros protocolos criptográficos para operação de VPN, no entanto, muitas das ferramentas existentes são proprietárias dificultando a análise de sua segurança (ex. NordVPN, ExpressVPN, PureVPN, Hamachi etc).

\section{$3.2-$ Ferramentas}

Durante o levantamento bibliográfico, foi notório que a quantidade de ferramentas encontradas é consideravelmente inferior a quantidade de protocolos. Esta seção apresenta as 
ferramentas identificadas, as quais utilizam os protocolos anteriormente citados.

\subsection{1-CloudVPN}

O CloudVPN cria redes (conexões SSL) de sobreposição não estruturadas sem criar automaticamente uma estrutura de encaminhamento de malha completa. Os nós se comunicam por mensagens de difusão e os caminhos são determinados de acordo com o atraso. Nesse caso, o CloudVPN possibilita o uso do roteamento multicaminhos com uma avaliação de caminhos de acordo com seus atrasos. Sendo assim, o protocolo Network Address Translation (NAT) pode ser usado, mas não há mecanismos para criar uma conexão direta entre dois hosts NAT (ROSSBERG; SCHAEFER, 2011).

Com isso, o CloudVPN pode ser caracterizado como um mecanismo de retransmissão. Conforme Rossberg e Schaefer (2011), tais mecanismos dificultam o transporte de tráfego em tempo real. Apesar de ser uma abordagem de configuração automática, o CloudVPN ainda requer uma quantidade substancial de configurações, principalmente porque uma topologia estática deve ser configurada. Dessa forma, não oferece meios de proteção de ponta a ponta. Isso se torna um problema quando dispositivos VPN são comprometidos (ROSSBERG; SCHAEFER, 2011).

\subsection{2 - OpenVPN}

O OpenVPN é uma ferramenta de código aberto e está disponível gratuitamente nas plataformas Windows, OS X e na maioria das plataformas Unix e Linux (LIU et al., 2009). O OpenVPN utiliza os chamados dispositivos Terminal Access Point (TAP) para capturar tráfego pelos processos do usuário e transmiti-los com segurança através de uma conexão TLS para outros hosts. Com isso, o tráfego pode ser protegido de forma transparente (ROSSBERG; SCHAEFER, 2011).

A segurança no OpenVPN é gerenciada pela biblioteca criptográfica OpenSSL que fornece forte segurança usando algoritmos padrão, como AES ou Blowfish. Além disso, usa um modo chamado Cipher Block Chaining (CBC), que torna o texto cifrado do bloco atual dependente do texto cifrado do bloco anterior. Dessa forma, não só impossibilita que um invasor veja padrões entre blocos com mensagens de texto simples idênticas, mas também evita a manipulação de um ou mais desses blocos (LIKHAR, 2012).

Em (LIU et al., 2009), conclui-se que o OpenVPN fornece uma implementação sólida e portátil, onde os clientes podem usar software padrão para se conectar a um sistema de simulação em tempo real. Nesse cenário, o OpenVPN fornece criptografia de dados, o que é particularmente desejável para uma implantação de emulação de longo prazo. O objetivo da emulação de rede em larga escala realizada em Liu et al. (2009) é que o resultado oferece, não apenas suporte a um caminho eficiente e flexível para o simulador em tempo real, mas também uma solução escalável para gerenciar aplicativos clientes.

Além disso, o estudo desenvolvido em Liu et al. (2009) mostrou que o gateway de simulação em tempo real usando o OpenVPN é uma abordagem viável, desde que a conectividade entre as máquinas clientes, o gateway de simulação e o simulador em tempo real seja suficientemente alta.

\section{RESULTADOS}

Foi realizada uma comparação, levando-se em conta as informações levantadas sobre cada protocolo e ferramenta identificada. Consideramos os seguintes conceitos de segurança (IMANE; TOMADER; NABIL, 2018):

- integridade: se o invasor utilizar engenharia reversa do protocolo e operar com um dispositivo móvel infectado para comunicar-se com os dispositivos médicos, pode-se alimentar os dispositivos com dados incorretos. Isso gera um impacto direto na saúde do paciente, uma vez que o médico pode tomar uma decisão errada por causa dos dados falsos.

- confidencialidade: os registros médicos eletrônicos devem ser confidenciais. Caso o invasor ataque um canal de comunicação, pode-se roubar os registros médicos de um paciente. Isso permite que o invasor não só extraia informações do tráfego de rede, mas também modifique um pacote em tempo real.

- privacidade: caso o invasor colete registros médicos indevidamente e os publique na Internet, será uma grave violação a privacidade dos pacientes.

Sendo assim, a Tabela 3 mostra o comparativo entre os protocolos levantados de acordo com a característica de integridade, confidencialidade e privacidade de cada um.

Tabela 3 - Comparativo dos protocolos levantados

\begin{tabular}{|c|c|c|c|}
\hline $\begin{array}{c}\text { Questões } \\
\text { importantes }\end{array}$ & CoAP & IPsec & TLS \\
\hline Integridade & Sim & Sim & Sim \\
\hline Confidencialidade & Sim & Sim & Sim \\
\hline Privacidade & Sim & Não & $\mathrm{Sim}$ \\
\hline
\end{tabular}

Em Albalas et al. (2018), os autores propuseram o uso do CoAP na camada de aplicação, proporcionando a obtenção dos serviços de integridade e confidencialidade. $\mathrm{O}$ CoAP foi implementado utilizando a técnica Elliptic Curve Cryptography (ECC) como um algoritmo de segurança subjacente. Além disso, em Tank, Upadhyay e Patel (2016), os autores afirmam que o uso do CoAP em conjunto com o Datagram Transport Layer Security (DTLS) garantem a integridade e confidencialidade. Em relação a privacidade, em Fuentes-Samaniego et al. (2015), os autores afirmam que qualquer par de nós, utilizando o CoAP juntamente com o DTLS, é capaz de configurar uma chave simétrica única e temporária, garantindo assim a privacidade dos dados.

Em Alghamdi, Lasebae e Aiash (2013), os autores analisaram os serviços de segurança fornecidos pelo IPSec. Os parâmetros foram avaliados de acordo com a arquitetura padrão de segurança X.805. Como resultado, conclui-se que o IPSec fornece os serviços de integridade e confiabilidade, no entanto, ele não possui o serviço de privacidade. Com isso, é possível concluir que o IPSec não seria uma boa opção quando aplicado a WBAN em ambiente médico.

No estudo de Rahman e Shah (2016), o protocolo TLS foi utilizado para proteger as mensagens, garantindo assim integridade e confidencialidade. Em relação a privacidade, afirma-se em Anderson, Paul e Mcgrew (2018) que o TLS fornece privacidade para aplicativos.

Com isso, tanto o protocolo CoAP, quanto o TLS seriam interessantes para a utilização no monitoramento remoto de pacientes. Isso se deve ao fato de que ambos 
garantem a integridade, confidencialidade e privacidade, sendo estes considerados serviços essenciais nesse escopo de aplicação.

Em relação as ferramentas levantadas, percebe-se que estas utilizam o protocolo SSL/TLS. Como o CloudVPN utiliza mecanismo de retransmissão, fato que dificulta o tráfego em tempo real, este não é o ideal para o contexto médico, uma vez que os dados médicos (principalmente em casos urgentes) precisam ser transmitidos o mais rápido possível. Além disso, o CloudVPN não oferece meios de proteção de ponta a ponta. Já o OpenVPN fornece um bom método de criptografia de dados e uma implementação sólida e portátil, sendo este a escolha ideal para o contexto de aplicação.

\section{CONCLUSÃO}

No presente artigo, foram detalhados os principais protocolos e ferramentas para a transmissão segura de dados. Portanto, o objetivo almejado foi atingido. Respondendo a questões de pesquisa, verificou-se que dentre os protocolos levantados, de acordo com critérios de integridade, confidencialidade e privacidade, os mais indicados seriam o CoAP e o TLS. O IPSec fornece os serviços de integridade e confiabilidade, mas não possui o serviço de privacidade. Com isso, assume-se que o IPSec não representa uma boa escolha em ambiente médico.

Em relação as ferramentas levantadas, nota-se que estas utilizam o protocolo SSL/TLS. O CloudVPN, por utilizar mecanismo de retransmissão, não é recomendado para tráfego em tempo real. No contexto médico, considerando a transmissão de sinais vitais, por exemplo, essa seria uma grande desvantagem. Ainda, em casos de quadros de urgência, dados precisariam ser transmitidos o mais rápido possível. Além disso, o CloudVPN não oferece proteção fim a fim. Já o OpenVPN oferece um bom método de criptografia de dados e uma implementação sólida e portátil, sendo este a escolha recomendada para o contexto de aplicação proposto.

Vale destacar que este estudo de escopo contribui para a área acadêmica ao servir como insumo teórico para demais pesquisadores que atuam no tema da pesquisa. Com isso, colabora-se com as etapas preliminares de pesquisas aplicadas ao desenvolvimento de novos produtos tecnológicos voltados para a área médica e para a realização de revisões sistemáticas da literatura sobre canais seguros para transmissão de dados médicos. Para pesquisas futuras, pretende-se realizar os testes nos protocolos e ferramentas identificados visando obter dados estatísticos e verificar se estes são, de fato, os mais indicados no contexto de transmissão de dados médicos.

\section{AGRADECIMENTOS}

Os autores do artigo gostariam de agradecer o apoio oferecido pelas agências DECIT/SCTIE/MS/CNPq/FAPEG na forma de recurso financeiro para a aquisição de equipamento, garantido pelo edital 12/2013.

\section{REFERÊNCIAS}

ALBALAS, Firas et al. Security-aware CoAP Application Layer Protocol for the Internet of Things using EllipticCurve Cryptography. The International Arab Journal of Information Technology, v. 15, n.3, p. 550-558, 2018.
ALGHAMDI, Thamer; LASEBAE, Aboubaker; AIASH, Mahdi. Security analysis of the constrained application protocol in the Internet of Things. In: Second International Conference on Future Generation Communication Technologies (FGCT 2013), 2., 2013, London. Proceedings... London: IEEE, 2013. p. 163-168.

ANDERSON, Blake; PAUL, Subharthi; MCGREW, David. Deciphering malware's use of TLS (without decryption). Journal of Computer Virology and Hacking Techniques, v. 14, n. 3, p. 195-211, 2018.

ARKSEY, H.; O’MALLEY, L. Scoping studies: towards a methodological framework. International Journal of Social Research Methodology, n. 8, vol. 1, p. 19-32, 2005.

BACHEGA, Stella Jacyszyn; TAVARES, Dalton Matsuo. Applications of petri nets in distributed processing: a scoping study. Int'l Conf. on Parallel and Distributed Processing Techniques and Applications, p. 109-115, 2015.

BACHEGA, Stella Jacyszyn; TAVARES, Dalton Matsuo. Uso de conceitos $\mathrm{e}$ atividades de green IT em universidades: um estudo de escopo. In: SIMPÓSIO DE ENGENHARIA DE PRODUÇÃO - SIENPRO, 1., 2017, Catalão. Anais... Catalão: UFG-RC, 2017. 10 p.

FUENTES-SAMANIEGO, Raul et al. A survey on wireless sensors networks security based on a layered approach. In: International Conference on Wired/Wireless Internet Communication (WWIC), 2015, Spain. Proceedings... Spain: Springer, 2015. p. 77-93.

IMANE, Sahmi; TOMADER, Mazri; NABIL, Hmina. Comparison between CoAP and MQTT in smart healthcare and some threats. In: 2018 International Symposium on Advanced Electrical and Communication Technologies (ISAECT), 2018, Roma. Proceedings... Roma: IEEE, 2018. $4 \mathrm{p}$.

LEVAC, D.; COLQUHOUN, H.; O’BRIEN, K. K. Scoping studies: advancing the methodology. Implementation Science, n. 5, vol. 69, p. 1-9, 2010.

LIKHAR, Praveen et al. Securing IEEE 802.11 g WLAN using OpenVPN and its impact analysis. arXiv preprint arXiv:1201.0428, 2012.

LIU, Jason et al. A real-time network simulation infrastructure based on OpenVPN. Journal of Systems and Software, v. 82, n.3, p. 473-485, 2009.

LIYANAGE, Madhusanka et al. Secure communication channel architecture for software defined mobile networks. Computer Networks, v. 114, p. 32-50, 2017.

MARCONI, Marina de Andrade; LAKATOS, Eva Maria. Fundamentos de metodologia científica. Editora Atlas. São Paulo, 2017.

PAI, Manohara MM; POOJARY, Boja; PAI, Radhika M. A WSN based environment and parameter monitoring system for human health comfort: a cloud enabled approach. EAI Endorsed Transactions On Scalable Information Systems, v.1, n.2, p. 1-8, 2014.

RAHMAN, Reem Abdul; SHAH, Babar. Security analysis of IoT protocols: A focus in CoAP. In: 2016 3RD MEC International Conference on Big Data and Smart City 
(ICBDSC), 3., 2016, Oman. Proceedings... Oman: IEEE, 2016. 7 p.

RASS, Stefan et al. Secure communication over softwaredefined networks. Mobile Networks and Applications, v. 20, n. 1, p. 105-110, 2015.

RAZA, Shahid et al. SecureSense: End-to-end secure communication architecture for the cloud-connected Internet of Things. Future Generation Computer Systems, v. 77, p. 40-51, 2017.

ROSSBERG, Michael; SCHAEFER, Guenter. A survey on automatic configuration of virtual private networks. Computer Networks, v. 55, n.8, p. 1684-1699, 2011.

ROWAN, Tom. VPN technology: IPSEC vs SSL. Network Security, v. 2007, n.12, p. 13-17, 2007.

SOUSA, Luiz Paulo de Oliveira, et al. Interconexão de um sistema experimental de monitoramento remoto de pacientes à uma rede de dados. Revista Sodebras [on line]. v. 12, n. 144, Dez. /2017, p. 140-145. ISSN 1809-3957. Disponível em: <http://www.sodebras.com.br/edicoes/N144.pdf>. Acesso em: 12 de set. 2017.

TANK, Birju; UPADHYAY, Hardik; PATEL, Hiren. Mitigation of privacy issues in IoT by modifying CoAP. In: 2016 INTERNATIONAL CONFERENCE ON INVENTIVE COMPUTATION TECHNOLOGIES (ICICT), 2016, India. Proceedings... India: IEEE, 2016. 4 p.

VAN DEN ABEELE, Floris et al. Integration of heterogeneous devices and communication models via the cloud in the constrained internet of things. International Journal of Distributed Sensor Networks, v. 11, n. 10, p. $1-17,2015$.

YI, Xun et al. Privacy protection for wireless medical sensor data. IEEE Transactions on Dependable and Secure Computing, v. 13, n.3, p. 369-380, 2016.

YUCE, Mehmet R. Implementation of wireless body area networks for healthcare systems. Sensors and Actuators A: Physical, v. 162, n.1, p. 116-129, 2010.

\section{COPYRIGHT}

Direitos autorais: os autores são os únicos responsáveis pelo material incluído no artigo.

Submetido em: 12/04/2019

Aprovado em: 08/05/2019 


\author{
Revista SODEBRAS - Volume 14 \\ $\mathrm{N}^{\circ} 161-\mathrm{MAIO} / 2019$
}

\title{
A EDUCAÇÃO E PRESERVAÇÃO AMBIENTAL NUMA TURMA DE $5^{\circ}$ ANO DO ENSINO FUNDAMENTAL I - BOA ESPERANÇA -ES
}

\author{
THE EDUCATION AND ENVIRONMENTAL PRESERVATION IN A CLASS OF \\ 5 YEARS OF ELEMENTARY SCHOOL $I$-BOA ESPERANCA-ES
}

\author{
MARCOS DAHER OLIVEIRA ${ }^{1}$; MARCUS ANTONIUS DA COSTA NUNES ${ }^{2}$ \\ 1; 2 - FACULDADE VALE DO CRICARÉ-SÃO MATEUS-ES; 2 - COORDENADOR DO MESTRADO \\ PROFISSIONAL EM GESTÃO SOCIAL, EDUCAÇÃO E DESENVOLVIMENTO REGIONAL, \\ marcosdaher16@hotmail.com; coordenadormestrado@gmail.com
}

\begin{abstract}
Resumo - O objetivo deste estudo foi discutir no ensino fundamental I à temática da preservação ambiental, esta realizada com alunos do $5^{\circ}$ ano de uma escola pública municipal de Boa Esperança-ES em 2017, em um espaço educativo não formal como meio de promover práticas socioambientais dentro do enfoque da sustentabilidade. A metodologia da pesquisa foi dentro da pesquisa-ação. Os resultados revelados pelos 75 sujeitos da pesquisa foram que as atividades realizadas colaboraram para aumentar a compreensão da interdependência entre homemnatureza. Conclui-se que as aulas práticas de preservação ambiental asseguradas numa área de preservação ambiental ampliaram o ensino $e$ o aprendizado sobre Meio Ambiente sensibilizando-os para a consciência ambiental pública e para a educação integral.
\end{abstract}

Palavras-chave: Educação. Preservação Ambiental. Alunos. Escola. Espaço Educativo não Formal.

Abstract - The objetive of this study was to discuss in elementary school I to the theme of environmental preservation this carried out with students of the 5 years of municipal publica scholl of Boa Esperança-ES em 2017 in education área not formal as a means of promoting practives sócio-environmental with the sustainability approach.The research methodology was within the researchaction.The results revealed by the 75 subjects of the research were that the activities performed collaborated to increase the understading of the interdependence betweenman-nature. It is study conclud that the proposed activities of environmental preservation assured in área of environmenttal preservation expanded the teaching and learningabout the environmental and the awareness for the promotion of integral education.

Keywords: Education. Preservation Environmental. Students. School. Space Education non Formal.

\section{INTRODUÇÃO}

O estudo do presente exposto teve como base investigadora a Educação Básica quanto processo contínuo de construção do sujeito, sendo o mesmo resultante de suas interações com o meio onde está inserido. Nesse sentido têmse o intuito de elencar e promover práticas educativas socioambientais em espaço educativo não formal, como mecanismo para oportunizar o aprendizado, no que tange a preservação ambiental.

A temática Meio Ambiente é apresentada como um dos temas transversais que tem como objetivo orientar o professor para efetivar uma educação em consonância com os pressupostos da formação de sociedades sustentáveis.

De acordo com os documentos legais atuais da Lei de Diretrizes e Bases da Educação Nacional (LDBEN) de 1996 ampliada em 2011 estabelece que na formação integral do aluno sendo fundamental saberes básicos de uma educação ambiental voltada para o uso de forma sustentável dos recursos naturais renováveis e não renováveis e ainda da compreensão por parte do educando que a terra é um organismo vivo em que as ações ambientais locais têm impactos globais para todos os seres vivos.

Na Constituição da República Federativa do Brasil de $1988 \mathrm{em}$ seu artigo 225 estabelece que no processo educativo a Educação Ambiental e sua preservação seja assegurada pelos órgãos públicos federal, estadual e municipal e principalmente pela educação, sendo esta a instituição social que tem como missão em relação à preservação ambiental promover a partir dos anos iniciais a consciência ambiental crítica dos alunos visando na sua construção permanente dentro do processo educativo ações ambientais educativas para o desenvolvimento da cultura da cidadania para a sustentabilidade.

A primeira Conferência Mundial das Nações Unidas realizada em Estocolmo na Suécia entre os dias 5 a 16 de junho de 1972 que teve a participação de 113 países inclusive o Brasil foi o principal marco legal na qual foi estabelecido metas para a preservação ambiental em todo o planeta e fez menção a necessidade da inclusão da educação para o cumprir os 26 princípios de preservação ambiental acordados (ONU,1972). Vale salientar, que inúmeras conferências mundiais sobre o enfoque ambiental têm sido organizadas pela ONU, sendo discussões veementes no que se refere a mudança no lidar om o meio e seus impactos.

É válido ressaltar, que a motivação do pesquisador é pautada em suas observações e na sua prática como docente da Rede Pública Estadual de Ensino, do Estado do Espirito Santo, tendo como campo de estudo e observação os discentes da Rede Estadual de Ensino, em específico o Ensino Fundamental I, em particular os alunos do $5^{\circ}$ ano, é possível pontuar que as abordagens quanto as práticas socioambientais, são contemplados no currículo das disciplinas, de modo a serem explanadas dentro e fora do âmbito escolar. 
A relevância social deste trabalho é apresentar possibilidades de práticas educativas socioambientais com alunos dos anos iniciais em particular do $5^{\circ}$ ano em uma área de preservação ambiental como meio para a aprendizagem de uma Educação Ambiental voltada para a preservação do Meio Ambiente local.

Diante da exposição justifica-se este estudo embasado em Layrargues e Lima (2014) ao apontar que a discussão sobre a preservação ambiental nas escolas públicas brasileiras do ensino fundamental ocorre dentro do espaço escolar. Em contrapartida as orientações das Diretrizes Curriculares Nacionais para Educação Ambiental (BRASIL, 2012) e da Secretaria do Meio Ambiente- Unidades de Conservação Ambiental (BRASIL, 2016) defendem que a preservação ambiental proposta pela educação seja em espaço educativo não formal, devido ao aluno estar inserido em uma realidade socioambiental da sua vivência cotidiana.

Aponta-se como problema de investigação por qual razão a professora da escola pesquisada tem assegurado às práticas educativas ambientais com os alunos do $5^{\circ}$ ano dentro do contexto escolar?

A hipótese levantada é que a professora não possui conhecimentos teóricos e metodológicos construídos no curso de formação inicial em Pedagogia sobre os princípios básicos da disciplina de Ecologia que orienta o professor de como realizar atividades socioambientais educativa em uma área de preservação ambiental.

Foi proposto como objetivo geral propiciar aos 75 sujeitos da pesquisa de uma escola pública municipal de Boa Esperança-ES, práticas socioambientais educativas em um espaço educativo não formal, em particular Área de Preservação Ambiental Pedra do Elefante localizada no município de Nova Venécia- ES.

\section{EDUCAÇÃO E A EDUCAÇÃO AMBIENTAL NOS DOCUMENTOS LEGAIS}

De acordo com a atual LDBEN no seu artigo 32 assevera que a formação integral do aluno exige do mesmo o conhecimento do meio físico e natural e, para acrescentar a recomendação legal Barbieri (2011) acrescenta que a educação deve promover meios para que o aluno tenha compreensão da realidade socioambiental local e a global.

Autores de referência em Educação Ambiental no Brasil na qual citamos Layrargues e Loureiro (2013), Gonzaga (2013) e Dias (2010) tem enfatizado que a proposta da preservação ambiental dentro da escola pública brasileira teve maior abrangência a partir de 2004 quando cerca de $92 \%$ das escolas públicas brasileiras afirmavam ter adotado práticas educativas de preservação ambiental, porém estes autores apontam que as mesmas têm sido efetivadas dentro do espaço escolar e forma pontual. Nos documentos legais das Diretrizes Curriculares Nacionais para a Educação Ambiental (BRASIL, 2012) orienta que a escola estabeleça uma educação voltada para preservação ambiental em espaço educativo não formal porque propicia ao aluno vivenciar experiências ambientais na qual o mesmo compreenda a interação entre homem e a natureza.

Nos Parâmetros Curriculares Nacionais (PCN) sobre |Meio Ambiente de 1997 reitera que uma das finalidades da Educação Ambiental visando a sua preservação alinhada com a sustentabilidade é uma das funções da educação em todos os níveis e modalidades. Na posição de Medeiros (2011) na qual entramos em acordo a preservação ambiental para promover aprendizado significativo é a priori que seja assegurada nos anos iniciais e estender-se em todo processo educativo da Educação Básica.

$\mathrm{Na}$ vigente Constituição afirma que à Educação Ambiental deve ser um dos componentes principais da Educação Básica a LDBEN complementa ao estabelecer como um dos propósitos da educação contemporânea deve propor meios para Educação Ambiental embasada nos princípios de uma preservação ambiental para a sustentabilidade sendo discutida no currículo dentro da metodologia da transdisciplinaridade, visando conforme aponta Corte e Corte (2015) o desenvolvimento da alfabetização ecológica dos alunos através de ações de ações educativas socioambientais em espaço educativo não formal, em particular em Área de Preservação Ambiental.

Na explicação de Costa e Juca (2015) no Brasil temos avançadas legislações sobre a Educação Ambiental, a saber, citamos a Lei n ${ }^{\circ} 9.795$ de 27 de Abril de 1999 e das atuais Diretrizes Curriculares Nacionais para a Educação Ambiental de 2012 e das orientações para a prática de educação ambiental na escola (BRASIL, 2007) estabelece uma educação na qual tenha como missão o desenvolvimento da consciência ambiental pública do aluno visando à transformação da realidade ambiental para construção permanente de uma educação para sociedades sustentáveis.

Na explicação de Lima (2011) e Carvalho (2013) essas importantes e avançadas legislações e diretrizes citadas, que apresentam aportes teóricos sobre a Educação Ambiental na educação dentro da proposta da preservação ambiental visando um comportamento ambiental alinhado ao uso dentro da sustentabilidade dos recursos naturais renováveis e não renováveis.

Na acepção de Saheb (2016) uma educação na atual contemporaneidade um dos seus pilares é mediante ao currículo legal, viabilizar uma preservação ambiental como também aponta a Secretaria do Meio Ambiente (BRASIL, 2016) dentro da abordagem crítica e emancipadora quer dizer o aluno é o sujeito ativo principal a partir da mediação do professor da sua alfabetização ecológica para a sustentabilidade.

Conforme aponta as Diretrizes Curriculares Nacionais para Educação Ambiental de 2012 a Educação Ambiental na Educação Básica tem sido orientada dentro da macrotendência crítica e emancipadora do sujeito porque a mesma parte do pressuposto de que a educação deve sensibilizar ao aluno que seu comportamento de preservação ambiental local tem efeito global devido a interdependência entre homem-natureza e do ensino ao aluno que alguns recursos naturais como os combustíveis fósseis são finitos e ainda que o lançamento de gases poluentes na atmosfera corrobora para o aumento do efeito estufa e consequentemente do aumento da temperatura da terra que inviabiliza a vida de inúmeras espécies, inclusive a humana.

\section{EDUCAÇÃO E EDUCAÇÃO AMBIENTAL EM ÁREA DE PRESERVAÇÃO AMBIENTAL}

De acordo com Silva (2016) o processo educativo é um processo permanente na vida do educando na sua trajetória na Educação Básica para a sua formação integral é fundamental uma educação embasada nos princípios da preservação para a formação de sociedade sustentável. Este mesmo autor aponta que na Declaração de Tbilisi em 1975 estabelece que um dos objetivos da Educação Ambiental fosse a preservação e o uso adequado dos recursos naturais e da proteção do meio natural e físico, ele aponta que nesta Conferência da 
Organização das Nações Unidas (ONU) teve como um dos princípios que a discussão sobre a preservação ambiental fosse contemplada dentro da educação formal e em espaço educativo não formal, visando promover a interação do aluno com o Meio Ambiente.

Na Agenda 21 nos seus capítulos 25 e 36 seguem a mesma linha de pensamento do autor anteriormente citado ao apontar a participação de crianças e adolescentes para a preservação ambiental, na qual a escola como principal instituição social deveria implementar ações educativas ambientais dentro da escola e em espaços educativos não formais, visando o desenvolvimento da consciência ambiental pública (ONU, 1992).

Na proposição de Vaine (2013) a utilização de área de preservação ambiental como meio para promover a Educação Ambiental, aproxima o aluno com a realidade ambiental local, na qual o mesmo participa de forma crítica e reflexiva.

$\mathrm{Na}$ visão de Gohn (2014) na mediação do processo educativo nos anos iniciais sobre o Meio Ambiente visa aumentar a sensibilização do aluno para com o entendimento dos problemas ambientais e da consciência ambiental para o exercício da cidadania sustentável.

$\mathrm{Na}$ afirmativa de Carvalho (2013) na qual concordamos a educação visando à preservação ambiental em espaço educativo não formal propicia a aprendizagem do conteúdo de ensino nas dimensões conceitual, procedimental e atitudinal acerca da preservação ao Meio Ambiente e de despertar no aluno o comportamento ambiental dentro da abordagem da sustentabilidade.

Na explanação de Dias (2010) uma das significativas contribuições a educação assegurada em espaço educativo socioambiental não formal é efetivar a formação da cultura científica dos alunos, para que os mesmos adquiram as competências básicas da ciência ecologia compreendendo as interações existentes entre homem e natureza.

Nas palavras de Nardi (2009) as quais entramos em acordo e foi desenvolvido esta pesquisa promover uma educação ambiental em área de preservação ambiental colabora para a construção de conceitos científicos de forma lúdica e cultural.

Concordando com Layrargues e Loureiro (2013) mesmo diante a democratização da Educação Ambiental no Brasil entre os anos de 2003 e 2004 principalmente no Ensino Fundamental II, a proposta de preservação ambiental tem sido assegurada dentro do ambiente escolar e de forma pontual e sendo da competência dos docentes das áreas de Ciências e de Geografia.

Seguindo a discussão dos autores supracitados um dos problemas da não efetivação da preservação ambiental em espaço educativo não formal como advoga Lopes (2013) e Silva (2016) tem sido a formação insatisfatória dos professores dos anos iniciais sobre os princípios teóricos e metodológicos do Meio Ambiente, porque para estes autores o professor com formação precária não possui conforme aponta Tardif (2012) saberes curriculares e disciplinares de como promover a preservação ambiental para a formação de alunos críticos e reflexivos acerca da necessidade da formação de sociedades sustentáveis.

\section{PRESERVAÇÃO AMBIENTAL NA PERSPECTIVA CRITTICA E EMANCIPADORA}

De acordo com Freire (2011) uma educação crítica e emancipadora visa formar alunos contemporâneos críticos e reflexivos para uma educação emancipadora do sujeito.
Nesta direção nas palavras de Matos (2013), Gonzaga (2013) a proposta de uma preservação ambiental dentro deste modelo exige de a escola oportunizar aos alunos experiência educativa de práticas ambientais dentro do paradigma da sustentabilidade, alfabetização ecológica e da consciência ambiental pública crítica visando a preservação dos recursos naturais renováveis e não renováveis.

$\mathrm{Na}$ perspectiva de Layrargues e Loureiro (2013) uma educação direcionada para a preservação ambiental crítica e libertadora tem como proposição oportunizar os alunos a vivência em espaço educativo não formal esta Área de Preservação Ambiental porque coloca o aluno diante da realidade ambiental local, e ainda propicia o conhecimento científico das relações ecológicas presente neste ecossistema sobre o Meio Ambiente promove a aprendizagem para o comportamento ambiental para a sustentabilidade.

Dias (2010) e Silva (2016) explicam que nas Diretrizes Curriculares Nacionais para a Educação Básica (BRASIL, 2013) reafirma a necessidade de a escola promover o ensino da preservação ambiental a priori nos anos iniciais e em segundo possibilitando ao aluno de tomada de decisão sobre a preservação ambiental alinhado ao comportamento ambiental em articulação com o objetivo da formação de sociedades sustentáveis.

Para Matos (2013) a educação para a preservação ambiental no $5^{\circ}$ ano do Ensino Fundamental I corrobora para a construção de um aluno que atua no seu Meio Ambiente local, em particular em Área de Preservação Ambiental como foi realizado neste estudo de forma crítica para questionar o seu próprio papel de sujeito ativo e responsável pela preservação ambiental dos ecossistemas.

\section{METODOLOGIA}

Em relação aos procedimentos metodológicos o estudo enquadra-se dentro do método bibliográfico. Em relação aos seus objetivos a pesquisa foi exploratória sobre o tema educação e preservação ambiental em espaço educativo não formal. Em relação à delimitação do tema de pesquisa propusemos a investigar a questão da preservação ambiental na educação com alunos do $5^{\circ}$ ano pertencentes ao Ensino Fundamental I.

Os sujeitos da pesquisa foram 75 alunos do $5^{\circ}$ ano pertencentes às turmas (A, B e C) sendo 25 alunos em cada uma das três turmas pesquisada. A pesquisa colaborativa foi realizada numa escola pública municipal localizada no município de Boa Esperança-ES. A pesquisa de campo foi realizada no mês de outubro de 2017 numa Área de Preservação Ambiental denominada Pedra do Elefante localizada no município de Nova Venécia-ES.

$\mathrm{Na}$ primeira etapa da pesquisa, os pesquisadores apresentaram como ocorreria o desenvolvimento da pesquisa à gestora da escola e, em seguida as professoras das três turmas participantes da pesquisa e, posteriormente foi apresentada a pesquisa para os 75 sujeitos da pesquisados. Os pesquisadores apresentaram os conceitos básicos sobre os princípios da preservação ambiental fazendo uso de recursos tecnológicos e, em seguida foram propostas várias atividades de preservação ambiental pelo pesquisador para serem realizadas na Área de Preservação Ambiental. Os alunos assistiram na escola a um filme sobre preservação ambiental em seguida fizeram produção textual individual.

A etapa seguinte foi realizada as atividades de preservação ambiental no espaço educativo não formal denominado Pedra do Elefante localizada no município de 
Nova Venécia-ES. Os pesquisadores organizaram atividades de práticas socioambientais voltadas para a sustentabilidade, explorando todos os espaços possíveis, visando à preservação dentro da proposta crítica e emancipadora.

Os sujeitos da pesquisa durante as atividades práticas foram apresentados pelos pesquisadores à interdependência entre homem- natureza em todo o roteiro estabelecido.

$\mathrm{Na}$ etapa final os alunos expuseram oralmente e também mediante a produção textual os conhecimentos adquiridos durante a atividade de campo desenvolvida.

$\mathrm{Na}$ escola no outro dia os mesmos fizeram produção textual sobre os conhecimentos adquiridos e na finalização ocorreu a socialização dos novos conhecimentos construídos pelos alunos.

Em relação às técnicas de coletas de dados recorreramse ao uso das entrevistas semiestruturadas individuais com um roteiro de 10 questões acerca do objeto de investigação, os sujeitos da pesquisa realizaram produção textual individual. Para a análise e tratamento dos dados coletados utilizou-se a metodologia da análise do conteúdo da Bardin (2011).

\section{RESULTADOS E DISCUSSÕES}

Conforme é examinado pelos documentos legais das Diretrizes Curriculares da Educação Ambiental (BRASIL, 2012), uma das propostas contemporâneas da educação é promover meios para o alunos adquirirem as competências básicas de preservação ambiental dentro da abordagem da sustentabilidade, estes dados entram com concordância com as orientações dos PCN,s de Meio Ambiente (BRASIL, 1997).Verifica-se que estes documentos são disponibilizados para todas as escolas da rede pública do país através das políticas de Educação Ambiental do governo federal.

Verifica-se conforme aponta Layrargues e Loureiro (2013) que a proposta de uma Educação Básica alinhada com a preservação ambiental visando à consciência ambiental pública do aluno ainda tem sido o desafio das escolas do Ensino Fundamental II, estes autores apontam que entre 2003 e 2004 as escolas públicas brasileiras têm afirmado adotar práticas de preservação ambiental dentro do currículo escolar, porém segundo estes autores este modelo tem ocorrido de forma pontual e em particular nas disciplinas de Ciências e de Geografia, em contrapartida conforme indica as recomendações legais do PCN esta temática deve transversalizar o currículo legal. Estes autores ainda apontam que este modelo de preservação ambiental conservacionista prevalece nas escolas públicas brasileiras inclusive nesta pesquisada.

Verificou-se que a prática da Educação Ambiental na escola pesquisada tem sido restrita ao espaço escolar, porém as orientações legais do Ministério do Meio Ambiente (BRASIL, 2016) orienta que a prática da preservação ambiental seja contemplada em espaço educativo não formal. Nessa escola pesquisada a proposta está de acordo com as orientações legais deste documento propostas para o ensino e o aprendizado da alfabetização ecológica para a sustentabilidade dentro de uma Área de Preservação Ambiental.

Ao examinar os documentos da Conferência Mundial de Tbilisi de 1975 e da Agenda 21 implementada na Conferência do Meio Ambiente e o Desenvolvimento Sustentável ocorrida no Rio de Janeiro em 1992 estabelece que a preservação ambiental deva ocorrer em espaço educativo não formal como meio de promoção da consciência pública ambiental do aluno para a sustentabilidade. Nas atividades realizadas com os sujeitos da pesquisa na etapa final os mesmos nos relatos nos textos produzidos relataram a compreensão entre a interdependência que o Homo sapiens tem da natureza, porque é dela que provêm os recursos naturais renováveis e não renováveis.

Constata-se na atual LDBEN (BRASIL, 1996) e o PCN,s de Meio Ambiente (BRASIL,1997) que a temática Educação Ambiental e sua preservação deve ser assegurado no currículo legal e o praticado dentro da transversalidade. Nota-se que na escola pesquisada a preservação ambiental para os alunos do $5^{\circ}$ ano foi ensinada de forma superficial, em data pontual e com fragmentação e ainda restrita ao espaço escolar. Essa realidade encontrada nesta escola pesquisada como apontam Dias (2010) e Gonzaga (2013) têm sido uma realidade em inúmeros contextos escolares do ensino fundamental II.

Os 75 sujeitos da pesquisa revelaram nas entrevistas que as aulas de preservação ambiental foram teóricas e dentro da sala. Essas respostas dos alunos conforme nos explicam está diretamente relacionada com a formação insuficiente dos professores que não possuem saberem disciplinares $\mathrm{e}$ curriculares como advoga Tardif (2012) para propor um ensino em espaço educativo não formal que tem maior potencialidade para promover aprendizagem significativa.

Verificou-se que os $100 \%$ dos alunos pesquisados revelaram que havia sido a primeira vez que tiveram a oportunidade de aprender sobre o Meio Ambiente mediante atividades práticas socioambientais em uma Área de Preservação Ambiental de forma lúdica e cultural. Na explicação de Nardi (2009), intercalar atividades práticas ambientais, é colocar os alunos em contato com a realidade ambiental local e sensibiliza-los para o comportamento ambiental público alinhado com formação de sociedades sustentáveis.

Foi revelado por $100 \%$ dos sujeitos pesquisados na entrevista que a atividade de preservação ambiental numa Área de Preservação Ambiental promoveu além da formação de conceitos básicos sobre ecologia, principalmente a compreensão da interdependência do homem para com a natureza, porque todos os recursos naturais são obtidos de forma direta ou indireta através do Meio Ambiente e compreenderam como aponta nos textos que o homem deve preservar o meio ambiente para manutenção da sua vida no planeta.

Constatou-se que os alunos pesquisados perguntaram as 03 professoras regentes de classe presentes nas atividades realizadas no espaço educativo não formal "por qual motivo elas nunca haviam proposto uma aula conforme a apresentada pelos pesquisadores". As mesmas revelaram devido à falta das competências básicas sobre os princípios científicos do Meio Ambiente. Para responder este importante questionamento dos alunos, recorremos a Silva (2016) em que sua tese de doutorado os alunos também fizeram o mesmo questionamento destes alunos. E, concordando com a autora um dos motivos é a formação insatisfatória destes professores em que no curso de Pedagogia os conhecimentos adquiridos sobre Meio Ambiente é diluído na disciplina de Metodologia do Ensino de Ciências, cabe ressaltar que este currículo deste curso é respaldado legalmente pelo órgão que regula todos os níveis e modalidade de ensino do país. Para a autora é emergente reorganização na matriz curricular do curso de Pedagogia incluindo disciplinas de Ciências 
Naturais e, nesta seja assegurado conteúdos de ensino de ecologia básica.

Nos textos produzidos pelos alunos pesquisados no final da pesquisa, foram citadas várias vezes a palavra preservação do Meio Ambiente local e global. Conforme aponta os alunos durante as atividades realizadas, tiveram compreensão da necessidade emergente da consciência ambiental. Para Layrargues e Loureiro (2013) dados similares foram apontados em suas pesquisas estes autores apontam que o novo conhecimento dos alunos sobre a importância da preservação ambiental foi construído devido o contato dos 75 alunos do $5^{\circ}$ ano numa Área de Preservação Ambiental porque este espaço educativo não formal promoveu a consciência ambiental pública dentro da abordagem da sustentabilidade.

\section{CONCLUSÃO}

O estudo evidenciou a relevância de a escola trabalhar com a temática da preservação ambiental no processo educativo, em particular para alunos do $5^{\circ}$ ano, porque estes sujeitos durante as atividades desenvolvidas numa Área de Preservação Ambiental revelaram a aprendizagens significativas de consciência ambiental pública.

Sublinha-se que neste trabalho apresentou uma Área de Preservação Ambiental como potencializador para a realização de práticas ecológicas socioambientais dentro da proposta crítica e libertadora, porque os alunos vivenciaram experiências ambientais de preservação ambiental local, e ao mesmo tempo tiveram conhecimento esperado para alunos do $5^{\circ}$ ano dos princípios básicos científicos do Meio Ambiente em seu entorno.

Foi apontado no trabalho que a vertente da preservação ambiental recomenda pela Secretaria do Meio Ambiente e das Diretrizes Curriculares Nacionais para a Educação Ambiental preconiza um ensino dentro da visão libertadora, emancipadora e crítica. As ações educativas realizadas nesta escola com citados sujeitos da pesquisa contemplaram essas exigências legais e possibilitou aos alunos o desenvolvimento da alfabetização ecológica para a sustentabilidade, conforme orienta Corte e Corte (2015).

A pesquisa apontou que o problema de investigação tem sido em detrimento da formação insuficiente das professoras que não possuem conhecimentos científicos específicos teóricos e metodológicos sobre o Meio Ambiente e, tem reduzido o ensino da preservação ambiental em atividades teóricas e em momentos pontuais do calendário escolar com atividades que não promove a inserção do aluno em espaços educativos não formais visando a consciência ambiental crítica de preservação dos recursos naturais e da compreensão que os mesmos são finitos e dependem da ação homem para o seu uso de forma sustentável.

A hipótese apontada mostra-se verdadeira diante da fala das professoras de cada uma das turmas que sinalizaram que nos cursos de Pedagogia na formação inicial não tiveram saberes disciplinas sobre os princípios básicos da ecologia e, sim a metodologia do ensino de Ciências que não tem essa proposta definida na grade curricular.

A contribuição do estudo foi apresentar subsídios teóricos acerca de uma educação para a preservação ambiental em espaço educativo não formal para alunos do $5^{\circ}$ ano que poderão ser utilizados pelos professores dos anos iniciais.
Uma das limitações da pesquisa foi analisar e interpretar os dados escritos relatados nos 75 textos sujeitos da pesquisa em que as escritas foram de difícil análise e exigiu repetidas leituras dos 75 textos produzidos pelos sujeitos pesquisados, principalmente dos produzidos por lápis.

O cotejamento da pesquisa entra em encontro com os dados recentes de estudos apontados neste texto produzidos pela literatura nacional dos autores de referência nessa área do conhecimento.

\section{REFERÊNCIAS}

BARBIERI, J.C. Educação Ambiental. 2.ed. São Paulo: Cortêz, 2011

BARDIN, L. Análise do conteúdo. São Paulo: Edições 70, 2011.

BRASIL. Constituição da República Federativa do Brasil. Brasília, 1988.

Lei de Diretrizes e Bases da Educação Nacional. Brasília, 1996.

Parâmetros Curriculares Nacionais. Brasília, 1997.

Diretrizes Curriculares Nacionais da Educação Básica. Brasília, 2013.

Diretrizes Curriculares Nacionais para Educação Ambiental. Brasília, 2012.

Secretaria do Meio Ambiente - Unidades de Conservação. Brasília, 2016.

Brasilia,1999.

Lei $n^{0} 9.795$ de Educação Ambiental.

. Conselho do Meio Ambiente: Educação e política para a sustentabilidade. Brasília, 2007.

CARVALHO, I. C. M. Educação, cidadania e justiça ambiental: a luta pelo direito a existência. São Paulo: Cortêz, 2013.

CORTE, T.D.; CORTE, D. Educação ambiental e alfabetização ecológica. Florianópolis: CONPEDI, 2015.

COSTA, A.S.; JUCA, R. L. C. Os desafios da educação ambiental na pós- modernidade. Florianópolis: CONPEDI, 2015.

DIAS, G. F. Educação ambiental: princípios e práticas. 10.ed. São Paulo: Gaia, 2010.

FREIRE, P. Pedagogia do oprimido. 50.ed. Rio de Janeiro: Paz e Terra, 2011.

GOHN, M.G. Educação formal e o educador social. 2.ed. São Paulo: Cortez, 2014.

GONZAGA, M.J.B. Concepção de educação ambiental presente na prática pedagógica de professores da escola pública de Natal. XXVI Simpósio da ANPAE, 2013.

LAYRARGUES, P.P.; LOUREIRO, C.B.F. Ecologia, política, justiça e educação ambiental crítica. Rio de Janeiro, 2013. 
LAYRARGUES, P.P.; LIMA, G.F.S. As macrotendências politico-pedagógica da educação ambiental brasileira. 2014.

LIMA, G.F. Educação ambiental, formação, identidades e desafios. Campinas: Papirus, 2011.

LOPES, A.C. A educação ambiental na formação de professores: um estudo das representações sociais (Dissertação de Mestrado) Centro Universitário de Volta Redonda- Rio de Janeiro, 2013.

MATOS, K.S.A.L. Educação ambiental e sustentabilidade. Fortaleza: UFC, 2013.

MEDEIROS, A.B. et al. A importância da educação ambiental na escola nas séries iniciais. Revista Faculdade Monte Belo. v.4, n.1, p. 19-23, 2011.

NARDI, R. O ensino de ciências e matemática. São Paulo: Cultura Acadêmica, 2009.

ONU. Organização das Nações Unidas. Estocolmo, 1972. . Organização das Nações Unidas. Belgrado, 1975.

Janeiro,1992.

Organização das Nações Unidas. Rio de

SAHEB, D. Uma reflexão sobre o meio ambiente no saber de Morin de ensinar para a condição humana. 2016.

SILVA, F.A.L. Educação ambiental crítica como política pública para as escolas do Rio de Janeiro: uma análise dos limites e possibilidades de uma atuação em membros internos da política pública (Tese de doutorado) UFRJ,2016.

TARDIF, M. Saberes docentes, saberes profissionais. 2.ed. São Paulo: Edições 70, 2012.

THIOLLENT, M. A metodologia da pesquisa-ação. 5.ed. Rio de Janeiro: Cortez, 2011.

VAINE, T. E. Ensinando ciências fora da escola. (Dissertação de Mestrado) UFTP, 2013.

\section{COPYRIGHT}

Direitos autorais: Os autores são os únicos responsáveis pelo material incluído no artigo.

Submetido em: 31/01/2019

Aprovado em: 15/04/2019 


\author{
Revista SODEBRAS - Volume 14 \\ $\mathrm{N}^{\circ} 161-\mathrm{MAIO} / 2019$
}

\title{
APLICAÇÕES DE SOFTWARES LIVRES PARA ANÁLISES DE SISTEMAS ENERGÉTICOS E OS RESPECTIVOS ESTUDOS DE EFICIÊNCIA ENERGÉTICA
}

\section{APPLICATIONS OF FREE SOFTWARE FOR ENERGY SYSTEM ANALYSIS AND THEIR ENERGY EFFICIENCY STUDIES}

\author{
RAFAEL AYRES SOARES ${ }^{1}$, MARCIO ZAMBOTI FORTES ${ }^{2 *}$, ANGELO CESAR COLOMBINI ${ }^{3}$ \\ $1 ; 2 ; 3$ - UNIVERSIDADE FEDERAL FLUMINENSE \\ $m z f @ v m . u f f . b r^{*}$
}

\begin{abstract}
Resumo - Este artigo tem como finalidade identificar e observar a utilização de softwares relacionados a eficiência energética, tomando como referência sua aderência ao assunto e sua livre utilização. A lista é composta por softwares nacionais $e$ internacionais e experimentados em um computador pessoal com sistema operacional Windows 7. Suas informações foram baseadas na utilização dos aplicativos e a partir foram apresentados comentários e opiniões sobre cada um dos softwares avaliados focando em: funcionalidade, interface e possiveis detalhes próprios de utilização. $O$ estudo também discute os resultados obtidos em alguns dos softwares listados a partir de estudos científicos.
\end{abstract}

Palavras-chave: Eficiência Energética. Simulação. Consumo de Energia. Análise Energética.

Abstract - This paper aims to identify and observe the use of energy efficiency software's, taking as a reference the subject and if it is free to use. The list is composed of Brazilian and international software and its publications have been applied in its use considering contribution in scientific studies. This paper presents comments and opinions about its functionality, the interface and the options are specific to each tool.

Keywords: Energy Efficiency. Simulation. Energy Consumption. Energy Analysis.

\section{INTRODUÇÃO}

Desde os primórdios o homem se relaciona com o seu entorno de maneira diferente dos demais seres vivos. Nos destacamos pela capacidade de construir ferramentas, superar obstáculos e transformar a adversidade em progresso. A busca incessante por novas formas de aperfeiçoamento é ininterrupta e cada vez mais nos deparamos com novas maneiras de adaptação. O mundo já não é o mesmo, e desta maneira se faz necessário a antevisão e percepção do quão relevantes serão nossas escolhas e atitudes. As ferramentas de trabalho e estudo também seguem o mesmo princípio, e novas tecnologias foram desenvolvidas a fim de encontrar soluções e meios alternativos que mantenham preservados os recursos naturais e suas particularidades. A utilização da energia e a preocupação com a maneira de sua obtenção vem tomando importante destaque nas últimas décadas. O surgimento de leis, incentivos e resoluções são mecanismos importantes neste processo e aumentam a responsabilidade sobre a utilização destes recursos.
O crescimento excepcional de equipamentos e tecnologias acarretou um aumento progressivo da demanda energética. Com essa elevação significativa e um desperdício cada vez maior, se fizeram necessários novos meios de utilização. $\mathrm{O}$ total de energia desperdiçada, segundo o Procel, chega a 40 milhões de Quilowatts hora, ou ao equivalente de US\$ 2,8 bilhões, por ano. Os consumidores - indústrias, residências e comércio desperdiçam 22 milhões de Quilowatts; as concessionárias de energia, por sua vez, com perdas técnicas e problemas na distribuição, são responsáveis pelos 18 milhões de Quilowatts restantes (DOROCHE et al., 2015).

Em 1985, no Brasil, foi criado pelo Ministério de Minas e Energia o Procel (Programa Nacional de Conservação de Energia Elétrica) que contempla ações e planejamentos referentes ao tema. Mesmo com as diversas formas de energias renováveis, a criação de políticas direcionadas a eficiência são vitais para a matriz energética atual.

O Procel disponibiliza ferramentas facilitadoras para técnicos do setor industrial começarem a agir em suas empresas. Tais ferramentas são programas que se propõem a analisar os usos da energia nas instalações industriais e, nesse trabalho, são chamados de modelos. Eles estão disponíveis na seção de simuladores do portal do Procel INFO na Internet (www.eletrobras.com/pci/). Recentemente foi publicada a norma ISO 50.001 pela Organização Internacional para Padronização (ISO) e, no Brasil, pela Associação Brasileira de Normas Técnicas (ABNT). Ela trata da gestão de sistemas energéticos e pode vir a impulsionar o autodesenvolvimento de boas práticas de consumo de energia pelas indústrias, considerando o desenvolvimento das certificações vinculadas a esta norma. Uma comprovação deste fato é o elevado número de pesquisas relacionadas ao tema e pelo número de patentes depositadas (SILVA et al., 2018).

As ferramentas internacionais também serão mencionadas neste estudo. O departamento de energia do governo americano - AMO/DoE (Advanced Manufacturing Office - Department of Energy) - .se destaca por suas contribuições e desenvolvimento de softwares livres destinados a eficiência energética em processos industriais.

O AMO é o único escritório de desenvolvimento de tecnologia dentro do governo dos EUA dedicado a melhorar a eficiência energética, os materiais, a produtividade e a competitividade dos fabricantes em todo o setor industrial. As origens do Departamento de Energia dos EUA e do Escritório de 
Eficiência Energética e Energia Renovável (EERE) remontam a 1973 e 1974, quando a Administração Federal de Energia, a Administração de Pesquisa e Desenvolvimento de Energia e o Conselho de Recursos de Energia foram estabelecidas. A AMO reúne fabricantes, entidades sem fins lucrativos, organizações de pesquisa e instituições de ensino superior para identificar desafios; catalisar inovações; e desenvolver tecnologias.

Além de ferramentas utilizadas em diversos processos industriais como refrigeração, aquecimento, máquinas entre outros que serão discutidos posteriormente, também são muito recorrentes e utilizadas ferramentas livres destinadas a residências. O usuário pode simular carga, demanda, consumo, fatura da energia elétrica entre outras possibilidades. A otimização energética do projeto pode ser realizada levando em consideração importantes informações, como localização, orientação geográfica do cômodo ou área, carga da instalação, tipo do sistema, estudos de viabilidade possíveis como radiação solar, carga térmica, consumo, entre outras ferramentas que iremos apresentar neste artigo.

Esse artigo tem o objetivo de mapear alguns dos softwares livres nacionais e internacionais mais utilizados e disponíveis na web, além de trazer observações sobre sua interface, suportabilidade necessária, idioma, utilização e resultados. A maior parte das ferramentas listadas foi desenvolvida pelo Procel e pelo departamento de energia do governo americano - DoE (Department of Energy).

\section{DESCRIÇÃO DA METODOLOGIA}

\section{1 - Parâmetros Determinantes à Listagem das Aplicações}

Para o levantamento dos softwares que serão listados neste artigo foram levados em consideração inicialmente a temática comum a efetividade energética e sua utilização inteiramente gratuita por parte do usuário. Outros parâmetros também considerados foram relacionados a utilização e suportabilidade das ferramentas incluídas segundo seu funcionamento ideal em uma máquina acessível com sistema operacional Microsoft Windows.

$\mathrm{O}$ estudo abrange aplicações direcionadas tanto a intervenções industriais como residenciais, englobando ferramentas básicas e outras de devida complexidade. As aplicações foram divididas em conformidade com seu ramo de atuação, e quando reunidas características de dois ramos distintos foram incluídas nos dois subgrupos. Para a observação e obtenção das ferramentas livres foram levados em consideração sítios referências na web, dentre estes: departamentos de governo, fabricantes de equipamentos, entidades e programas governamentais de conservação de energia. Nesta listagem se destacam o Procel (Programa Nacional de Conservação de Energia ), DoE - AMO (Advanced Manufacturing Office| Department of Energy), NAIMA (The North American Insulation Manufacturers Association) e o Governo do Canadá (Government of Canada). Também existem fabricantes de equipamentos na listagem dos desenvolvedores, tais como "Dialux company", ABB e WEG.

Os softwares listados foram divididos em cinco subgrupos apresentados na Tabela 1 .

Tais subgrupos foram criados a partir das características das ferramentas obtidas mediante busca na rede. Os softwares estão listados na Tabela 2. Há ainda uma infinidade de ferramentas de livre acesso que não foram listadas neste estudo devido ao limite físico deste meio.
Tabela 1 - Subgrupos de ferramentas livres focadas neste artigo

\begin{tabular}{c} 
SUBGRUPOS \\
\hline SISTEMAS MOTRIZES E AR COMPRIMIDO \\
CALOR E AQUECIMENTO \\
REFRIGERAÇÃO E RESFRIAMENTO \\
BOMBEAMENTO E VENTILAÇÃO \\
ILUMINAÇÃO E ESTUDOS ENERGÉTICOS \\
\hline Fonte: Autores, 2019.
\end{tabular}

Tabela 2 - Aplicações pesquisadas e avaliadas

\begin{tabular}{|c|c|}
\hline MODELO & DISPONIBILIZAÇÃO \\
\hline BDMOTOR & Procel \\
\hline MOTORMASTER+ & DoE \\
\hline SEE+ & WEG \\
\hline TRALOSSCALC & WEG \\
\hline MARK IV PLUS & Procel \\
\hline AIRMASTER+ & DoE \\
\hline $\mathrm{E} 3 \mathrm{AC}$ & Procel \\
\hline SSST & DoE \\
\hline SSAT & DoE \\
\hline SSTM & DoE \\
\hline 3E PLUS & NAIMA \\
\hline PHAST & DoE \\
\hline DIMENSOL & Procel \\
\hline RETSCREEN & GOVERNMENT OF \\
\hline INTERNACIONAL & CANADA \\
\hline BEP & Procel \\
\hline PSAT & DoE \\
\hline EPANET & EPA \\
\hline PUMPSAVE & $\mathrm{ABB}$ \\
\hline FSAT & DoE \\
\hline FANSAVE & $\mathrm{ABB}$ \\
\hline CWSAT & DoE \\
\hline SEEP JANELAS & SEEP/Procel \\
\hline DIALUX & DIALUX COMPANY \\
\hline RADIASOL2 & Procel \\
\hline ENGUIA & Procel \\
\hline ENERGYPLUS & DoE \\
\hline ENERGY & DoE \\
\hline FOOTPRINT TOOL & DoE \\
\hline $\begin{array}{l}\text { PEPEX } \\
\text { SAGEE }\end{array}$ & $\begin{array}{l}\text { DoE } \\
\text { Procel }\end{array}$ \\
\hline SINPHA & Procel \\
\hline
\end{tabular}

\section{DESCRIÇÃO DAS APLICAÇÕES}

\section{1- Sistema Motriz e Ar Comprimido}

Focado no tema sistemas motrizes e/ou sistemas de ar comprimido foram destacados 7 softwares de livre uso e listados na Tabela 3 .

Tabela 3 - Ferramentas livres para análises de sistemas de força motriz e ar comprimido

\begin{tabular}{cc}
\hline MODELO & DISPONIBILIZAÇÃO \\
\hline BDMOTOR & Procel \\
MOTORMASTER+ & DoE \\
SEE+ & WEG \\
TRALOSSCALC & WEG \\
MARK IV PLUS & Procel \\
AIRMASTER+ & DoE \\
E3AC & Procel \\
\hline
\end{tabular}

Fonte: Autores, 2019. 
BDMOTOR - Este software é uma ferramenta útil na análise de substituir ou reparar motores, considerando questões econômicas, carga do equipamento e sua vida útil. Por meio de um banco de dados e duas formas de análise: dimensionamento de um motor em uso e comparação entre dois motores. A análise é feita considerando a carga no eixo através da medição de três grandezas: corrente média de linha (A), velocidade (rpm) do eixo e a potência trifásica de entrada $(\mathrm{kW})$. O banco de dados abrange motores de indução trifásicos com tensões de 220,380 e $440 \mathrm{~V}$ e potência mecânica de 0,25 a 250 cv. Versão: 4.21 (de 02/2008); Idioma: Português. Desenvolvido por Procel.

MOTORMASTER+ - Com esta ferramenta o usuário controla além da seleção dos motores, o seu gerenciamento. É possível ter acesso a um vasto catálogo de máquinas de corrente alternada. O usuário que utiliza esta ferramenta também tem acesso a aplicações para inventário, controle de manutenção, eficiência, além de estimativa de economia e geração de relatórios ambientais. Também é possível analisar os dados em moedas distintas, editar perdas e determinar os motores mais indicados.

Em seu catálogo são encontrados motores do mercado internacional testados sob as normas do Institute of Electrical and Electronic Engineers-IEEE e os testados sob a metodologia do International Electrical Commission-IEC. Foi desenvolvido pela DOE/AMO - Advanced Manufacturing Office Departmento of Energy.

Somente pode ser baixado por contato direto por e-mail e está disponível nos idiomas: inglês, espanhol e francês

SEE + WEG - Com este se faz possível a simulação da aplicação de motores elétricos de alta eficiência com foco na redução do consumo de energia elétrica na indústria e gerar relatórios completos de viabilidade de troca de um ou mais motores elétricos. É possível calcular o potencial de economia que o usuário pode obter com a substituição devido dos motores em operação. Além da economia prevista, em reais $(\mathrm{R} \$)$ e quilowatt hora $(\mathrm{kWh})$, o SEE+ apresenta indicadores financeiros como VPL (Valor Presente Líquido) e TIR (Taxa Interna de Retorno). Desenvolvido por WEG BRASIL. Idioma: Português.

MARK IV PLUS - Esta é uma ferramenta utilizada para diagnóstico e gestão energética. $\mathrm{O}$ usuário fornece informações sobre sua instalação para estas configurações e a partir disso o programa cria um relatório com a análise do consumo e possíveis medidas de conservação a serem seguidas pelo usuário. Algumas das funções de análise do programa são: Análise de Contas de Energia, Análise Econômica, Ar Condicionado Central, Ar Condicionado de Janela, Caldeiras, Cogeração, Condensadores a Água, Fornos e Estufas, Iluminação, Motores, Quadros de Distribuição, Refrigeração, Transformadores e Tubulações. O módulo Principal deste programa reúne em um único relatório os resultados obtidos pelos demais módulos. Os módulos podem ser executados independentemente, porém o módulo de análise econômica é parâmetro para os demais.

AIRMASTER+ - Esta ferramenta analisa o uso de energia e as possibilidades de economia em sistemas de ar comprimido industriais. O programa é usado para basear as melhorias de operações existentes e futuras no modelo do sistema e avaliar a economia de energia em dólar de muitas medidas de eficiência energética. $\mathrm{O}$ programa gera relatórios baseados nos dados de entrada do usuário.
O programa permite analisar o fluxo de ar adequado baseado nas características do dia e para cada compressor; vazamentos de ar reduzidos; pressão de ar do sistema ou tempo de operação; melhor eficiência de uso final; uso de controles de descarga e sequenciador automático; ajuste de pontos de ajuste em cascata; adição do volume do receptor principal. A ferramenta atende bem as necessidades dos usuários, contudo não há novas atualizações. O download só poderá ser realizado mediante contato por e-mail com o desenvolvedor. Foi desenvolvido pelo DOE/AMO que não está mais dando suporte a esse software. Idioma: Inglês

E3AC - Esta ferramenta é uma Planilha Excel que permite o cálculo das perdas em sistemas de ar comprimido. Fornece também os resultados em energia e custos das perdas. A partir da entrada de dados, que é realizada por meio de formulários acessados através de uma barra de ferramentas, são gerados resultados para o sistema.

Desenvolvido por Procel. Idioma: português

\section{2 - Calor e Aquecimento}

A Tabela 4 apresenta a listagem dos principais softwares focados aos estudos de calor e aquecimento.

Tabela 4 - Ferramentas para Sistemas Caloríficos

\begin{tabular}{cc}
\hline MODELO & DISPONIBILIZAÇÃO \\
\hline SSST & DoE \\
SSAT & DoE \\
SSTM & DoE \\
3E PLUS & NAIMA \\
MARK IV PLUS & Procel \\
PHAST & DoE \\
DIMENSOL & Procel \\
RETSCREEN & GOVERNMENT OF \\
INTERNACIONAL & CANADA \\
\hline
\end{tabular}
Fonte: Autores, 2019.

STEAM SYSTEMS - SSST/SSAT/SSTM - As Ferramentas Steam Systems ajudam os usuários a realizar autoavaliações de seus sistemas de vapor. Este conjunto de três softwares englobam de forma completa os sistemas de vapor e sua eficiência analisando práticas de operação do sistema em caldeira, operacionais da planta e distribuição, e de operação de recuperação. Em sua utilização são sugeridas inúmeras maneiras de economizar energia e aumentar a produtividade. As aplicações SSAT, SSTM e SSST fazem parte deste modelo de análises, contudo há diferenças entre as aplicações entre si, relacionadas aos sistemas de vapor. Desenvolvido por DOE/AMO. Idioma: Inglês

3E PLUS - É uma ferramenta de gestão energética industrial usada para simplificar a determinação do isolamento térmico necessário para redução do consumo de energia. $\mathrm{O}$ simulador se baseia em parâmetros como custo de combustível, instalação, manutenção, taxa de impostos - é possível editar o valor referência de acordo com a localidade e seus tributos - além de outros fatores econômicos relevantes. Esta ferramenta realiza o cálculo do isolamento para proteção em diversas condições, realiza o cálculo da espessura de isolamento para controle de condensação, e determina as emissões e reduções de gases tóxicos além da temperatura da superfície, perda de calor e ganho de eficiência. O software opera na língua inglesa. Desenvolvido 
pela North American Insulation Manufacturers Association (NAIMA).

PHAST - Esta ferramenta introduz métodos para melhorar a eficiência térmica de equipamentos de aquecimento. Com isso seus usuários industriais podem avaliar os equipamentos de aquecimento dos processos que consomem combustível ou eletricidade e assim identificar os equipamentos que consomem mais energia. Também pode ser usada para gerar um balanço de calor que identifica as principais áreas de uso de energia sob várias condições operacionais e testa cenários hipotéticos com opções para reduzir o uso de energia. Desenvolvido por DOE/AMO. Idioma: Inglês

DIMENSOL - Esta ferramenta possibilita ao usuário o dimensionamento de sistemas de aquecimento solar de água. Análises econômicas e de investimento do sistema dimensionado. A interface do programa tende a facilitar a utilização através de sequência própria de dimensionamento do sistema. Permite avaliar a radiação incidente nos coletores, projetos de consumo de acordo com locais e fração solar da instalação. O programa conta ainda com um banco de dados de cidades e componentes permitindo ainda a inserção de novos componentes pelo usuário. Versão atual: 1.1 (de 02/2010). Desenvolvido por Procel. Idioma Português

RETSCREEN INTERNACIONAL - Este programa consiste de vários módulos de análise em Excel, entre os quais destacam-se: Aquecimento solar de ar, Aquecimento solar de água, Aquecimento solar passivo, Bombas de calor geotérmicas, Estádio esportivo \& Supermercado, Energia eólica, pequenas hidrelétricas, Instalações fotovoltaicas, Cogeração e Aquecimento por biomassa. A análise de projetos de energia limpa é uma ferramenta de suporte à decisão que pode ser usada universalmente para avaliar a produção e economia de energia, os custos durante o tempo de vida, a redução das emissões, análise financeira e de risco para vários tipos de tecnologias eficientes ou renováveis (RET). Idioma: português. Governo do Canadá

\section{3 - Refrigeração e Resfriamento}

A Tabela 5 apresenta a listagem de alguns softwares disponíveis para estudos da área de refrigeração e resfriamento.

Tabela 5 - Ferramentas para análises em sistemas de refrigeração e resfriamento

\begin{tabular}{cc}
\hline MODELO & DISPONIBILIZAÇÃO \\
\hline CWSAT & DoE \\
SEEP JANELAS & SEEP/Procel \\
MARK IV PLUS & Procel \\
3EPLUS & NAIMA \\
\hline \multicolumn{2}{c}{ Fonte: Autores, 2019.}
\end{tabular}

CWSAT - SPOTENCIAL SISTEMA DE ÁGUA GELADA - CHILLER - A ferramenta possibilita modelar uma variedade de parâmetros. Estes sistemas são: Sistemas resfriados a ar e a água, sistemas com múltiplos chillers de tamanhos diferentes e/ou tipos de chillers operando em conjunto, sistemas de fluxo variável.

A partir do sistema o programa analisa e apresenta o resultado através de gráficos de barras comparando o consumo de energia e custos operacionais do sistema atual e proposto, sumário das economias, valores de consumo dos chillers, bombas e torres de resfriamento sob várias condições. A ferramenta atende bem as necessidades dos usuários, contudo não há novas atualizações. $\mathrm{O}$ download só poderá ser realizado mediante contato por e-mail com o desenvolvedor. Foi desenvolvido pelo DOE/AMO que não está mais dando suporte a esse software. Idioma: Inglês

SEEP JANELAS - Este simulador analisa o desempenho energético de janelas, o qual calcula a energia desperdiçada pelas janelas atuais no verão e no inverno. E quanto mais baixo for esse valor, melhor será a qualidade da janela. A eficiência energética apresenta-se através de uma classe energética, classificação já familiar do consumidor devido a escala ser semelhante à dos eletrodomésticos e também à do Certificado Energético da habitação.

Com uma utilização simples e intuitiva, com pequenas explicações sobre os vários elementos que compõem a janela, esta ferramenta permite que todos possam simular a classe energética das janelas da sua habitação. Desenvolvido por SEEP/Procel. Idioma: Português

\section{4 - Bombeamento e Ventilação}

Os sistemas de bombeamento e ventilação podem ser avaliados pelos softwares indicados na Tabela 6 .

Tabela 6 - Ferramentas para análises em sistemas de bombeamento e ventilação

\begin{tabular}{cc}
\hline MODELO & DISPONIBILIZAÇÃO \\
\hline BEP & Procel \\
PSAT & DoE \\
EPANET & EPA \\
PUMPSAVE & ABB \\
FSAT & DoE \\
FANSAVE & ABB
\end{tabular}

Fonte: Autores, 2019.

BEP - OPERAÇÃO DE BOMBAS EM PARALELO Este programa permite determinar a melhor opção de operação em paralelo de um conjunto de bombas em função da vazão e pressão desejados, indicando quais bombas devem funcionar e com qual rotação. Desenvolvido por Procel. Idioma: português

PUMPING SYSTEM ASSESSMENT TOOL - Esta ferramenta avalia as potenciais oportunidades de economizar energia de sistemas de bombeamento, de acordo com os dados medidos. também ajuda os fabricantes a avaliar a eficiência das operações do sistema de bombeamento. É possível salvar e recuperar arquivos log, valores padrão e curvas de sistemas e compartilhar com outros usuários. O uso deste programa é ideal para ajudar usuários industriais na avaliação de diferentes modificações do sistema e determinar quais os benefícios energéticos.

O PSAT testa cenários hipotéticos para várias opções, a fim de reduzir o uso de energia ou usar o otimizador automático com dados dos padrões do Instituto Hidráulico e dados de desempenho do motor do banco de dados do MotorMaster+. Desenvolvido por DOE/AMO. Idioma: inglês

EPANET - O programa permite executar simulações diversas de origem estática e dinâmica do comportamento hidráulico e de qualidade da água em redes de distribuição pressurizada. O EPANET permite obter os valores da vazão em cada tubulação, da pressão em cada nó, da altura de água em cada reservatório de nível variável e da concentração de espécies químicas através da rede durante o período de simulação, subdividido em múltiplos intervalos de cálculo. Adicionalmente, além de espécies químicas, o modelo simula o cálculo da condição da água e sua validade, o rastreio da origem de água em qualquer ponto da rede. Foi desenvolvido pela Agência 
Norte-Americana de Proteção Ambiental (EPA - Environment Protection Agency).

PUMPSAVE - O programa possibilita comparar o controle por acionamento de velocidade variável com o controle como estrangulamento, on/off e acoplamentos em bombas. $\mathrm{O}$ software também calcula a energia e dinheiro economizados, assim como o retorno de capital e valor presente líquido. Apesar de desenvolvido para o dimensionamento e especificação de acionamentos de velocidades variável da $\mathrm{ABB}$, pode ser utilizado para estimar as economias obtidas de qualquer fabricante. Desenvolvido por ABB. Idioma: Inglês.

FSAT - A ferramenta permite identificar e avaliar as oportunidades de economia de energia em sistemas de ventiladores. Permite ainda que os usuários industriais avaliem várias modificações do sistema para determinar as configurações ideais do sistema. Também é possível através do programa testar cenários personalizados a fim de minimizar o consumo de energia do sistema.

Com o FSAT - Fan System Assessment é possível determinar a eficiência do sistema e quantificar o potencial de economia para uma determinada substituição do sistema. O programa requer apenas informações básicas sobre os ventiladores e seus motores, estimando o trabalho realizado pelo sistema. Utilizando características de desempenho típicas para os ventiladores. Idioma: inglês. Desenvolvido por DOE/AMO.

FANSAVE - Este software nos permite comparar o controle por acionamento de velocidade variável (AVV) e controles tradicionais em ventiladores. Também é possível calcular a energia e o recurso financeiro economizado com a aplicação de um sistema de controle AVV. Apesar de desenvolvido para o dimensionamento e especificação de acionamentos de velocidades variável da $\mathrm{ABB}$, pode ser utilizado para estimar as economias obtidas com AVVs de qualquer fabricante. Idioma: inglês. Desenvolvido por ABB.

\section{5 - Iluminação e Estudos Energéticos}

Os estudos de sistemas de iluminação e consumos energéticos diversos podem ser efetuados com softwares listados na Tabela 7.

Tabela 7 - Ferramentas para análises de iluminação e estudos

\begin{tabular}{cc}
\multicolumn{2}{c}{ energéticos } \\
\hline MODELO & DISPONIBILIZAÇÃO \\
\hline DIALUX & DIALUX COMPANY \\
RADIASOL2 & Procel \\
ENGUIA & Procel \\
ENERGYPLUS & DoE \\
ENERGY & DoE \\
FOOTPRINT TOOL & DoE \\
PEPEX & Procel \\
SAGEE & Procel \\
SINPHA & Fonte: Autores, 2019.
\end{tabular}

DIALUX - Software que possibilita ao usuário o cálculo luminotécnico com interface semelhante ao CAD. Também é possível, a partir dele, importar arquivos com dados fotométricos de fabricantes e calcular a iluminância para superfícies de trabalhos distintas. Também é possível realizar os cálculos para áreas externas. Idioma: multilíngue, inclusive português. Desenvolvido por Dialux Company.
RADIASOL2 - Radiasol2 utiliza internamente modelos matemáticos disponíveis na literatura, desenvolvidos por outros autores ou por integrantes do Procel. No programa os cálculos são realizados através de rotinas que determinam o efeito da inclinação da superfície receptora e da anisotropia da radiação solar em suas componentes direta e difusa. $\mathrm{O}$ usuário pode selecionar o modelo de distribuição da radiação e obterá na tela, imediatamente, um conjunto de dados adicionais na forma de tabelas ou gráficos. O sistema incorpora um banco de dados contendo informações de mais de 2000 estações meteorológicas em todo o mundo, das quais cerca de 200 no Brasil. Está incluído também um mecanismo exclusivo para a sintetização de dados sequenciais de radiação solar em intervalos diário, horário e de 5 em 5 minutos. Idioma: português. Desenvolvido por Procel.

ENGUIA - Esta ferramenta web analisa conta de luz e equipamentos instalados em edificações. A partir disso gera um plano de redução de consumo. É aplicável em pequenas residências e empresas de pequeno e médio porte. Necessário fazer o cadastro no site para ter acesso as funcionalidades da plataforma web. Idioma: Português. Desenvolvido por Procel

ENERGYPLUS - Este software realiza simulação energética em edificações. Alguma de suas análises são: Aquecimento, condicionamento ambiental, iluminação, ventilação e outros fluxos de energia. Inclui simulações inovadoras como intervalos de tempo menores que uma hora, sistemas modulares, conforto térmico e sistemas fotovoltaicos. Idioma: inglês. Desenvolvido por DOE/AMO

ENERGY FOOTPRINT TOOL - Esta ferramenta é capaz de rastrear até vinte tipos de consumo de energia (eletricidade, gás natural, etc.) e vinte variáveis relevantes relacionadas (níveis de produção, graus-dia, horas de operação, taxas de ocupação, etc.) por um período de até dez anos. Tipos de energia personalizados e fatores relacionados podem ser facilmente adicionados conforme necessário. $\mathrm{O}$ uso final de energia é monitorado anualmente. Os usuários podem criar até 10 grupos principais de uso final de energia (áreas de processos, áreas de construção, sala de aquecimento, etc.), cada qual pode incluir até 30 componentes individuais (caldeiras, ventiladores, bombas, luzes, etc.). Desenvolvido por DOE/AMO.

PEPEx - PLANT ENERGY PROFILE EXCEL - Este é um aplicativo que pode ser executado com qualquer navegador e fornece a informação necessária aos gerentes de plantas industriais necessárias para identificação de potenciais de economia. Com o PEP é possível visualizar o consumo total de energia da planta, assim como identificar os principais consumidores de energia, sumarizar a distribuição dos custos com energia e indicar áreas que necessitam de uma análise mais detalhada, de forma gráfica e fácil de ser interpretada. O PEPEx fornece aos usuários um relatório personalizado, que pode ser impresso e que demonstra os detalhes das compras de energia, como a energia é consumida, o custo potencial e a economia de energia, e uma lista dos próximos passos que podem ser seguidos para economizar energia. Idioma: inglês. Desenvolvido por DOE/AMO.

\section{SAGEE - SISTEMA DE APOIO À DECISÃO} PARA A GESTÃO DA EFICIÊNCIA ENERGÉTICA -

O programa permite as empresas uma visão ampla de sua situação em relação a eficiência energética. Envolve questões diversas, tais como condições específicas de utilização de energia. Assim as empresas poderão traçar uma projeção de melhoria e evolução de seu desempenho neste quesito. Resulta um diagnóstico da situação atual da Gestão da 
Eficiência Energética na empresa avaliada. Identificação de Pontos Fracos e Questões Problemáticas. Identificação de Oportunidades de Melhorias (Plano de melhorias). Desenvolvido por Procel. Idioma: Português

SINPHA - SISTEMA DE INFORMAÇÃO DE POSSE E HÁBITOS DE USO DE APARELHOS ELÉTRICOS - O Sistema de Informação de Posses e Hábitos de Uso de Aparelhos Elétricos - SINPHA, foi desenvolvido para apresentar os indicadores obtidos a partir dos dados das "Pesquisas de Posse e Hábitos de Consumo de Energia - PPH", e possibilitar cruzamentos desses dados, simulações da curva de carga e do impacto de projetos de substituição de lâmpadas. Estão disponíveis no SINPHA as informações elaboradas com base nas Pesquisas de Posse de Equipamentos e Hábitos de Consumo Energia realizadas pela Eletrobras/Procel nos anos de 1997 e 2004-2006. As informações são exibidas em termos absolutos e percentuais e, sempre que possível, é feita a expansão para a população correspondente. Os resultados podem ser visualizados em gráficos e tabelas. Desenvolvido por Procel. Idioma: Português.

\section{UTILIZAÇÃO DAS FERRAMENTAS}

As ferramentas mencionadas são amigáveis e utilizadas para diferentes fins. Há uma infinidade destas auxiliando projetos diversos e contribuindo para a conservação de energia e eficiência energética. Abaixo estão apresentadas aplicações dessas ferramentas em artigos e estudos para tratamento de dados e auxílio em ações de eficiência.

4.1 - Caso 1 - Utilização do "Bd Motor” em Avaliação e Otimização de Motores Elétricos de Indução (RAMOS et al., 2009)

A ferramenta de simulação apresenta um banco contendo inúmeros motores de diversos fabricantes nacionais. É possível realizar a análise de apenas uma máquina e também a comparação entre duas máquinas, sendo uma em uso e outra nova. Outra aplicação é a obtenção do dimensionamento baseando-se na condição de operação do motor. Há no programa a aba "Dimensionar por" onde é possível definir parâmetros de entrada, assim há um cruzamento dos dados para que sejam estabelecidas as condições de operação. O programa atende a critérios claros de análise para eleger um "status" para o motor, e são estes: "sobredimensionado", "avaliar substituição", "bem dimensionado" e "subdimensionado".

Quanto a sua interface, o simulador é bem intuitivo e apresenta janelas claras e indicações bem definidas, conforme ilustrado na Figura 1.

Se tratando da análise financeira, o simulador requer que o usuário realize a entrada de dados essenciais para tal verificação, como carregamento, moeda, carga e horas de funcionamento.

Este procedimento foi aplicado nos acionamentos onde o carregamento do motor tipo padrão encontrava-se abaixo de $75 \%$. Neste caso, o custo da substituição incluiu, além do motor de alto rendimento, as modificações necessárias para a sua adaptação à máquina, em função das diferenças de dimensões entre os mesmos. Esse estudo foi realizado em um exaustor de gases de uma caldeira a lenha utilizada na geração de vapor, que opera 8.000 horas/ano. O motor original instalado, de potência nominal de $200 \mathrm{CV}$, era do tipo standard, 6 polos, trifásico, $380 \mathrm{~V}$. Através de medição no motor determinou-se o valor da potência ativa de $62,5 \mathrm{~kW}$ e fator de potência de 0,66 . Em seguida, com o programa de simulação, obteve-se o valor de $37 \%$ para o carregamento deste acionamento. Caso o acionamento fosse efetuado por um motor de $200 \mathrm{CV}$, alto rendimento, o programa de simulação apresentou um valor de potência igual a 59,5 kW. Instalando-se o motor de alto rendimento de $200 \mathrm{CV}$, obtevese através de medições, o valor de $58 \mathrm{~kW}$ para a potência ativa e 0,54 para o fator de potência. O Tempo de Retorno do Investimento para esta substituição foi de 31 meses. Caso o acionamento fosse efetuado por um motor de $100 \mathrm{CV}$, alto rendimento, o programa de simulação apresentou um valor de potência igual a $59 \mathrm{~kW}$.

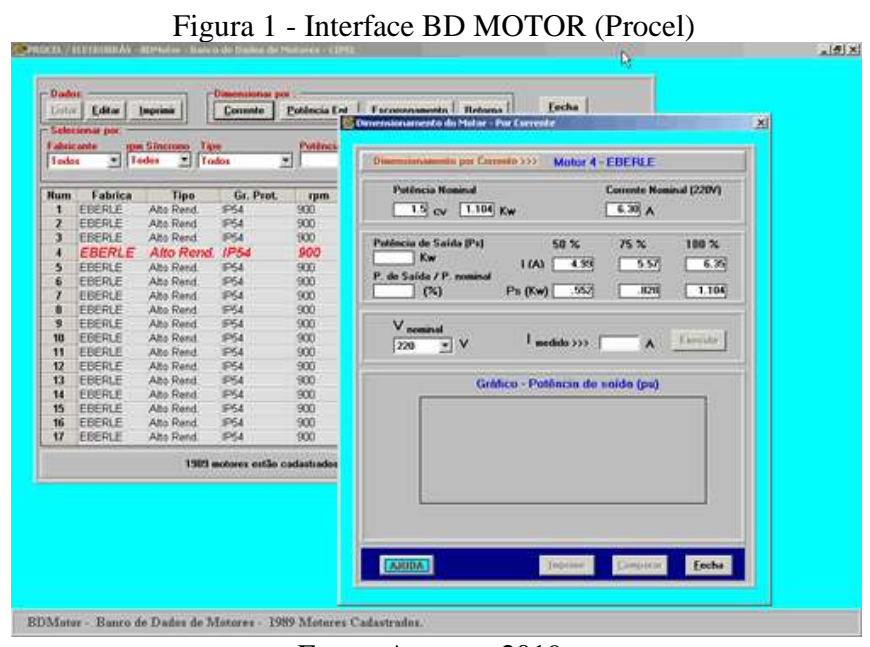

Fonte: Autores, 2019.

Instalando-se o motor de $100 \mathrm{CV}$, alto rendimento, obteve-se, através de medições, o valor de $55,8 \mathrm{~kW}$ para a potência ativa e 0,8 para o fator de potência. O Tempo de Retorno do Investimento para esta substituição foi de 12 meses.

Finalmente realizou-se um estudo para verificar se um motor de $75 \mathrm{CV}$, alto rendimento, teria conjugado suficiente para acelerar esta carga desde o repouso até sua velocidade de funcionamento, num tempo inferior ao de rotor bloqueado. O motor simulado acionou a carga em 6 segundos, valor este satisfatório, se comparado com o tempo de rotor bloqueado fornecido no catálogo do fabricante, de 18 segundos. Desta forma, instalando-se o motor de $75 \mathrm{CV}$, alto rendimento, obteve-se o valor de $55,5 \mathrm{~kW}$ para a potência ativa e 0,86 para o fator de potência. O Tempo de Retorno do Investimento para esta substituição foi de 8 meses.

A Figura 2 apresenta os dados obtidos, onde se pode observar a vantagem do redimensionamento motriz em função do rápido retorno do investimento.

Figura 2 - Gráfico comparativo de retorno de investimento para motores genérico

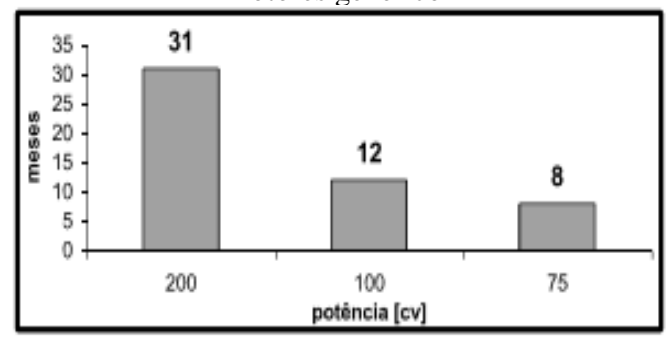

Fonte: RAMOS et al., 2009. 
O redimensionamento motriz proporciona um rápido retorno do investimento, mesmo considerando o custo de adaptação do motor. $\mathrm{O}$ fator de potência do motor melhora e evita-se gastos desnecessários de correção, através da instalação de capacitores. $\mathrm{O}$ valor da economia proporcionada com as substituições confirmou os valores previstos pelo programa de simulação, podendo ser utilizado com bastante precisão em estudos de eficiência energética em sistemas motrizes.

\section{2 - Caso 2 - Utilização do Software "Dimensol” para} Estudo Comparativo de Irradiação Solar em Diversas Localidades do Brasil (CASTRO et al., 2015)

O simulador em questão utiliza banco de dados contendo dados da irradiação de acordo com sua localização. Com ele é possível dimensionar, orçar e avaliar o sistema em questão e sua eficiência. É desenvolvido pelo Procel e Versão atual: 1.1 (de 02/2010).

A interface do Dimensol está designada na Figura 3. Primeiramente deve-se selecionar o local da busca e após realizada a seleção da cidade deve-se escolher o coletor utilizado. Outra possibilidade é não utilizar o banco de dados adicionando dados ao programa. A definição da orientação, localização, radiação e refletância total também deve ser configurada para que os resultados estejam de acordo. Finalmente devemos informar a quantidade de água em consumo e analisar os resultados em "cálculos".

Figura 3 - Interface do Simulador

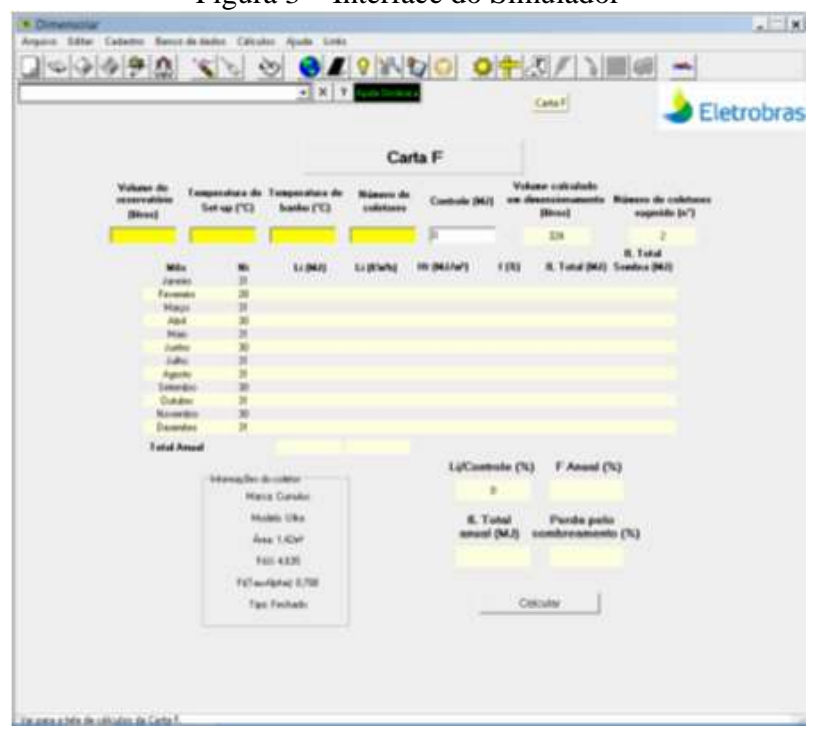

Fonte: CASTRO et al., 2015.

De acordo com simulações feitas no software Dimensol, para as localidades de baixa irradiação solar, como por exemplo Curitiba (PR), em sistemas de aquecimento solar com os coletores de $1 \mathrm{~m}^{2}$ de área, tanto da linha Ultra quanto da linha Premium, faz-se necessária a instalação de 3 placas. Para os coletores de $1,42 \mathrm{~m}^{2}$ e de $2 \mathrm{~m}^{2}$ de ambas as linhas, são sugeridas a utilização de somente duas placas. Como a placa de 1,42 $\mathrm{m}^{2}$ da linha Ultra é a mais barata, utilizou-se para fins do cálculo do custo do sistema o preço médio pesquisado desse modelo. A placa de $1 \mathrm{~m}^{2}$ da mesma linha é mais barata que a de $1,42 \mathrm{~m}^{2}$, porém, como são necessárias 3 placas neste caso, o custo total com coletores solares é maior do que com as placas de $1,42 \mathrm{~m}^{2}$.

O dimensionamento do sistema foi realizado com o auxílio do software Dimensol. Nele são inseridas as características do coletor solar e sua instalação, o consumo de água na residência e a localização onde será instalada. A temperatura e aquecimento da água que o software utiliza para o banho está entre $37^{\circ} \mathrm{C}$ e $40^{\circ} \mathrm{C}$. Para cada cidade, seu banco de dados contém informações a respeito da irradiação total e da temperatura ambiente média para cada mês de cada cidade. A partir de cálculos o software informa a quantidade de placas necessárias a serem instaladas. Para as simulações foram utilizados os mesmos valores de albedo, ângulo de orientação e de inclinação que nos sistemas fotovoltaicos.

Nas regiões Sul e Sudeste, para residências com padrão de consumo semelhante ao estudado e situadas nas capitais dos estados, com exceção de Curitiba, a instalação de um sistema fotovoltaico para o abastecimento elétrico com um sistema de aquecimento solar de água para o banho (sistema híbrido) se mostrou a alternativa mais barata para o consumidor e que, consequentemente, lhe traria maiores benefícios econômicos. Nessas cidades, o preço do $\mathrm{kWh}$ consumido ao se adquirir esses sistemas ficou na faixa de $\mathrm{R} \$$ 0,32 a $\mathrm{R} \$ 0,35$, ou seja, um valor menor do que aquele pago às concessionárias locais como mostrado na tabela 11 nos estudos de Castro et al (2015) e referenciada na figura 4.

\begin{tabular}{|c|c|c|c|c|c|}
\hline Cidades & $\begin{array}{c}\text { Caso mais } \\
\text { barato }\end{array}$ & $\begin{array}{l}\text { Preço final do } \\
\text { kWh }\end{array}$ & $\begin{array}{l}\text { Tarifa } \\
\text { local }\end{array}$ & $\begin{array}{c}\text { Variaçäo } \\
\%\end{array}$ & $\begin{array}{c}\text { Viabilida } \\
\text { de }\end{array}$ \\
\hline Campinas & Sit. 3/Hibrido & RS 0,35 & $\mathrm{R} \$ 0,45$ & $23 \%$ & $\operatorname{Sim}$ \\
\hline Sāo Paulo & Sit. 3/Hibrido & $R S 0,34$ & $\mathrm{R} \$ 0,40$ & $14 \%$ & Sim \\
\hline Bela Horizonte & Sit. 1/Hibrido & RS 0,33 & $R \$ 0,60$ & $45 \%$ & Sim \\
\hline Rio de Janeiro & Sit. 1 e $2 /$ Hilbrido & AS 0,32 & $\mathrm{R} \$ 0,46$ & $31 \%$ & Sim \\
\hline Vitória & Sit. 1 e $2 /$ Hibrido & R $\$ 0,32$ & $\mathrm{R} \$ 0.52$ & $39 \%$ & Sim \\
\hline Curitiba & Sit. 1/Puro & $R \$ 0,37$ & $\mathrm{R} \$ 0,47$ & $20 \%$ & Sim \\
\hline Florianopolis & Sit, 1/Hibrido & PS 0,32 & $\mathrm{R} \$ 0,50$ & $35 \%$ & Sim \\
\hline Porto Alegre & Sit. 1/Hibrido & $R S 0,32$ & $R \$ 0,44$ & $26 \%$ & Sim \\
\hline Salvador & Sit. 1 e $2 /$ Puro & en $\$ 0,32$ & $\mathrm{R} \$ 0,47$ & $33 \%$ & Sim \\
\hline Aracaju & Sit. 3/Puro & RS 0,29 & $R \$ 0,44$ & $35 \%$ & Sim \\
\hline Maceió & 5it. 3/Puro & $\mathrm{A} \$ 0,28$ & $\mathrm{R} \$ 0,43$ & $35 \%$ & Sim \\
\hline Recife & Sit. 3/Puro & RS 0,29 & $\mathrm{R} \$ 0,49$ & $41 \%$ & Sim \\
\hline Joכ̄o Pessoa & Sit. 3/Puro & RS 0,28 & $\mathrm{R} \$ 0,43$ & $35 \%$ & Sim \\
\hline Natal & Stt. 3/Puro & An $\$ 0,28$ & $\mathrm{R} \$ 0,48$ & $42 \%$ & Sim \\
\hline Fortaleza & Sit. 3/Puro & RS 0,30 & $\mathrm{R} S 0,37$ & $19 \%$ & Sim \\
\hline Teresina & Sit. 3/Puro & $\operatorname{R} \$ 0,29$ & $R \$ 0,43$ & $32 \%$ & Sim \\
\hline Săo Luis & Sit. $1 /$ Hibrido & RS 0,33 & $\mathrm{R} \$ 0,43$ & $24 \%$ & Sim \\
\hline Belém & Sit. 1/Puro & RS 0,32 & $R \$ 0,68$ & $52 \%$ & Sim \\
\hline Manaus & Sit. 1/Puro & $R S 0,33$ & $\mathrm{R} \$ 0,39$ & $16 \%$ & Sim \\
\hline Macapá & Sit. 1/Puro & RS 0,32 & $R \$ 0,25$ & $-29 \%$ & Não \\
\hline Palmas & 5it. 3/Puro & RS 0,31 & $\mathrm{R} \$ 0,59$ & $47 \%$ & Sim \\
\hline Rio Branco & Sit. 1/Puro & R $\$ 0,33$ & $\mathrm{R} \$ 0,54$ & $39 \%$ & Sim \\
\hline Porto Velho & Sit. 1/Puro & RS 0,32 & RS 0,52 & $38 \%$ & Sim \\
\hline Boa Vista & Sit. 3/Puro & RS 0,33 & $\mathrm{R} \$ 0,24$ & $-39 \%$ & Não \\
\hline Cuiabá & Sit. 1/Puro & AS 0,32 & $\mathrm{R} \$ 0,54$ & $41 \%$ & Sim \\
\hline Goiânia & Sit. 3/Puro & RS 0,31 & $\mathrm{R} \$ 0,44$ & $29 \%$ & Sim \\
\hline Campo Grande & Sit. 1/Puro & R 50,32 & $\mathrm{R} \$ 0,47$ & $32 \%$ & Sim \\
\hline Brasilia & Sit. $3 /$ Puro & RS 0,32 & $\mathrm{R} \$ 0,34$ & 796 & Sim \\
\hline
\end{tabular}

4.3 - Caso 3 - Utilização do Software "EPANET" como Suporte em Análise e simulação da influência da precipitação pluviométrica no sistema de produção de água de Belém-PA (complexo Bolonha) com o uso do EPANET (MHP NOGUEIRA, et al., 2018).

Com esta aplicação se faz possível realizar análises em tubulações hidráulicas distintas avaliando a pressão em cada nó e vazão. Também é possível calcular as condições e qualidade da água e a sua origem. O software dispõe de um ambiente integrado que permite editar dados de contribuição de rede, corredor hidráulico e simulações de qualidade de água. É possível visualizar os resultados em uma variedade de formatos. Também é possível incluir mapas de rede, mesas de dados, gráficos de séries temporais, e enredos de contorno com avaliações sucessivas das demandas nodais. 
Considerando, no início, a condição de vazamento nulo (FT $=1$ ), as pressões são produzidas pelo simulador, o vazamento é calculado e as demandas nodais avaliadas através de uma condição de abastecimento para cada nó (pressão mínima e pressão desejada para a demanda requerida) até que o desvio máximo das pressões anteriores e atuais seja menor que a tolerância imposta. Assim que a primeira condição é satisfeita, o fator de consumo é ajustado através de um balanço de massa entre a vazão de abastecimento total, o vazamento total, a demanda efetivamente abastecida aos consumidores, a demanda de abastecimento de referência e o fator de consumo anterior.

Neste trabalho utilizou-se o EPANET para simular o sistema de produção de água do complexo Bolonha, localizado dentro dos limites do parque do Utinga, na cidade de Belém do Pará, onde foram executadas as simulações estáticas e dinâmicas do comportamento hidráulico da rede de produção até sua distribuição nas Estações Elevatórias de Água Tratada - EAT, além de verificação da influência sazonal da precipitação da chuva na produção de água, consumo e custo com energia elétrica para comparar as simulações computacionais com os meses do ano de 2014. A Simulação através do EPANET permitiu representar cada item de um sistema de produção de água como sendo um conjunto de trechos ligados a nós. Os trechos representam as tubulações, bombas e válvulas de controle e os nós representam pontos de consumo, junções, reservatórios de nível fixo (RNF) e reservatórios de nível variado (RNV). Adicionalmente aos componentes físicos dos sistemas, o EPANET permitiu definir três categorias de informação sobre a rede: curvas (da bomba, de rendimento, de volume e de perda de carga); padrões (de variação do consumo, de funcionamento de bombas, preço de energia e etc.); controles (que descrevem o comportamento e os aspectos operacionais do sistema de distribuição de água). As figuras 5 e 6 representam esta aplicação.

Figura 5 - Mapa da rede depois de criados os nós, RNF, RNV, bombas e tubos, com a influência da precipitação anual de 2014 (COSANPA, 2015)

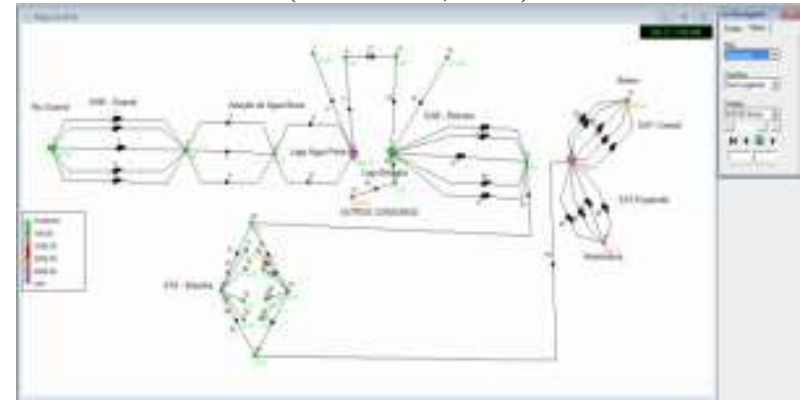

Fonte: (MHP Nogueira, et al., 2018).

Figura 6 - Mapa da rede depois de criados os nós, RNF, RNV, bombas e tubos, sem a influência da precipitação anual de 2014 (Cosanpa, 2015)

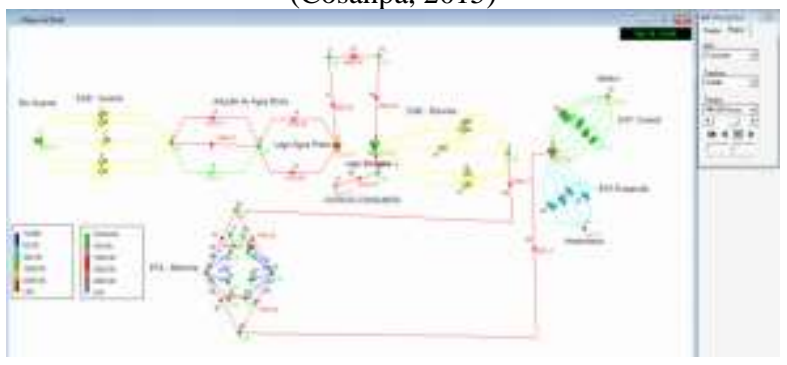

Fonte: (MHP Nogueira, et al., 2018).
Para a realização da simulação foram utilizados 12 cenários hidráulicos referentes aos doze meses do ano de 2014. Cenário 01 a 12 - sistema de produção de água do complexo Bolonha funcionando com todos os mananciais interligados, com a influência da sazonalidade da chuva e distribuição nas zonas central e expansão. Também foram simulados para efeito de comparação de consumo energético os 12 cenários sem a contribuição da precipitação do ano de 2014. Após a realização da simulação estática e dinâmica, partiu-se para a análise dos resultados dos indicadores hidráulicos no decorrer dos meses de 2014, adotou-se uma faixa de 360 horas para cada mês analisado.

Analisando a variação das pressões e cargas hidráulicas nos 12 meses do ano de 2014, verificou-se que todas as pressões analisadas se encontravam de acordo com o que é estabelecido pelas normas vigentes. Analisando-se a variação das velocidades e perda de carga nos 12 meses do ano de 2014 observa-se que as perdas de carga de algumas bombas encontravam-se com os valores negativos (Figura 7). Este fato se deu pela elevação de carga produzida pela bomba. E outras com a perda de carga igual a zero, este valor indica que a Bomba estava desligada.

Figura 7 - Precipitação anual de 2014

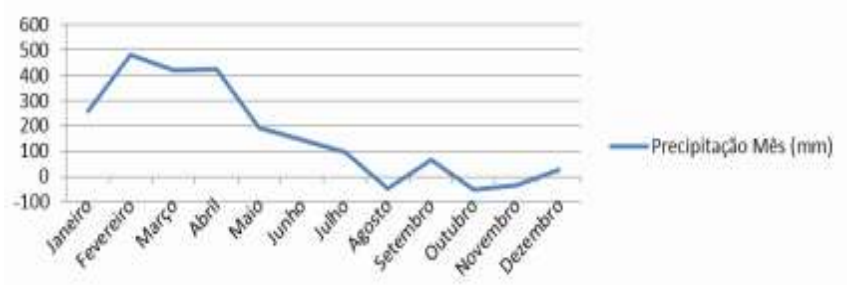

Fonte: (MHP Nogueira, et al., 2018).

Analisando a Figura 8 extraida do estudo de MHP Nogueira et al (2018), pode-se verificar que os meses de maior volume se deram nos meses de fevereiro $(1338,511 / \mathrm{s})$, março $(1161,86$ 1/s) e abril $(1177,14 \mathrm{l} / \mathrm{s})$ e os meses de menor volume precipitado os meses de agosto (-134,99 1/s), outubro $(-148,041 / s)$ e novembro $(-92,211 / s)$.

Figura 8 - Custo mensal - Com precipitação x Sem precipitação

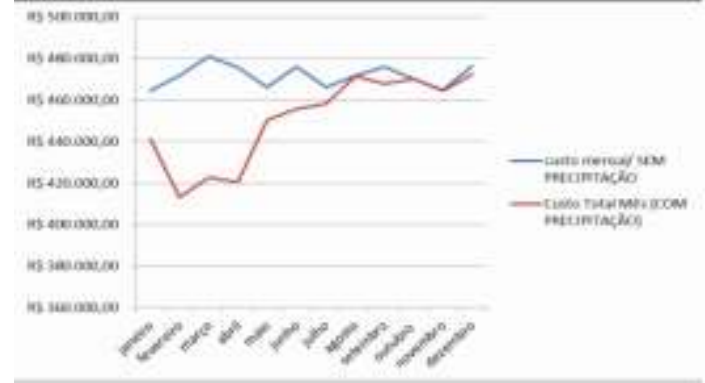

Fonte: (MHP Nogueira, et al., 2018).

Estes valores negativos valores de evaporação foram maiores que o de precipitação.

Quanto aos resultados obtidos nos componentes hidráulicos de produção de Água, verificou-se que em alguns trechos havia uma pressão menor que a exigida pela NBR 12218/94, os motivos para tal fato é que a rede de produção de água trabalha com trechos em regime de condutos abertos, e as pressões na rede são influenciadas pelos níveis dos reservatórios que estão conectados e também pela ocorrência de parada de bombas quando os reservatórios atingem seu nível máximo de volume. As pressões dentro do que estabelece a Norma somente foram encontradas nas saídas 
dos bombeamentos, o mesmo ocorreu com as velocidades encontradas no sistema

Verificou-se que na operação de produção de água a hidrologia é um fator problemático, pelo fato das precipitações se comportarem de diversas formas durante o ano, gerando uma consequência de chuvas de grande intensidade ou volume e pela ausência de chuvas em longos períodos de estiagem. A ausência de chuvas por longos períodos reduz as vazões dos lagos Bolonha e Água Preta, gerando uma diminuição dos níveis desses reservatórios, essas reduções geram um aumento no funcionamento das bombas da EAB-Guamá, onde nesses casos chegam a funcionar com até 6 bombas, ou seja, aumentando o custo de consumo de energia, além de danos ao meio ambiente por reduzir a diluição de poluentes. Já no caso de períodos de grande intensidade de chuva, como no primeiro semestre de 2014 verificou-se a grande influência do ciclo hidrológico no processo de produção de água. Essa influência gerou para a companhia de saneamento do Pará um índice de economia anual com gastos de energia elétrica de $4,45 \%$, que representa o valor de $\mathrm{R} \$ 251.763,90$.

Com base nessas informações, conclui-se que a elaboração e execução de um projeto de produção de água deve-se levar em consideração a preservação de nascentes, vegetação ciliar, conhecimentos hidráulicos, hidrologia e crescimento populacional e que o auxílio de programas computacionais como o EPANET podem ajudar na construção de um projeto bem elaborado com o intuído de planejar e melhorar o desempenho hidráulico, operação diária, situações de cenários futuros e ainda criar medidas que possam reduzir os custos com energia elétrica.

4.5 - Caso 4 - Sistema de Gestão de Energia Elétrica Utilizando o Energyplus: uma Aplicação Voltada aos Edifícios Inteligentes (AG Nazário et al., 2016)

O Simulador em foco foi criado a partir dos programas BLAST e DOE-2 e distribuído pelo Departamento de Energia dos Estados Unidos. O programa possui capacidade de simulação de carga térmica e análise energética de edificações e seus sistemas. O programa possui capacidade de simulação diferenciada, tais como "time-step", de cálculo menor que uma hora, sistema modular, possibilidade de cálculo de infiltração de ar além de índices de conforto térmico e integração com sistemas fotovoltaicos e outros sistemas.

Este estudo de caso é voltado a gestão da energia da faculdade de Tecnologia (FATEC) SENAI, que está localizada na cidade de Cuiabá e apresentado de forma resumida na figura 9 .

Figura 5 - Levantamento do consumo mensal da FATEC

\begin{tabular}{l|r|r|r|r}
\hline \multicolumn{1}{c|}{ Aparelhos Elétricos } & KW & Dias & Horas & \multicolumn{1}{c}{$\mathrm{kWh}$} \\
\hline $\begin{array}{l}\text { Ar-Condicionado } \\
\text { (30 Qtde) }\end{array}$ & 1,4 & 22 & 12 & 11.088 \\
\hline $\begin{array}{l}\text { Computador } \\
\text { (600 Qtde) }\end{array}$ & 0,2 & 22 & 12 & 31,68 \\
\hline $\begin{array}{l}\text { Lâmpada Fluorescente } \\
\text { (260 Qtde) }\end{array}$ & 0,04 & 22 & 12 & 2,75 \\
\hline Consumo mensal: & & 12.102 \\
\hline
\end{tabular}

Fonte: (AG Nazário et al., 2016).

Com base no consumo mensal $(\mathrm{kWh})$ evidenciada na figura 9, dos aparelhos edifício eletrônicos descritos foi realizada simulação no Energyplus e no SketchUp (software gráfico) considerando a média de utilização diária dos equipamentos nos seguintes horários (07:30 às 11:30/13:30 às 17:30/18:00 às 22:00). Esta simulação permite o estudo de sombreamento de um sistema de gestão de energia através de um sistema fotovoltaico (Figura 10).

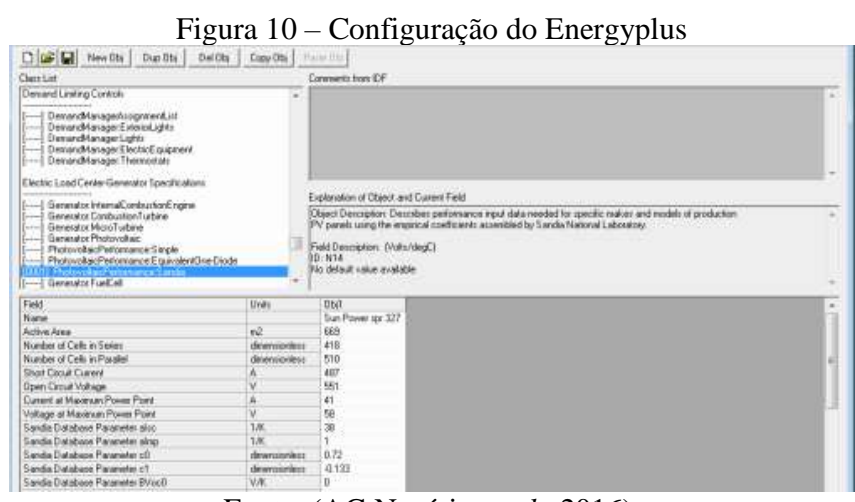

Fonte: (AG Nazário et al., 2016).

Na simulação computacional do Energyplus, pode ser feita a estimativa energética, integrando as variáveis de energia do sistema fotovoltaico ao sistema de energia da edificação. Para fins de desenvolvimento da simulação do comportamento da edificação foram elencadas tais etapas: Foram listadas as variáveis e horários de utilização dos equipamentos, definição do arquivo climática da região em questão, definição do período de janeiro a dezembro para simulação. Para os resultados da simulação foi utilizado o plugin da ferramenta que permite a inserção da geometria da edificação, simular a posição que receberia a maior radiação.

Na Figura 11 apresentada por AG Nazário et al (2018), esta apresentado o resultado do balanço de energia através de um dos modelos da ferramenta, sendo o total de energia consumida pela edificação no ano (145.224 kWh) e a capacidade inicial de geração de energia do sistema fotovoltaico $(72.612 \mathrm{kWp})$, para atender $100 \%$ da edificação. O método deverá fazer a gestão da oferta das placas em 50\%, buscando fornecer energia sempre que possível antes de importar da rede elétrica convencional. Desta forma a geração atende em parte o consumo interno da edificação privilegiando o horário de maior consumo. A Figura 12 apresenta outros resultados importantes deste estudo.

Figura 11 - Consumo energético da edificação e da geração fotovoltaica

\begin{tabular}{|c|c|}
\hline DESCRICX̃OO & Resultados em $\mathrm{kWh}$ \\
\hline Geração de energia fotovoltaica & $72.612,00$ \\
\hline Resfriamento & $133.056,00$ \\
\hline Iluminação & 934,5024 \\
\hline Computador & $11.232,00$ \\
\hline Consumo energético total & $145.224,00$ \\
\hline
\end{tabular}

Figura 12 - Simulação do balanço energético das cargas

\begin{tabular}{l|r} 
DESCRIÇÃO & RESULTADOS EM KWH \\
\hline Consumo da Edificação & 145.224 \\
\hline Oferta Sistema Fotovoltaico & 72.612 \\
\hline Energia da Rede Elétrica & 72.612 \\
\hline
\end{tabular}

Fonte: (AG Nazário et al., 2016). 
O estudo de AG Nazário et al (2018) apresentou formas de gerenciar as variáveis de oferta de energia do sistema de geração fotovoltaica e o consumo de energia. Através da simulação foi seguida a filosofia de um edifício inteligente, mediante análise e planejamento de um modelo de gestão de energia da FATEC SENAI Cuiabá-MT. Evidenciou-se que o gerenciamento do consumo interno pode ser uma saída estratégica a fim de evitar grandes investimentos em um maior número de placas fotovoltaicas. Para atender $100 \%$ da edificação, o método deverá fazer a gestão da oferta das placas que poderá gerar em média $(50 \%)$ do consumo interno, buscando fornecer energia antes de importar outros $50 \%$ da rede elétrica, privilegiando horários nos quais ocorre um maior consumo do sistema de refrigeração da edificação.

Este método viabiliza a implantação do sistema FV em etapas, podendo aumentar a potência instalada por meio da incorporação de módulos adicionais. A utilização dos recursos computacionais (Energyplus, SketchUp) possibilitou a simulação das fases de implementação do edifício inteligente, buscando a melhor forma de otimização. Os resultados referentes a simulação podem ser considerados satisfatórios neste estudo.

\section{RESULTADOS OBTIDOS}

A utilização das ferramentas dispostas neste artigo é de grande importância para suas aplicações. Em sua utilização é importante que seja de fácil entendimento tanto no funcionamento quanto na leitura dos resultados. Algumas observações acerca dos simuladores e sua utilização estão destacadas na sequência deste artigo.

Sistemas Motriz e Ar Comprimido - As aplicações destinadas a sistemas motrizes podem realizar análises importantes, contudo somente alusivas a motores. Em análises de outros sistemas motrizes as ferramentas se mostraram menos eficientes e preparadas. Já quanto aos softwares que se destinam a sistemas de ar comprimido, sua abrangência é totalmente congruente e efetiva. Com estes últimos é possível avaliar tanto equipamentos quanto sistemas.

Calor e Aquecimento - As ferramentas destinadas a sistemas caloríficos e de aquecimento compreendem em suas funções amplas utilidades estes tipos de sistema. Estas abrangem de forma clara e direta projetos, sistemas e equipamentos.

Refrigeração e Resfriamento - Algumas destas ferramentas apresentaram complexidades em suas interfaces e utilização. Contudo, abordam de uma maneira excelente as técnicas necessárias a análise de processo de resfriamento e refrigeração. A maioria destas aplicações atua como um ranking de pontos para análise e comparação.

Bombeamento e Ventilação - Estes softwares apresentaram boa interface e fácil utilização. A maior parcela das ferramentas em análise se destina apenas a equipamentos. Sendo assim, sua análise de sistemas é limitada.

Iluminação e Estudos energéticos - Neste subgrupo há uma infinidade de aplicações com excelentes interfaces e emprego acessível. Englobam infinitos modelos de análises e meios para seus diagnósticos em diferentes estudos.

\section{CONCLUSÕES}

A nova configuração e preocupação com os recursos energéticos do mundo demandam cada vez mais ferramentas de análise e tomada de decisão relacionadas a este tema. Com a evolução tecnológica das últimas décadas, além da necessidade de estudos de viabilidade e da valorização dos recursos naturais e financeiros, paulatinamente novas aplicações estão sendo desenvolvidas a fim de proporcionar tais estudos. Diante do exposto é notável o benefício advindo da utilização de ferramentas computacionais que dispõem de métodos matemáticos extremamente úteis tratando deste conteúdo. A compensação energética coligada ao aumento das tarifas de energia nos últimos tempos são as principais razões ao crescente aumento destes simuladores.

Os softwares vinculados a este estudo abrangem de forma excelente os objetivos de seus usuários em diagnósticos simples e/ou complexos, além de permitirem a sua fácil utilização pelo público comum, por serem didáticos e intuitivos. Nas seções precedentes foram apresentados o resumo de suas aplicações, o foco de aplicação, os resultados, e também a interface da aplicação. Também foi possível verificar o impacto destas em sua utilização, onde foram analisados casos de seu emprego em estudos científicos, e seus resultados observados foram avaliados como satisfatórios e adequados.

Foi possível evidenciar no caso 1 a análise de um redimensionamento motor utilizando o software "BD Motor". A ferramenta possibilitou um estudo abrangente da condição do motor em uso e das alternativas para solução do problema em questão. A tomada de decisão foi amparada por comparações técnicas plausíveis entre o motor em uso e um novo motor com dados compatíveis com a carga. No caso 2 notou-se a importância da ferramenta "Dimensol" para avaliação da forma mais eficiente de utilização da energia renovável. Com o software foi possível definir a fonte mais eficiente para diferentes cidades brasileiras através da comparação das possíveis fontes de energia primária. Evidenciou-se no caso 3 que o simulador "EPANET" é extremamente indicado para estudos minuciosos em sistemas hidráulicos dirigidos pela pressão. Utilizando métodos propostos pelo programa foi possível separar o sistema em diferentes nós, e assim facilitando os resultados e os pontos críticos avaliados pelo sistema em um estudo de sistema hidráulico dirigido pela pressão. Já no caso 4 o software "Energyplus" auxiliou o usuário em um estudo de gestão energética voltado a um projeto de geração fotovoltaica. Com a ferramenta foi possível analisar o ponto ótimo de custo e geração e dessa forma tornar o investimento do projeto mais acessível ao usuário. Também foram realizados modelos para este cálculo. Por fim as aplicações foram avaliadas como suficientes, mesmo havendo alguma diferença entre as interfaces e abrangências.

É importante ressaltar a infinidade de simuladores disponíveis livremente na web para inúmeras finalidades. Neste artigo foram citadas apenas algumas ferramentas livres. É importante que o usuário final defina a ferramenta mais adequada a seu projeto, os parâmetros que dispõem e a sua atividade fim e execute diversas simulações com cenários distintos para uma análise critica dos resultados.

\section{REFERÊNCIAS}

ABB - PumpSave - Disponível em: https://new.abb.com/drives/software-tools/pumpsave. Acesso em: 25/03/2019.

AG Nazário, et al., 2018. Sistema de Gestão de Energia Elétrica Utilizando o Energyplus: uma Aplicação Voltada aos Edifícios Inteligentes. Disponível em: http://www.fiemt.com.br/arquivos/3015_sistema_de_gestao _de_energia_eletrica_utilizando_o_energyplusuma_aplicacao_voltada_aos_edificios_inteligentes.pdf. Acesso em 24/03/2019 
CASTRO, Rodolfo Damásio de, et al., 2015. Energia solar térmica e fotovoltaica em residências: estudo comparativo em diversas localidades do Brasil. Disponível em: http://repositorio.unicamp.br/handle/REPOSIP/265829. Acesso em 08/01/2019.

CEPEL. Centro de Pesquisas de Energia Elétrica. Rio de Janeiro, Disponível em: http://www.cepel.br/ >. Acesso em: $21 / 03 / 2019$

DoE AMO - Department of Energy's Office of Energy Efficiency and Renewable Energy. Disponível em: https://www.energy.gov/eere/amo/advanced-manufacturingoffice. Acesso em /12/2019.

Insulation Institute - NAIMA - 3EPLUS - Acesso em 24/03/2019 Disponível em: https://insulationinstitute.org/tools-resources/free-3e-plus/

MARQUES, M. C. S.; HADDAD, J.; MARTINS, A. R. S. Conservação de Energia: Eficiência Energética de Equipamentos e Instalações. Terceira. Itajubá, 2006.

MHP Nogueira, et al., 2018. Análise e simulação da influência da precipitação pluviométrica no sistema de produção de água de Belém-PA (Complexo Bolonha) com o uso do EPANET. Acesso em 24/03/2019. Disponível em: https://revista.ufrr.br/rct/article/view/4989.

Natural Resources of Canada - RET Screen - Disponível em: https://www.nrcan.gc.ca/energy/software-tools/7465 Acesso em 24/03/2019.

Procel Info - Centro Brasileiro de Informação de Eficiência Energética. Simuladores. Disponível em: http://www.procelinfo.com.br/main.asp?TeamID=\%7B796B68 CB-2559-401F-A481-DC3D145F572E\%7D. Acesso em $19 / 12 / 2018$.

RAMOS, M. C. E. S et al., 2009. Aplicação de Simulação Computacional na Avaliação e Otimização de Motores Elétricos de Indução Visando a Conservação de Energia. Disponível em: http://www.iiis.org/CDs2009/CD2009CSC/CISCI2009/Papers

Pdf/C952RI.pdf. Acesso em 08/01/2019

Recursos e Ferramentas WEG - Disponível em: https://www.weg.net/institutional/BR/pt/support/resourcesand-tools. Acesso em 25/03/2019.

SILVA, R. R. D. et al., 2013. Modelos para Analises de Sistemas Energéticos Industriais Aplicado a Estudos de Eficiência Energética, 239 - Mestrado (Mestre em planejamento de Sistemas Energéticos). Faculdade de Engenharia Mecânica , Universidade Estadual de Campinas, Campinas. Disponível em: http://repositorio.unicamp.br/handle/REPOSIP/264458. Acesso em 18/12/2018

United States Environmental Protection Agency - EPA EPANET - Disponível em: https://www.epa.gov/waterresearch/epanet - Acesso em: 25/03/2019.

\section{COPYRIGHT}

Direitos autorais: Os autores são os únicos responsáveis pelo material incluído no artigo. 
OTIMIZAÇÃO DO TEMPO DE VIDA ÚTIL DE ELETRODOS UTILIZADOS EM UM PROCESSO DE SOLDA NA CARROCERIA EM UMA EMPRESA AUTOMOBILÍSTICA

\author{
OPTIMIZING THE USEFUL LIFE TIME OF ELECTRODES USED IN A \\ WELDING PROCESS IN THE BODY IN AN AUTOMOBILE COMPANY
}

\author{
NILO ANTONIO DE SOUZA SAMPAIO'; ALZIRA RAMALHO PINHEIRO DE ASSUMPÇÃO²; HELENA \\ MARIA PERIM DE ALMEIDA ${ }^{3}$; JÉSSICA CRYSTINA RAMOS MEDON DE OLIVEIRA; \\ LUMA BRITTO PINTO ${ }^{5}$ \\ $1 ; 2 ; 3 ; 4 ; 5$ - FACULDADE DE TECNOLOGIA, UNIVERSIDADE DO ESTADO DO RIO DE JANEIRO, \\ RESENDE, RJ, BRASIL \\ nilo.samp@terra.com.br,alzirarpa@gmail.com,helena@gmail.com,jessica@gmail.com,luma@gmail.com
}

\begin{abstract}
Resumo - O descarte de eletrodos antes do final da vida útil está entre um dos desperdícios mais frequentes da indústria automobilística. À luz disso, esta pesquisa otimizou a vida útil dos eletrodos em uma indústria automobilística situada na cidade de Resende, Rio de Janeiro, por meio da criação de uma "Central de Eletrodos". Os dados referentes ao consumo dos eletrodos foram coletados no setor de almoxarifado. A partir desses dados, analisou-se a viabilidade financeira para implantação do projeto. $O$ projeto foi instalado $e$ aperfeiçoado de acordo com as necessidades diárias do setor. Os resultados mostraram que a implantação da Central reduziu a demanda pela compra de novos eletrodos. Dessa forma, conclui-se que objetivo deste trabalho foi alcançado e a implantação da Central de eletrodos reduzindo desperdícios e os custos.
\end{abstract}

Palavras-chave: Otimização. Eletrodo. Custo e Desperdício.

\begin{abstract}
The disposal of electrodes before the end of their life span is among one of the most frequent waste problems in the automotive industry. In light of this, this research optimized the use of electrodes in an automotive industry in the city of Resende, Rio de Janeiro, through the creation of an "electrode center". Data on electrode consumption were collected in the warehouse sector. From these data, the financial viability for project implementation was analyzed. The project was installed and improved according to the daily needs of the sector. The results show that the implantation of the electrode center reduced the demand for new electrodes. Therefore, it is concluded that the goal of this work was reached while the implantation of the electrode center had a positive impact on the reduction of waste and costs.
\end{abstract}

Keywords: Electrode. Cost. Financial Viability.

\section{INTRODUÇÃO}

Em uma montadora localizada em Resende verificou-se a necessidade de reduzir os custos de produção dos veículos. Foram analisadas as etapas de produção como estampagem das chapas, união da carroceria, pintura e montagem final. Através do Benchmarking realizado com outras montadoras, constatouse a possibilidade de reduzir o custo de produção dos veículos nas etapas de união da carroceria por solda com a otimização da vida útil dos eletrodos, que são utilizados na soldagem das chapas. Estes eletrodos são colocados nas pinças de solda através do porta eletrodo como ilustrado na Figura 1.
Figura 1 - Máquina de Soldar

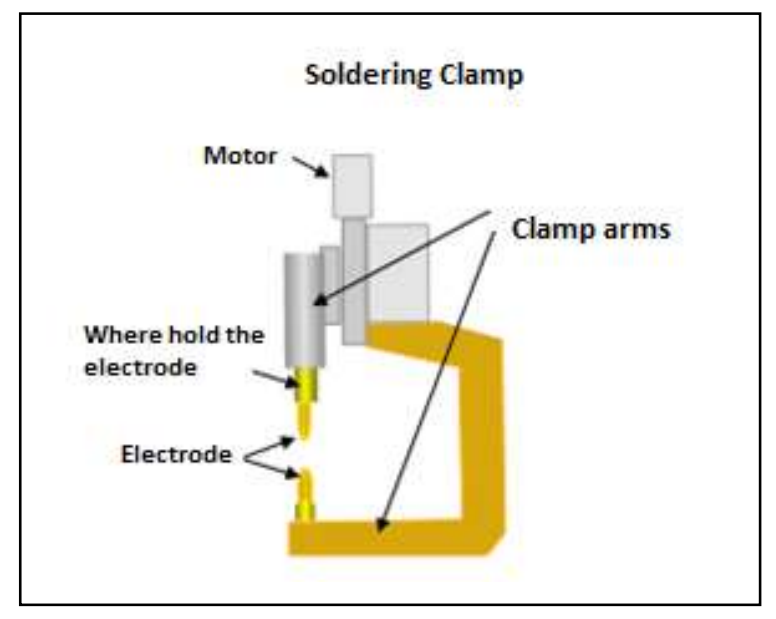

Fonte: Próprios Autores.

Para Cunha (2009), encontrar a fórmula exata para reduzir os custos de uma empresa é um desafio menos tortuoso se estabelecido a partir de um planejamento bem elaborado, principalmente se adotado antes de se fazer um investimento qualquer no negócio. A alta competitividade e a enorme carga tributária, aliada às mudanças constantes do mercado e a busca incessante dos clientes por produtos e serviços de alta qualidade e preços mais acessíveis cria mais dificuldades para as empresas permanecerem no mercado. Com as margens sobre os preços cada vez mais comprimidas pela concorrência, torna-se importante o trabalho dos administradores na busca pela redução de custos, principalmente de desperdícios e excessos que se verificam na organização, obtendo assim, lucratividade para a mesma e garantindo sua sobrevivência no mercado (ZANLUCA, 2009).

À luz dessas considerações, esse projeto visa otimizar o tempo de vida útil dos eletrodos através da instalação de uma Central de distribuição e tratamento dos eletrodos que foram utilizados. Nesta Central será realizada a verificação do estado dos eletrodos. Os que possuem vida útil serão tratados e redistribuídos para outras operações que iriam solicitar eletrodos novos e que, com a implantação da Central, não será necessário. 
Além disso, a Central de Eletrodos também será responsável por juntar todos os eletrodos descartados a fim de vendê-los e converter o valor da venda em compra de novos eletrodos e abastecer as linhas de soldagem.

Com a implantação desta Central é possível não somente reduzir custos com eletrodos novos através da melhoria na gestão, do tratamento e redistribuição dos que ainda podem ser utilizados, mas também estabelecer o controle de consumo de cada linha o que não ocorre atualmente.

Os objetivos específicos são: reduzir o custo com eletrodos novos consumidos na produção dos veículos, instalar uma Central de Eletrodos para tratamento, controle, distribuição e descarte, controlar o consumo de eletrodos por área, garantir que os eletrodos descartados estão no final de vida útil.

\section{METODOLOGIA}

Neste trabalho foram utilizados alguns princípios como Monozukuri, Ciclo PDCA e Kaizen, 5S, dentre outros conhecimentos descritos a seguir. Através do uso de tais ferramentas, obteve-se um trabalho sustentável, com redução de custo e, também buscando sempre a melhoria contínua, mesmo depois da implementação do projeto.

A definição do processo de soldagem de pontos por resistência elétrica, ligado ao setor metalúrgico, é o processo de união de metais, com finalidade de moldar partes de metal em estruturas. Na soldagem por resistência, as peças são pressionadas uma contra a outra, por meio de eletrodos, onde o calor da soldagem é gerado pela resistência a um fluxo de corrente elétrica que transita nas partes a serem unidas. Segundo a Lei de Joule $\left(\mathrm{Q}=\mathrm{KRI}^{2} \mathrm{~T}\right)$, essa alta corrente ocasiona uma quantidade de calor $(\mathrm{Q})$ proporcional ao tempo $(\mathrm{T})$, resistência elétrica $(\mathrm{R})$ e intensidade de corrente $(\mathrm{I})$, permitindo que a superfície das peças a serem soldadas atinja o ponto de fusão.

É necessário manter o equilíbrio entre tempo, pressão e aquecimento para realizar esse tipo de soldagem. Para obtenção da fusão apropriada, a temperatura no centro da solda para deve atingir $1300^{\circ} \mathrm{C}$ e a superfície de contato com o eletrodo não deve ultrapassar $900^{\circ} \mathrm{C}$. A resistência deve ser elevada na região de contato entre as peças a serem soldadas para atingir essa temperatura. O tempo de fluxo da alta corrente afeta o calor produzido. Quanto maior o tempo de fluxo de corrente, maior o botão de solda. A pressão dos eletrodos nas chapas afeta diretamente na resistência na superfície de contato entre os materiais e no calor gerado. É necessário encontrar um meio termo apropriado para a pressão.

Os eletrodos de contato têm como finalidade, não somente, fazer fluir a corrente elétrica através do ponto de solda formado por seu contato com as peças, mas também, transferir a força de compressão para a chapa. Uma alta intensidade de corrente elétrica é conduzida através dos eletrodos. Devido a isto, durante a soldagem, o eletrodo deve resistir a altas pressões e não deve haver elevado aquecimento. Por essa razão, os eletrodos são constituídos por material de elevada resistência mecânica, dureza, condutividade elétrica.

Um dos tipos de soldagem por resistência é a soldagem por pontos. Neste tipo de solda, a região de contato entre as peças é unida por pontos onde calor e pressão são aplicados. O calor da soldagem é gerado pela resistência a uma corrente elétrica que flui através do contato entre as peças. O procedimento utiliza alta pressão, alta intensidade de corrente elétrica e baixa tensão. É fundamental um bom contato entre as peças para uma boa solda. Quando encerra a intensidade de corrente, a pressão é conservada enquanto o metal se solidifica. Após atuar em cada ponto, os eletrodos são afastados da superfície. Nesse processo, a corrente é centralizada em um único ponto na junta e são utilizados eletrodos cilíndricos. Na Figura 2 é possível acompanhar todas as etapas da aplicação de pontos de solda por soldagem ponto a ponto, descritas acima.

Figura 2 - Estágios de Solda à ponto

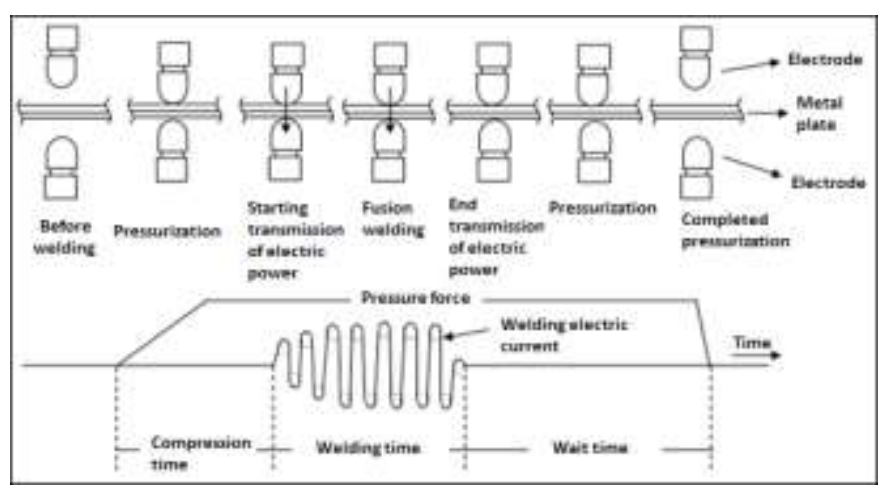

Fonte: Próprios Autores

O programa 5S é uma metodologia criada e idealizada no Japão, nos anos 60, visando à melhoria do ambiente das empresas, que eram muito sujas e desorganizadas, e ainda, acabar com o desperdício, diminuir o número de acidentes pessoais e impessoais e melhorar a produtividade das empresas (FILHO, 2003). É uma ferramenta organizacional que ajuda a manter o ambiente de trabalho limpo, organizado e produtivo. Seu nome provém de palavras que, em japonês, iniciam com $\mathrm{S}$. $\mathrm{Na}$ tradução para o português, foram interpretados como Sensos, não somente para manter o nome $5 \mathrm{~S}$, mas porque refletem melhor o significado das palavras em japonês (UDESC, 1996), correspondendo a "Seiri, Seiton, Seisô, Seiketsu e Shitsuke", que equivale a, respectivamente, senso de Organização ou utilização, senso de Arrumação ou Ordem, senso de Limpeza, senso de Padronização ou Saúde, senso de Disciplina. A implementação dessa metodologia ajuda na redução de desperdício e, consequentemente, na redução de custos. Aperfeiçoa também, o aproveitamento do espaço físico da empresa devido ao não armazenamento de materiais desnecessários. O programa objetiva: melhorar o ambiente de trabalho, reduzir o desperdício, evitar acidentes de trabalho, aperfeiçoar os processos, melhorar a moral dos funcionários e incentivar a criatividade (ZANELLA, 2009). É uma ferramenta de fácil compreensão, porém sua aplicação pode não ser considerada tão simples, já que depende do envolvimento de todos, além de implicar em mudanças em hábitos e atitudes.

Seiri - Senso de organização ou utilização: senso de organização ou utilização consiste em analisar os locais de trabalho e classificar os objetos segundo sua utilidade ou frequência de uso e retirar do ambiente tudo o que não necessita estar neste local (UDESC, 1996). É analisado o que é relevante para a execução do serviço, e assim, descartado.

Seiton - Senso de arrumação ou ordem: o senso de arrumação ou ordem organiza materiais, objetos e informações possibilitando acesso rápido e fácil. Deve-se usar o conceito de que o primeiro material que entra é o primeiro que deve sair, assim como é preciso padronizar a nomenclatura dos objetos, evitando que um material tenha vários nomes e para que todos os colaboradores falem apenas um idioma dentro da empresa (FILHO, G, 2003). Com isso, este senso não somente aumenta a facilidade e rapidez para encontrar aquilo que é procurado, mas também evita a compra desnecessária de materiais. 
Seiso - Senso de limpeza: após efetuar o Seiton (senso de arrumação ou ordem), é necessário manter os objetivos, materiais, equipamentos limpos, e isso não significa apenas tirar a poeira. É fundamental que cada pessoa mantenha o material ou equipamento em condições de uso. O senso de limpeza tem como benefícios: prevenção de acidentes, refletindo na redução de afastamentos de funcionários; ambientes de trabalho mais limpos e seguros; combate aos desperdícios; redução de poluição e agressões ao meio ambiente e maior controle na conservação de materiais (ANDRADE, 2007).

Seiketsu - Senso de padronização ou saúde: o senso de padronização ou saúde tem como principal finalidade manter os três primeiros S' (organização, arrumação e limpeza) operando da maneira correta, padronizar o que foi feito. O ambiente de trabalho deve ser mantido sempre favorável à saúde e a higiene. Osada (1992) aponta esse senso como sendo o resultado de concentração constante em organização, arrumação e limpeza. Além disso, é preciso manter rotinas definidas e esforços constantes para manter os sensos anteriores.

Shitsuke - Senso de disciplina: o último senso é a manutenção de todos descritos anteriormente. Após a implementação dos $4 S^{\prime}$ é necessário manter o que foi feito. Este senso é considerado o mais difícil de ser alcançado, pois depende do comprometimento de todos e modificam a cultura e comportamento das pessoas.

O diagrama de Pareto é uma ferramenta estatística que ajuda nas escolhas de como agir mediante a apresentação de um problema. É composto por um histograma no qual os itens são apresentados em ordem decrescente, apresentando no mesmo gráfico a linha do percentual acumulado destes itens. (YEMAL et al, 2018).

O diagrama de Pareto torna possível a visualização das causas de um problema da maior para a menor frequência ou gravidade identificando de maneira clara a localização das causas vitais que originaram o problema. É utilizado para estabelecer uma ordem ou priorização nas causas de problemas das mais diversas naturezas (OLIVEIRA, S. E; ALLORA, V; SAKAMOTO, F. T. C., 2006).

\section{DESENVOLVIMENTO}

$\mathrm{Na}$ empresa analisada, a linha de produção pode ser dividida em dois tipos diferentes: a linha manual, onde a soldagem e manipulação das pinças de solda são feitas por operadores, e a linha automática, que realiza os pontos de solda através de robôs. A linha automática possui ao todo sessenta robôs, que é dividida em duas partes, e cada uma possui trinta robôs. Na primeira parte da linha vinte e oito robôs estão em operação e utilizam eletrodos do tipo 16 standard e 13 standard e a troca de eletrodos desta parte da linha automática ocorre durante o segundo turno, a cada quarenta e oito horas. Deve-se citar que dois robôs estão desativados. A segunda parte da linha automática possui trinta robôs em operação que utilizam os cinco tipos de eletrodos existentes na linha de produção. A troca dos eletrodos desta parte da linha é feita para alguns robôs diariamente apenas no segundo turno. Outros robôs realizam trocas duas vezes ao dia, sendo a primeira na hora do almoço e, posteriormente, no segundo turno.

Em grande maioria, os eletrodos são retirados das linhas automáticas ainda com vida útil nos períodos de troca programados como mencionado anteriormente, e de possível verificação conforme a Figura 3. Isso ocorre para evitar que seja necessário realizar a troca durante o período de produção, atrasando a produção dos veículos.

Figura 3 - Comparação de um Eletrodo Novo, na verdade Eletrodo Descartado, e Eletrodo Descartado no final de sua vida útil

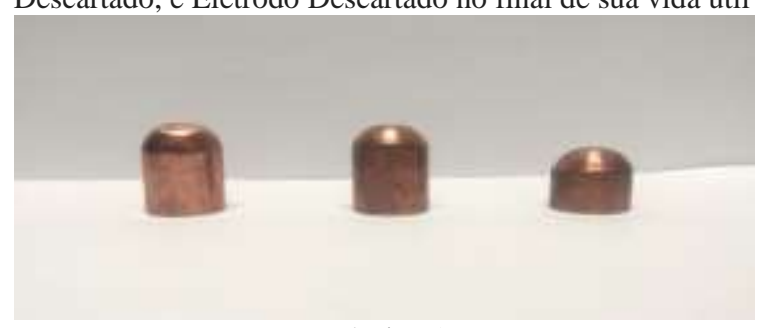

Fonte: Próprios Autores.

Segundo uma norma desta montadora, é necessário fresar os eletrodos a cada trezentos pontos de solda aplicados para garantir a qualidade. Um eletrodo 16 standard pode ser fresado em torno de nove vezes até chegar ao final de sua vida útil, garantindo assim cerca de dois mil e setecentos pontos de solda.

São utilizados atualmente cinco tipos de eletrodos para realizar o processo de soldagem por resistência nas partes da carroceria dos veículos fabricados pela montadora em questão. Destes tipos de eletrodos serão reutilizados os do tipo 13 standard e 16 standard por possuir maior massa de vida útil e por representar cerca de $90 \%$ do consumo total de eletrodos, conforme apresentado no gráfico 1 .

Figura 4 - Quantidade de cada tipo de eletrodo consumido durante novembro de 2016

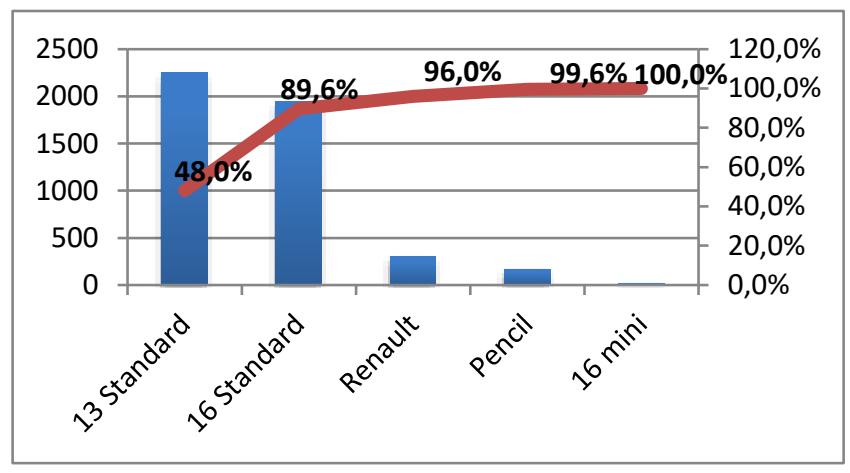

Fonte: Próprios Autores.

Esses tipos de eletrodos são os mais requisitados e têm maior massa de vida útil quando comparado aos outros tipos disponíveis. Na Figura 5 é possível observar a diferença de um eletrodo do tipo 16 standard novo e outro que foi utilizado até o fim, mostrando assim a diferença da massa de vida útil que é possível ser utilizada.

Figura 5 - Eletrodo Novo e Ideal descartado padrão 16

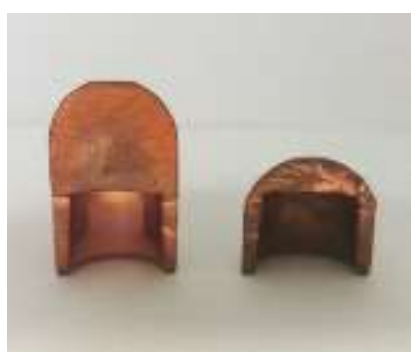

Fonte: Próprios Autores. 
Estes dois tipos de eletrodos possuem algumas similaridades como, por exemplo, o formato, o diâmetro da área de contato do eletrodo com as chapas de metal e o material que são feitos. Existem também algumas diferenças nas dimensões destes modelos e que podem ser observadas na figura 7 .

Figura 7 - Eletrodecaracterística

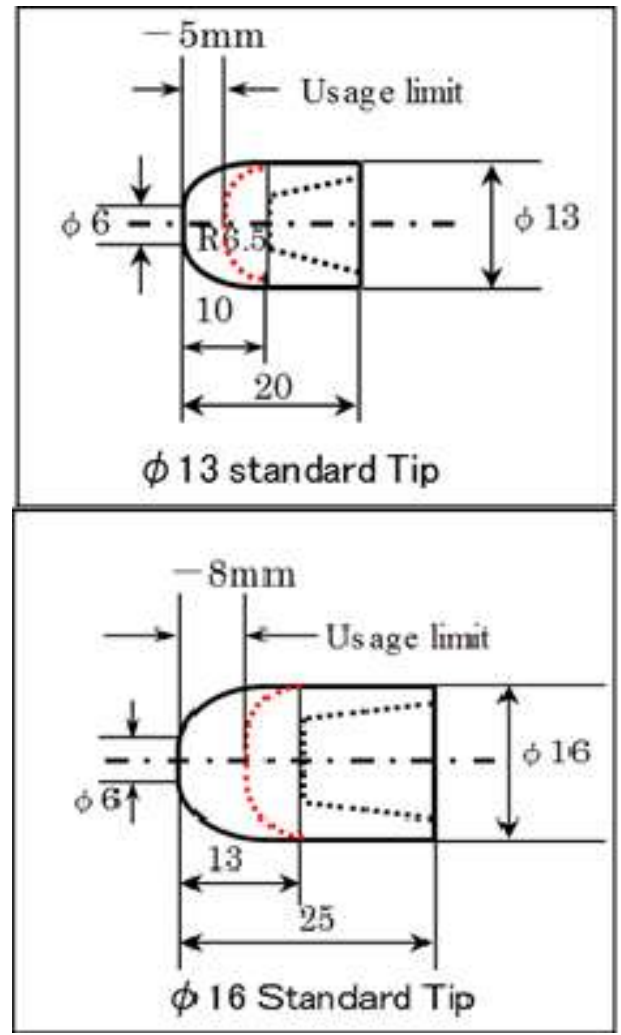

Fonte: Próprios Autores.

Das linhas manuais que podem utilizar eletrodos fresados, verificou-se que é possível reutilizar cerca de $30 \%$ dos eletrodos do total de eletrodos novos que foram requisitados para a realização dos processos.

Durante a coleta de dados foram solicitadas ao almoxarifado as informações

das requisições de eletrodos novos dos últimos meses do ano. Com estas informações, pode-se obter o consumo anual de eletrodos até o ano de 2016. Pode-se observar no gráfico 2 que o consumo de eletrodos vem aumentando com o passar dos anos.

Figura 6 - Novo consumo de eletrodos

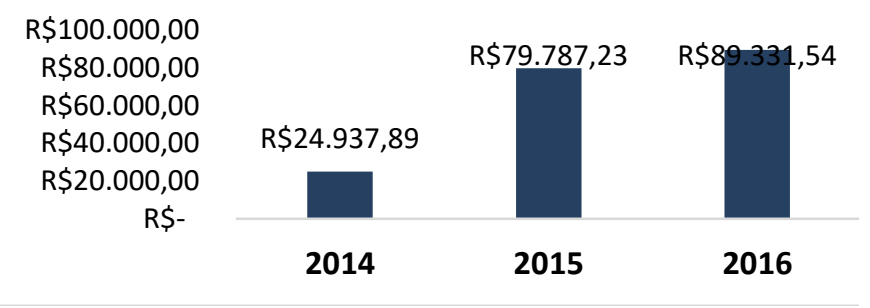

Fonte: Próprios Autores.

\section{RESULTADOS}

Para o acompanhamento do consumo de eletrodos e consequentemente calcular a redução de consumo dos mesmos, foi elaborada uma planilha de controle na qual o número de eletrodos é imputado, juntamente com a data de solicitação dos mesmos e as áreas que realizaram o requerimento. Com isso, foi possível realizar o acompanhamento mensal de redução do consumo de eletrodos novos.

Na Figura 8 são apresentados os valores que representam em percentual a redução no consumo de eletrodos novos. Neste gráfico é possível observar que a partir de janeiro houve um crescimento significativo da redução, no entanto nota-se que a partir de Maio esta redução passou a diminuir bruscamente. Isto ocorreu devido ao desligamento do operador da Central de Eletrodos, o que impactou muito no rendimento do projeto, já que por não ter uma pessoa trabalhando no posto durante o turno, para não impactar a produção dos veículos foram solicitados muitos eletrodos novos uma vez que o estoque de eletrodos tratados foi reduzindo. Devido a essa ocorrência, os resultados demonstram que a eficiência da Central de Eletrodos depende diretamente do controle e gestão de consumo implementados pela mesma. Esta é a única maneira para obter resultados satisfatórios.

Figura 8 - Redução no novo consumo de eletrodos

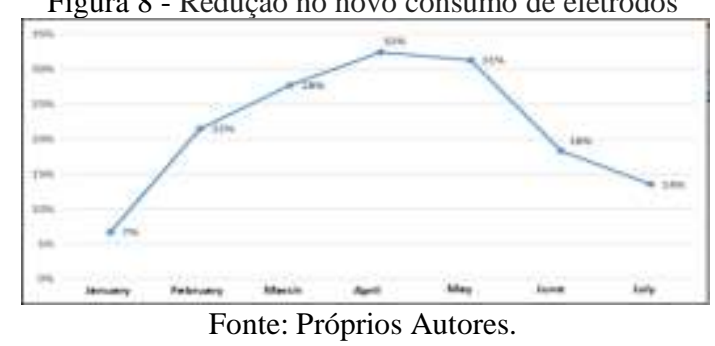

É importante ressaltar que serão considerados os resultados apenas até abril, quando o projeto estava operando perfeitamente (durante os 30 dias do mês) e com as informações baseadas até esse período será realizado uma previsão da redução total anual devido à implementação deste projeto.

Após a implantação da Central de Eletrodos em janeiro de 2017 os resultados obtidos desde janeiro até abril do mesmo ano foram bastante satisfatórios. O gráfico 4 mostra que o total de eletrodos solicitados pela produção até o mês de abril foi de 11295 eletrodos. Destes 6937 são novos eletrodos e 4358 foram reutilizados e redistribuídos na linha. O que representa uma redução de $38,6 \%$ referente à quantidade total de eletrodos novos.

Figura 9 - Pedido de eletrodo até abril

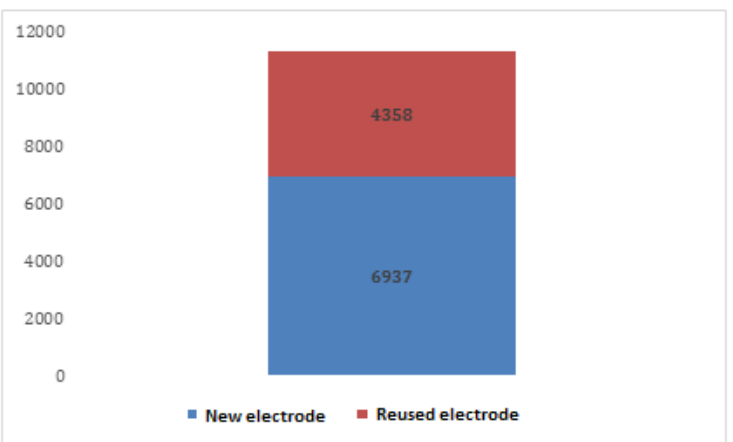

Fonte: Próprios Autores. 
Ao realizar a comparação do valor gasto com eletrodos novos na condição anterior e a situação após a implementação do projeto, tem-se uma redução de custo para todos os tipos de eletrodos. Como ilustrado na Figura 9 vê-se que, apesar de ter sido definido ainda na época do projeto que apenas dois tipos de eletrodos (13 Standard e 16 standard) seriam reutilizados, conseguiu-se obter redução de custo em todos os tipos de eletrodos. Isto ocorreu porque durante a avaliação dos eletrodos que tinham sido descartados, anterior à implementação do projeto, foram encontrados muitos eletrodos novos na caixa do descarte. Com isso pode-se também redistribuí-los para a linha de produção.

Figura 10 - Novo consumo de eletrodos antes e depois da montagem da estação de preparação de eletrodos

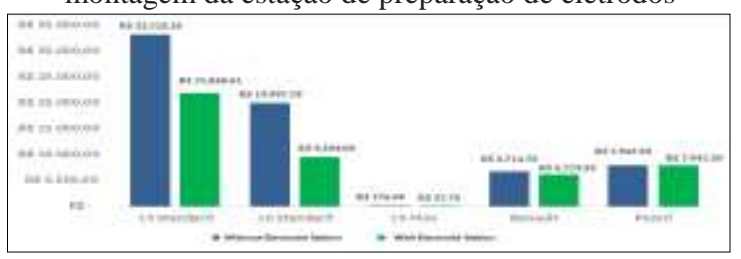

Fonte: Próprios Autores.

De acordo com os resultados mostrados na Figura 10, o total de redução nos custos foi de $\mathrm{R} \$ 22.492,31$, que representa aproximadamente $32 \%$ de redução de custo referentes ao consumo de eletrodos de solda.

Com estes resultados obtidos em quatro meses da Central de Eletrodos funcionando é possível prever a redução de custo anual através da projeção dos valores. Desta maneira tem-se uma previsão de redução anual de custos de $\mathrm{R} \$$ $67.476,93$, o que justifica o funcionamento da Central de Eletrodos uma vez que o custo anual do operador para a empresa em questão é de $\mathrm{R} \$ 60.000,00$. Com isso pode-se afirmar que a implementação do projeto é viável porque a redução de custos proveniente da eficiência do projeto é maior que o investimento necessário para mantê-lo em funcionamento e ainda restam $\mathrm{R} \$ 7.476,93$ de saldo positivo anual. Além desta comparação pode-se prever o tempo de Payback referente aos investimentos necessários para a instalação deste projeto. Levando em consideração a venda de cerca de 1271,20 quilogramas de cobre provenientes dos eletrodos que já Monozukuri com a produção harmoniosa com a sociedade, tornando a fabricação dos veículos mais sustentável uma vez que visa minimizar do descarte de materiais através da reutilização dos materiais aplicando e a redução dos desperdícios.

\section{CONCLUSÃO}

O desenvolvimento deste trabalho mostra que os objetivos pretendidos foram alcançados. A instalação do novo posto de trabalho acarretou a redução de custos com a compra de novos eletrodos de solda. Foi também desenvolvida a gestão de controle de consumo dos eletrodos. Otimizou-se a utilização dos eletrodos e garantiu-se que estão sendo descartados no final da vida útil, reduzindo assim o desperdício de material.

O desligamento do operador que trabalhava na Central mostra que a eficiência foi reduzida drasticamente, aumentando novamente o impacto nos custos com eletrodos novos. Deste modo, o funcionamento da Central de Eletrodos é essencial para a redução de custos e estão no final da vida útil por um preço médio de $\mathrm{R} \$ 12,00$ por quilograma de Cobre, arrecada-se o valor de $\mathrm{R} \$ 15.254,40$ para abater no valor de que foi necessário investir $\mathrm{R} \$ 35.334,38$ para a implementação da Central de Eletrodos. Desta maneira, restam $\mathrm{R} \$ 20.079,98$ que devem ser abatidos em dois anos e oito meses devido ao saldo anual positivo de R $\$ 7.476,93$, sendo esse tempo o nosso tempo de Playback estipulado.

\section{REFERÊNCIAS}

ANDRADE, Luiza. Ciclo PDCA: como ele pode melhorar seus processos?. Disponível em: <https://www.siteware.com.br/metodologias/ciclo-pdca/>. Acesso em: 20 nov. 2007.

DE OLIVEIRA, Simone Espindola; ALLORA, Valerio; SAKAMOTO, Frederico Tadashi Carvalho. Utilização conjunta do método UP' (Unidade de Produção -UEP') com o Diagrama de Pareto para identificar as oportunidades de melhoria dos processos de fabricação: um estudo na agroindústria de abate de frango. 2006. 37, 48 p. . (Mestre em Gestão Empresarial) - Fundação Getúlio Vargas, [S.1.], 2006. Disponível em: <http://www.custoseagronegocioonline.com.br/numero2v2/ Diagrama\%20de\%20pareto.pdf>. Acesso em: 09 dez. 2016.

FILHO, Geraldo Vieira. Gestão da qualidade Total: uma abordagem prática. Alínea Editora, Campinas, SP 2003.

YEMAL, José Alberto; GUERREIRO, Evandro Prestes; FILHO, Ulysses Martins Moreira, Metamorphosis of Philosophy 5s And its Deployments in the Brazilian Context. Revista Sodebras [on line]. v.13, n.156, Set./2018, p.1418. ISSN 1809-3957. DOI: https://doi.org/10.29367/issn.1809-3957.2018.156

UNIVERSIDADE DO ESTADO DE SANTA CATARINA. Cartilha da Qualidade. Florianópolis: Ed. da UDESC. 1996 $58 \mathrm{p}$.

\section{COPYRIGHT}

Direitos autorais: Os autores são os únicos responsáveis pelo material incluído no artigo.

Submetido em: 09/04/2019 Aprovado em: 13/05/2019 